\title{
On the molecular pharmacology of EndothelinA receptors : or how EndothelinA agonists can make a difference
}

Citation for published version (APA):

Compeer, M. G. (2013). On the molecular pharmacology of EndothelinA receptors : or how EndothelinA agonists can make a difference. [Doctoral Thesis, Maastricht University]. Uitgeverij BOXPress. https://doi.org/10.26481/dis.20130920mc

Document status and date:

Published: 01/01/2013

DOI:

10.26481/dis.20130920mc

Document Version:

Publisher's PDF, also known as Version of record

Please check the document version of this publication:

- A submitted manuscript is the version of the article upon submission and before peer-review. There can be important differences between the submitted version and the official published version of record.

People interested in the research are advised to contact the author for the final version of the publication, or visit the DOI to the publisher's website.

- The final author version and the galley proof are versions of the publication after peer review.

- The final published version features the final layout of the paper including the volume, issue and page numbers.

Link to publication

\footnotetext{
General rights rights.

- You may freely distribute the URL identifying the publication in the public portal. please follow below link for the End User Agreement:

www.umlib.nl/taverne-license

Take down policy

If you believe that this document breaches copyright please contact us at:

repository@maastrichtuniversity.nl

providing details and we will investigate your claim.
}

Copyright and moral rights for the publications made accessible in the public portal are retained by the authors and/or other copyright owners and it is a condition of accessing publications that users recognise and abide by the legal requirements associated with these

- Users may download and print one copy of any publication from the public portal for the purpose of private study or research.

- You may not further distribute the material or use it for any profit-making activity or commercial gain

If the publication is distributed under the terms of Article $25 \mathrm{fa}$ of the Dutch Copyright Act, indicated by the "Taverne" license above, 


\section{ON}

\section{the Molecular Pharmacology of ENDOTHelin A RePPTORS}

OR HOW

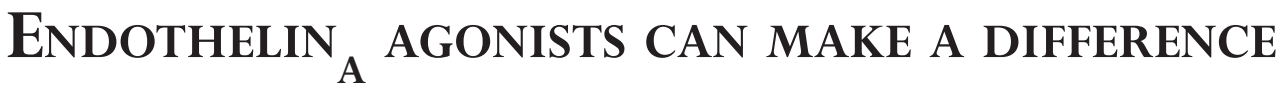


The studies presented in this thesis were financially supported by Dutch Top Institute Pharma projects T2-301: Renin Angiotensin System Blockade beyond Angiotensin II and T2-108: Metalloproteases and Novel Targets in Endothelial Dysfunction and were performed within the Cardiovascular Research Institute Maastricht (CARIM), which is acknowledged by the Royal Dutch Academy of Arts and Sciences (KNAW).

This thesis is printed with the financial support of Altos Venture Ltd and Scheldemond College.

(C) 2013, MG Compeer

ISBN:

9789088916694

Design and layout: MG Compeer

Printed by:

Proefschriftmaken.nl || Uitgeverij BOXPress

Published by:

Uitgeverij BOXPress, 's-Hertogenbosch 


\title{
On the Molecular Pharmacology of Endothelin ${ }_{A}$ Receptors
}

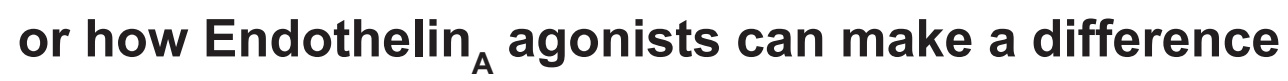

\author{
PROEFSCHRIFT
}

Ter verkrijging van de graad van doctor aan de Universiteit Maastricht, op gezag van de Rector Magnificus, Prof. dr. L.L.G. Soete, volgens het besluit van het College van Decanen,

in het openbaar te verdedigen op vrijdag 20 september 2013 om 10.00 uur

door

Matthijs Gerrit Compeer

Geboren op 8 februari 1985 te Vlissingen 


\section{Promotor}

Prof. dr. Jo G.R. De Mey

\section{Beoordelingscommissie}

Prof. dr. Harry A.J. Struijker Boudier (voorzitter)

Prof. dr. A.H. Jan Danser (Erasmus MC, Rotterdam)

Prof. dr. Johan W.M. Heemskerk

Prof. dr. Tilman M. Hackeng

Dr. Paul M.H. Schiffers 


\section{Contents}

$\begin{array}{lll}\text { Chapter } 1 & \text { Introduction }\end{array}$

Chapter 2 Stimuli of Sensory-Motor Nerves Terminate Arterial

Contractile Effects of Endothelin-1 by CGRP and

Dissociation of ET-1/ET $\mathrm{A}_{\mathrm{A}}$ Receptor Complexes

Chapter 2.1 Supplementary Data concerning Chapter 2

Chapter $3 \quad$ Endothelin-1 and -2: Two Amino Acids Matter

Chapter $4 \quad$ Endothelin-1 and Endothelin-2 Initiate and Maintain Contractile Responses by Different Mechanisms in Rat Mesenteric and Cerebral Arteries

Chapter 5 Agonist-Dependent Modulation of Arterial Endothelin Receptor Function

Chapter 5.1 Supplementary Data concerning Chapter 5 105

Chapter 6 Discussion and Future Directions

Chapter $7 \quad$ Summary

Chapter 8 Samenvatting

Appendix Dankwoord

List of Publications

About the Author 



\section{Chapter 1}

INTRODUCTION

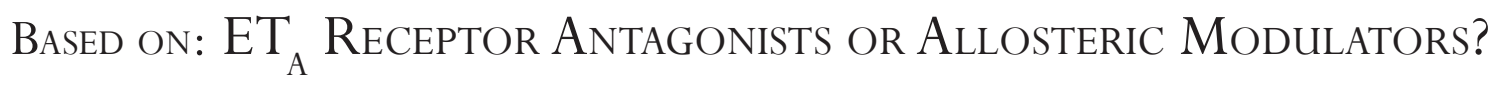
Jo GR De Mey, Matthijs G Compeer, Pieter Lemkens, Merlijn JPMT Meens

Trends Pharmacol Sci. 2011 Jun;32(6):345-51 


\section{The Endothelins}

The existence of an endothelium-derived contractile factor (EDCF) was predicted in 1982 [1]. In 1988, Masashi Yanagisawa and colleagues reported on the identification of one of these EDCFs, which they named endothelin (ET) [2]. In mammals, this peptide belongs to a family of in total 3 isopeptides, ET-1, ET-2 and ET-3 [3]. Their amino acid sequences are shown in Fig. 1.1. Effects of these peptides are mediated via two types of receptors, Endothelin $n_{A}\left(E T_{A}\right)$ and Endothelin $n_{B}\left(E T_{B}\right)$ receptors [4], that display only $50 \%$ sequence homology [5]. Both receptor subtypes are G-protein coupled receptors (GPCRs), subtype A [6,7], but as this receptor family is known to signal also via systems other than G-proteins [8], the preferred term is 7 transmembrane domain receptors (7TMRs), as they cross the cellular membrane 7 times.

In the vasculature, mainly $\mathrm{ET}_{\mathrm{A}}$ receptors mediate vasoconstriction and vasospasm and are therefore considered an interesting, large potential therapeutic target [9, 10]. The $E T_{B}$ receptors on the other hand are involved in endothelium-dependent vasodilatations in the vasculature, counteracting the effects of $\mathrm{ET}_{\mathrm{A}}$ receptors, as well as scavenging and clearance of circulating ET [11-13]. The endogenous agonists $\mathrm{ET}-1$ and ET-2 bind and activate $\mathrm{ET}_{\mathrm{A}}$ receptors with similar affinity and efficacy, (in the low or subnanomolar range), whereas ET-3 binds with much lower affinity to these $\mathrm{ET}_{\mathrm{A}}$ receptors [14] (Fig. 1.1). All three ETs bind with similar affinity and activate with similar efficacy $\mathrm{ET}_{\mathrm{B}}$ receptors. Therefore, ET-1 and ET-2 are considered nonselective ET-receptor agonists and ET-3 is a somewhat selective ( 30 fold), or $\mathrm{ET}_{\mathrm{B}}$ preferring agonist $[15,16]$.

The most studied isoform, ET-1, is a 21 amino acid, bicyclic paracrine mediator [17, $18]$ and is the most abundant $E T$ isoform in the vasculature. Via $\mathrm{ET}_{\mathrm{A}}$ receptors, it can induce a variety of responses such as contractions and spasm in the vasculature, cellular proliferation, inflammation and oxidative stress [9, 10]. ET-2 is abundant in the urogenital and gastrointestinal systems [19-21] and differs from ET-1 in amino acid structure at positions 6 and 7 in the N-terminal loop [3] (Fig.1.1). Despite these structural differences, ET-2 is considered an $\mathrm{ET}_{\mathrm{A}}$ agonist similar to ET-1, as these have similar affinity and efficacy [4, 10] (Fig.1.1). ET-3 is mainly known for its roles during embryonic development [22] and as a neurotransmitter in the adult central nervous system [23]. It differs in 6 amino acids from ET-1 and ET-2, which may explain its preference for $\mathrm{ET}_{B}$ over $\mathrm{ET}_{\mathrm{A}}$ receptors [14] (Fig. 1.1). 


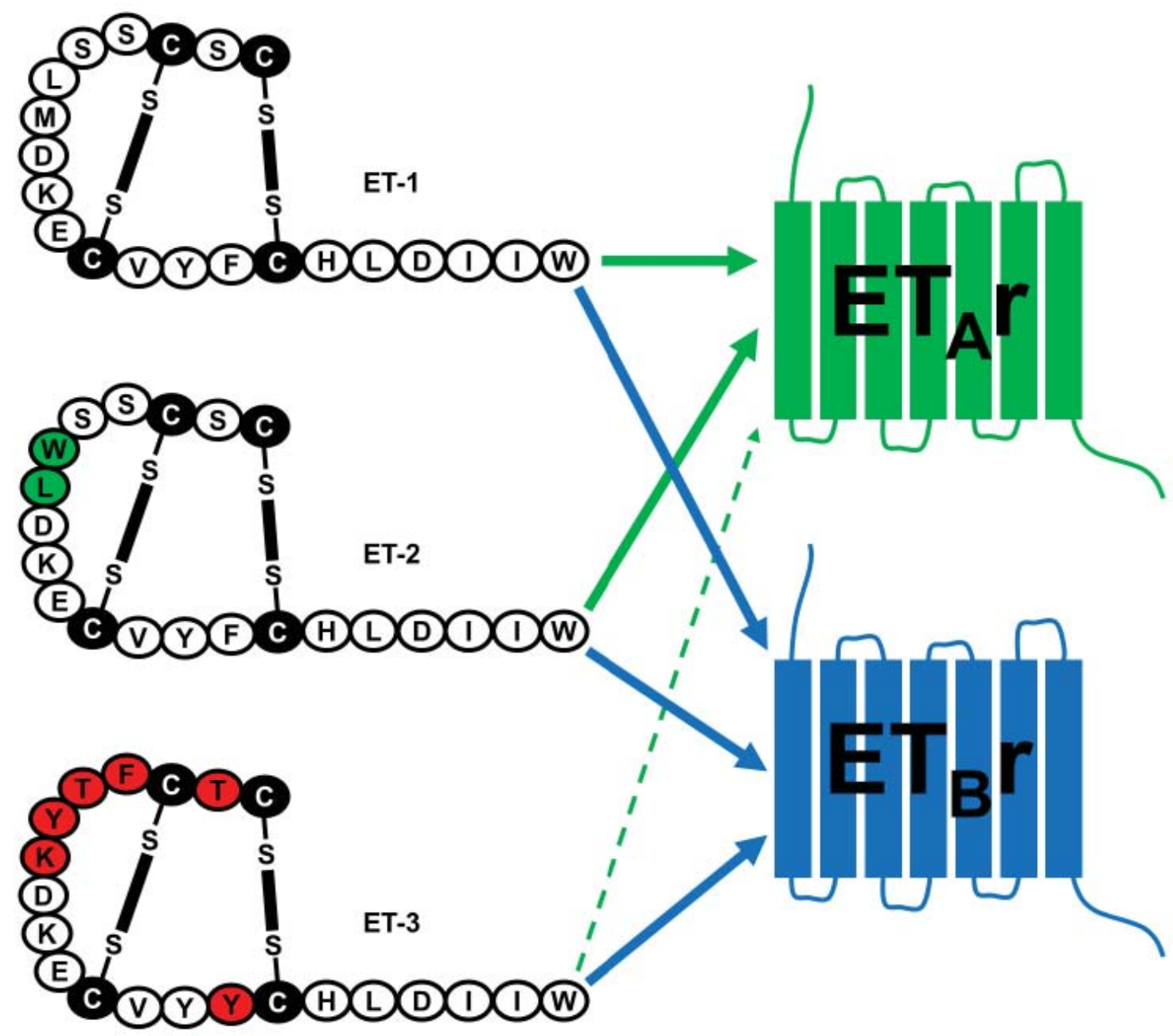

Figure 1.1. Amino acid structure of three ET isoforms and their preference for ET receptors.

Each ET isoform has its own gene, precursor peptides and enzymes to form the final effector 21 amino acid bicyclic peptide [3, 24], so (regulation of) expression of each isoform is distinct from the others.

\section{The Endothelin receptors}

An $\mathrm{ET}_{\mathrm{A}}$ receptor is a flexible 7TMR protein that can isomerize between inactive and active conformations. Binding of an endogenous agonist to its orthosteric binding site on the receptor promotes transition of the receptor from an inactive to an active state that can interact with intracellular proteins involved in signal transduction [25]. The $\mathrm{ET}_{\mathrm{A}}$ receptor interacts with several of these intracellular G-proteins, including $G_{0} \alpha, G_{i 3} \alpha, G_{i 1} \alpha, G_{i 2} \alpha$ and $G_{q} \alpha / G_{11} \alpha$. It depends on the agonist used to activate the $\mathrm{ET}_{\mathrm{A}}$ receptor which specific $\mathrm{G}$-protein further mediates downstream signaling [26]. 
These downstream mechanisms can involve calcium influx and activation of phospholipase C- $\beta$ (PLC- $\beta$ ), protein kinase C (PKC) and Rho-Kinase, and these intracellular mediators can in turn act as effectors of vasospasms, oxidative stress, cellular proliferation etc [10].

The $\mathrm{ET}_{\mathrm{A}}$ receptor can be phosphorylated by G-receptors kinases (GRKs) and can subsequently bind arrestins [27-29]. Originally it was proposed that activated $G$ proteins, GRK activity and arrestin binding cause desensitization, tachyphylaxis, internalization and tolerance of agonist-induced effects [30]. However, because $\mathrm{ET}_{\mathrm{A}}$ mediated vasoconstrictor responses persist for a long time, chronically activated $\mathrm{ET}_{\mathrm{A}}$ seems to be little affected by these negative feedback mechanisms. The long-lasting responses may involve tight binding of agonists to their receptors [31, 32], but this would not explain the molecular mechanisms of ongoing signaling by activated $\mathrm{ET}_{\mathrm{A}}$.

$\mathrm{ET}_{\mathrm{A}}$ activation is promoted by binding of the endogenous peptidergic agonists to their orthosteric binding sites on the receptor. As previously mentioned, ET-3, which differs on 6 amino acid positions from ET-1 and ET-2 (Fig. 1.1), has much lower affinity for $\mathrm{ET}_{\mathrm{A}}$ receptors compared to ET-1 and ET-2 [4]. Truncation, amidation or extension of the C-terminal Trp $^{21}$ of ET-1 abolishes binding [33-35]. The linear analogue 4 ${ }^{\mathrm{Ala}} \mathrm{ET}-1$, in which both disulfide bonds are absent due to cysteine to alanine replacement, also does not bind to $\mathrm{ET}_{\mathrm{A}}$ receptors [36, 37]. These observations indicate that the C-terminal tail, selected amino acids in the $\mathrm{N}$-terminal loop and both disulfide bonds are all required for polyvalent binding of endogenous peptides to $\mathrm{ET}_{\mathrm{A}}$ receptors $[38$, 39]. The orthosteric binding site of $\mathrm{ET}_{\mathrm{A}}$ receptors would thus contain more than one functional domain. Studies using site-directed mutagenesis, chimeric receptors and photoaffinity labeling indicate that these orthosteric binding domains are located between transmembrane helices 1, 2, 3 and 7, and between transmembrane helices 4, 5 and 6 of $\mathrm{ET}_{\mathrm{A}}$ receptors [40-43], (Fig. 1.2).

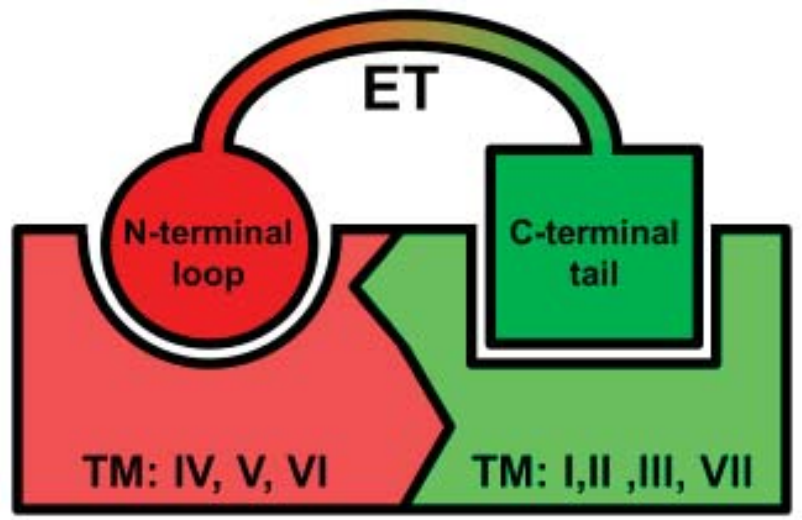

$E T_{A} r$
Figure 1.2. Schematic representation of the interaction between $E T$ and $\mathrm{ET}_{\mathrm{A}}$. The initial interaction occurs when the ET C-terminal tail binds to the domain on $\mathrm{ET}_{\mathrm{A}}$ consisting of TM I-III and VII. Consecutively the ET N-terminal loop can bind to another binding domain on $\mathrm{ET}_{\mathrm{A}}$ consisting of TM IV-VI. 


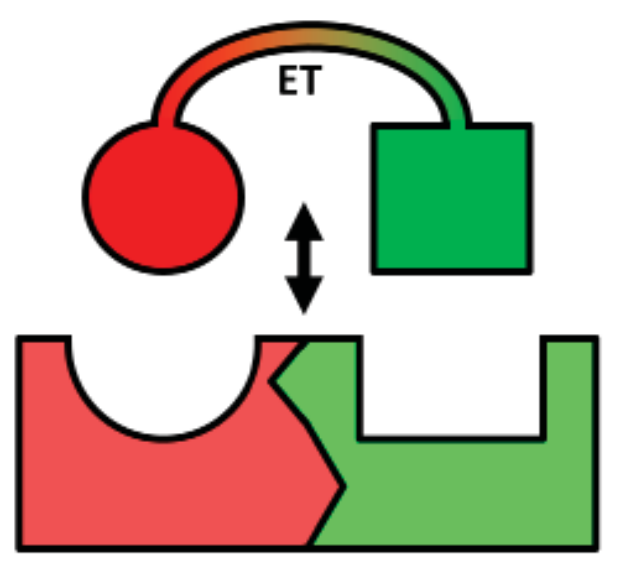

$\mathrm{ET}_{\mathrm{A}} \mathrm{r}$

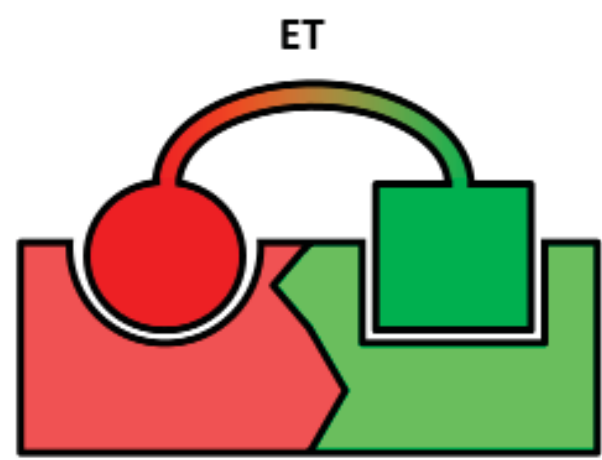

$\mathrm{ET}_{\mathrm{A}} \mathrm{r}$

Figure 1.3. The 'dynamic' interaction of $E T$ with $\mathrm{ET}_{\mathrm{A}}$ receptors. When the dissociation rate constant $\left(\mathrm{k}_{-1}\right)$ is considerably less than the association rate constant $\left(\mathrm{k}_{+1}\right)$, a low concentration can locally act with high potency as a tight binding paracrine mediator.

Conditions of dynamic equilibrium govern most classical and modern theories of molecular pharmacology [44]. These conditions do not easily apply to $\mathrm{ET}_{\mathrm{A}}$ in view of the slow dissociation of $\mathrm{ET}-1 / \mathrm{ET}_{\mathrm{A}}$ receptor complexes [32, 45, 46]. Hence, reported affinity measures such as the 'equilibrium' dissociation rate constant $\mathrm{K}_{\mathrm{d}}$ are mere approximations. When the dissociation rate constant of the agonist/receptor complex $\left(k_{-1}\right)$ is considerably less than its association rate constant $\left(k_{+1}\right)$, very low concentrations of agonist can act locally with high potency because $\mathrm{K}_{\mathrm{d}}=\mathrm{k}_{-1} / \mathrm{k}_{+1}$ (Fig. 1.3) $[47,48]$.

This is an effective mechanism for a paracrine mediator. However, conditions of dynamic equilibrium become hard to establish in routine experimental settings such as acute concentration-response studies. Not only is the agonist concentration a crucial factor, but the duration and history of agonist exposure (and therefore the patience of the scientist) also become determining factors that influence binding and effects. Theoretically, both tightness of agonist/receptor complexes and slow reversibility of receptor activation can contribute to long-lasting agonism. Both mechanisms complicate the potential of an antagonist to inhibit the agonist-induced responses. Additionally, physiology requires a counterbalancing system, likely to be located in the arterial wall itself, to functionally antagonize the persistent constrictor responses induced by ETs. Candidate functional antagonists include endotheliumderived nitric oxide (NO), the release of which can be stimulated by ET-1 [49], or vasodilator neurotransmitters from peri-arterial sensory-motor nerves, of which the release can also be stimulated by ET-1 $[50,51]$. 


\section{Receptor antagonists}

An antagonist is still frequently seen as an agent that can occupy an orthosteric binding site on the receptor (i.e. where the endogenous ligand binds to, and activates, the receptor) without altering the activation of the receptor: a neutral competitive antagonist [25]. In general pharmacology, however, an antagonist is defined as a drug that reduces the action of another drug, generally an agonist [47]. An antagonist can therefore be a chemical antagonist, a functional antagonist, a physiological antagonist, a neutral competitive antagonist, an inverse agonist and a negative allosteric modulator.

An allosteric modulator is, as its name suggests, a compound that modulates a receptor by binding to a site on the receptor, other than the orthosteric site; an allosteric site (Fig. 1.4). These allosteric sites are an interesting drug target for several reasons. Evolution may pressure a receptor to accommodate endogenous ligands on an orthosteric site, but may spare an allosteric site from this pressure. An allosteric site might therefore be a drugable target unique to its receptor,which infers that targeting an allosteric site could yield drugs with greater receptor subtype selectivity, a more physiological signaling profile and a greater efficacy/safety profile [52].

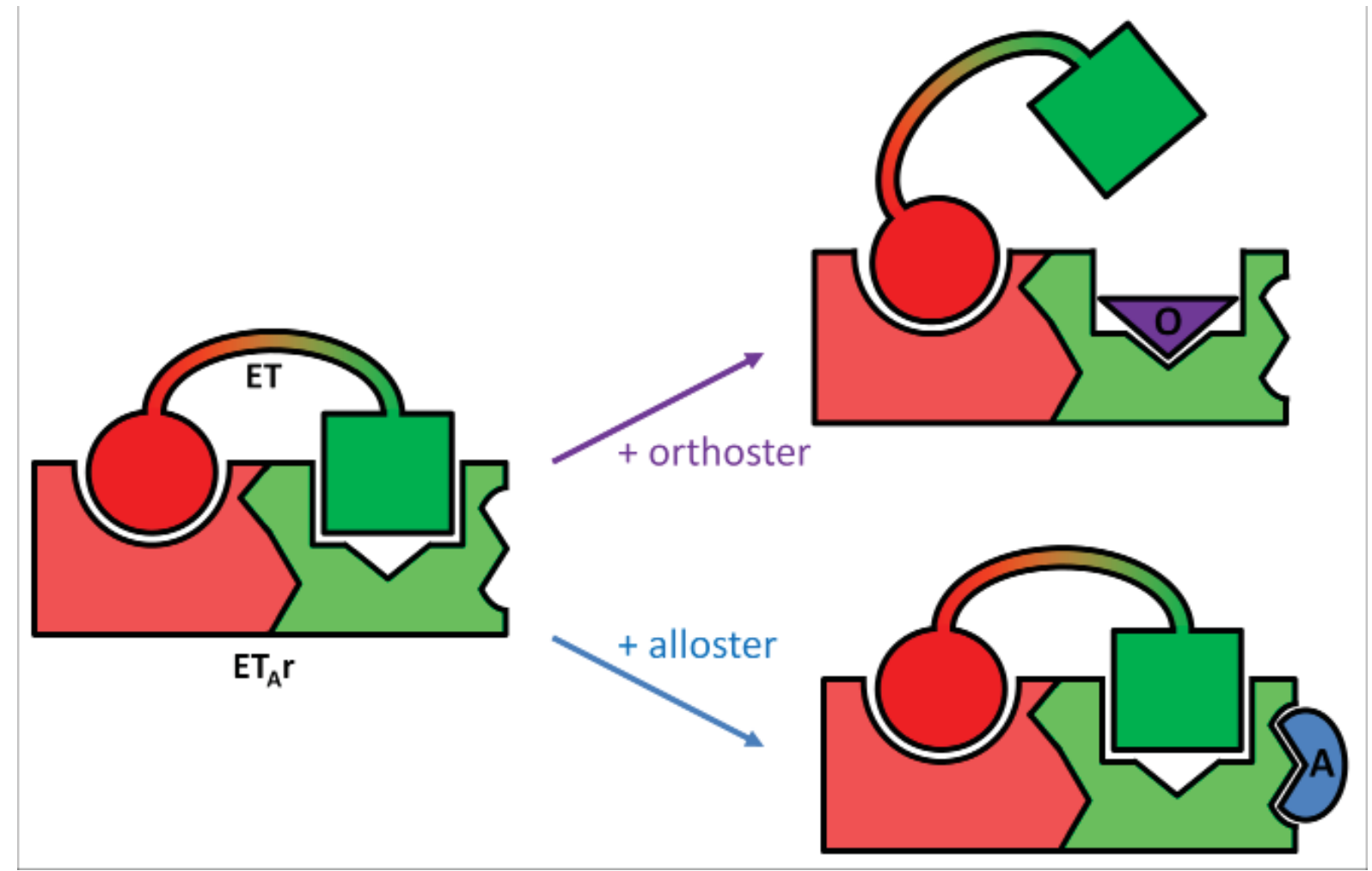

Figure 1.4. Mechanisms by which an antagonist can interact with an agonist/receptor complex. An orthosteric antagonist would bind to a site on the receptor shared with the agonist. An allosteric antagonist can bind to a distinct site on the receptor, away from the agonist binding site. 
The concept of allosterism in itself describes one kind of interaction by a compound (with its receptor) (Fig. 1.4), but the nature of an alloster can necessitate detailed nomenclature [53]. Positive allosteric modulators (PAMs) and negative allosteric modulators (NAMs), i.e. ligands that increase or decrease receptor activity, respectively, can be further specified into enhancers, enhancer-inhibitors and allocompetitors, amongst others.

To complicate the matter even further, labeling a compound an orthoster or alloster is all a matter of perspective [54]. An endogenous ligand of a 7TMR can be considered an orthoster as it increases receptor activation by binding to the extracellular site. However, an intracellular bound G-protein alters receptor activity and could therefore be considered an orthoster, which automatically makes the endogenous ligand on the extracellular site of the receptor an alloster.

So what about ET receptor antagonists (ERAs)? Soon after the discovery of ET-1 and the cloning of its $\mathrm{ET}_{\mathrm{A}}$ and $\mathrm{ET}_{\mathrm{B}}$ receptors, low molecular weight compounds were identified that can prevent the binding of radioactively labeled ET-1 [55, 56]. These ERAs initially resulted from screening efforts (e.g. BQ123 [57] and bosentan [58]) and later, rational drug design focused on the C-terminal hexapeptide that is common to all endogenous ET peptides, resulting in several classes of ERAs available nowadays [59], of which a few well-described ERAs are listed in Table 1.1.

Table 1.1. Characteristics of widely used ERAs.

\begin{tabular}{|l|l|l|l|ll|l} 
Name & Class & MW & ET $_{A}$ IC $_{50}$ (nM) & ET $_{\text {B }}$ IC $_{50}$ (nM) & Selective \\
\hline BQ123 [57] & peptide-based & 611 & 22 & 18000 & $\mathrm{ET}_{\mathrm{A}}$ \\
FR139317 [60] & peptide-based & 591 & 0.53 & 4050 & $\mathrm{ET}_{\mathrm{A}}$ \\
PD156707 [61] & butenolide & 507 & 0.31 & 417 & $\mathrm{ET}_{\mathrm{A}}$ \\
BMS193884 [62] & biphenyl sulfonamide & 395 & 1.4 & 1900 & $\mathrm{ET}_{\mathrm{A}}$ \\
Bosentan [58] & pyrimidine sulfonamide & 552 & 4.7 & 95 & -
\end{tabular}

Some of these discriminate between ET receptor subtypes, whereas others do not [63]. Literature suggests that all ERAs act as neutral competitive antagonists. However, ERAs can prevent agonist binding, but do not reverse established agonistreceptor complexes in membrane preparations [32, 46], adding evidence for the tight nature of the agonist/receptor complexes. As a result, certain ERAs prevent responses to ET-1 but do not influence responses that were initiated by the peptide [31]. As mentioned earlier, the endothelin system is (still) considered as a promising therapeutic target [9, 64]. Antagonizing the ET-receptors, either selectively against $\mathrm{ET}_{\mathrm{A}}$ or non-selectively against both $\mathrm{ET}_{\mathrm{A}}$ and $\mathrm{ET}_{\mathrm{B}}$, is currently the preferred approach, 
rather than targeting ET-production [65] or ET breakdown [66]. In addition to its obvious potential in the cardiovascular system, in which currently the only clinically approved ET receptor antagonists, bosentan $\left(\right.$ Tracleer $^{\circledR}$ ) and ambrisentan (Volitris ${ }^{\circledR}$ ) are used to treat pulmonary arterial hypertension $[67,68]$, targeting the ET system is considered in other pathophysiological conditions. Because ET-1 and its receptors have emerged as relevant players in tumor growth and metastasis, by e.g. regulating mitogenesis and cell survival [69], its therapeutic window in treatment of cancer, specifically ovarian cancer, is currently being studied [8]. Targeting $\mathrm{ET}_{\mathrm{A}}$ receptors in cancer would not only benefit cancer treatment, but also cancer-related pain [70]. And in other types of pain, whether the pain is related to an inflammatory responses or an acute pain, ET-1 appears to induce nociception that could be treated, to some extent, by the use of ERAs [71]. And since ET-1 regulates cell proliferation and extracellular matrix turnover, patients that suffer from scleroderma is another patient group that could benefit from anti-ET drugs [72].

\section{Relevance for anti-ET therapy}

Some of the clinical trials with ERAs have been less successful than anticipated [13, $55,56]$, perhaps as a result of underestimation of the complexity of the molecular pharmacology of $\mathrm{ET}_{\mathrm{A}}$ receptors. To resolve this, it will be necessary to define the signaling mechanisms during the long-lasting effects resulting from $\mathrm{ET}_{\mathrm{A}}$ stimulation. Testing of reversing or curative effects of putative antagonists, either functional or acting on $\mathrm{ET}_{\mathrm{A}}$, should take into consideration that ET-1 dissociates only slowly from $\mathrm{ET}_{\mathrm{A}}$ receptors.

Functional antagonists of $\mathrm{ET}_{\mathrm{A}}$ receptors are any vasodilator compound that (in) directly relaxes $\mathrm{ET}_{\mathrm{A}}$ mediated vasoconstriction. In a recent study this is the case for not only NO and calcitonin gene-related peptide (CGRP), but also for forskolin (direct stimulus of adenylate cyclase), isoproterenol ( $\beta$-adrenergic stimulus of adenylate cyclase) and pinacidil ( $\mathrm{K}_{\text {ATP }}$-channel opener) [73].

It is worth considering currently available, but also future ERAs, as negative allosteric modulators. Criteria of allosterism that could be addressed [54, 74, 75] include distinct effects on apparent agonist affinity and efficacy, probe/agonist-dependence and system dependence. These approaches could result in drugs that become more effective when the endogenous ET system is more activated, and in drugs that can discriminate between $\mathrm{ET}_{\mathrm{A}}$ mediated effects of the distinct endogenous agonists $\mathrm{ET}$ 1, ET-2 and ET-3. 


\section{Aim of this thesis}

$\mathrm{ET}_{\mathrm{A}}$ receptors have a rather unique pharmacology regarding their interactions with their endogenous ligands. This is not compatible with homeostasis of the vascular system, unless an endogenous system exists that counterbalances effects of the tight agonism of the $\mathrm{ET}_{\mathrm{A}}$ agonists. Therefore, firstly we aimed to find which physiological mechanism could effectively counterbalance the vascular responses to $\mathrm{ET}$-1-induced, $\mathrm{ET}_{\mathrm{A}}$ mediated responses (Chapter 2).

Because this a-typical receptor pharmacology complicates utilizing the therapeutic potential of targeting the $\mathrm{ET}_{\mathrm{A}}$ receptors in various pathologies, we secondly aimed to characterize to which extent the amino acid structure of the endogenous agonists contributes to the tight binding to and activation of $\mathrm{ET}_{\mathrm{A}}$ receptors (Chapter 3 ).

Thirdly, we aimed to determine which of the intracellular signaling mechanisms is responsible for the long-lasting, persistent responses to $\mathrm{ET}_{\mathrm{A}}$ agonists (Chapter 4).

Fourthly, we aimed to define in more detail the interaction of $E T s$ with $\mathrm{ET}_{\mathrm{A}}$ receptors and to define a role for allosteric modulators rather than neutral competitive antagonists to interact with $\mathrm{ET}_{\mathrm{A}}$ receptors (Chapter 5).

Finally, we will discuss the implications of our findings and how, in the future, our work can contribute to better, more effective compounds to (therapeutically) target $\mathrm{ET}_{\mathrm{A}}$ receptors (Chapter 6). 


\section{References}

1. De Mey, J.G., et al. (1982) Endothelium-dependent inhibitory effects of acetylcholine, adenosine triphosphate, thrombin and arachidonic acid in the canine femoral artery. J Pharmacol Exp Ther 222, 166-173

2. Yanagisawa, M., et al. (1988) A novel potent vasoconstrictor peptide produced by vascular endothelial cells. Nature 332, 411-415

3. Inoue, A., et al. (1989) The human endothelin family: three structurally and pharmacologically distinct isopeptides predicted by three separate genes. Proc Natl Acad Sci U S A 86, 2863-2867

4. Davenport, A.P. (2002) International Union of Pharmacology. XXIX. Update on endothelin receptor nomenclature. Pharmacol Rev 54, 219-226

5. Rubanyi, G.M., and Polokoff, M.A. (1994) Endothelins: molecular biology, biochemistry, pharmacology, physiology, and pathophysiology. Pharmacol Rev 46, 325-415

6. Aramori, I., and Nakanishi, S. (1992) Coupling of two endothelin receptor subtypes to differing signal transduction in transfected Chinese hamster ovary cells. J Biol Chem 267, 12468-12474

7. Lin, H.Y., et al. (1991) Cloning and functional expression of a vascular smooth muscle endothelin 1 receptor. Proc Natl Acad Sci U S A 88, 3185-3189

8. Rosano, L., et al. (2010) The importance of endothelin axis in initiation, progression, and therapy of ovarian cancer. Am J Physiol Regul Integr Comp Physiol 299, R395-404

9. Barton, M., and Yanagisawa, M. (2008) Endothelin: 20 years from discovery to therapy. Can J Physiol Pharmacol 86, 485-498

10. Masaki, T. (2004) Historical review: Endothelin. Trends Pharmacol Sci 25, 219224

11. Fukuroda, T., et al. (1994) Clearance of circulating endothelin-1 by ETB receptors in rats. Biochem Biophys Res Commun 199, 1461-1465

12. Johnstrom, P., et al. (2005) Positron emission tomography using 18F-labelled endothelin-1 reveals prevention of binding to cardiac receptors owing to tissuespecific clearance by ET B receptors in vivo. Br J Pharmacol 144, 115-122

13. Schneider, M.P., et al. (2007) Contrasting actions of endothelin ET(A) and ET(B) receptors in cardiovascular disease. Annu Rev Pharmacol Toxicol 47, 731-759

14. Maggi, C.A., et al. (1989) The C-terminal hexapeptide, endothelin-(16-21), discriminates between different endothelin receptors. Eur J Pharmacol 166, $121-122$

15. Arai, H., et al. (1990) Cloning and expression of a cDNA encoding an endothelin receptor. Nature 348, 730-732 
16. Sakurai, T., et al. (1992) Molecular characterization of endothelin receptors. Trends Pharmacol Sci 13, 103-108

17. Ito, H., et al. (1993) Endothelin-1 is an autocrine/paracrine factor in the mechanism of angiotensin II-induced hypertrophy in cultured rat cardiomyocytes. $\mathrm{J}$ Clin Invest 92, 398-403

18. Shichiri, M., et al. (1991) Endothelin-1 is an autocrine/paracrine growth factor for human cancer cell lines. J Clin Invest 87, 1867-1871

19. Ko, C., et al. (2006) Endothelin-2 in ovarian follicle rupture. Endocrinology 147, 1770-1779

20. Levin, E.R. (1995) Endothelins. N Engl J Med 333, 356-363

21. Takizawa, S., et al. (2005) Differential expression of endothelin-2 along the mouse intestinal tract. J Mol Endocrinol 35, 201-209

22. Baynash, A.G., et al. (1994) Interaction of endothelin-3 with endothelin-B receptor is essential for development of epidermal melanocytes and enteric neurons. Cell 79, 1277-1285

23. Edery, P., et al. (1996) Mutation of the endothelin-3 gene in the WaardenburgHirschsprung disease (Shah-Waardenburg syndrome). Nature genetics 12, $442-$ 444

24. Masaki, T., et al. (1991) Molecular and cellular mechanism of endothelin regulation. Implications for vascular function. Circulation 84, 1457-1468

25. Deupi, X., and Kobilka, B.K. (2010) Energy landscapes as a tool to integrate GPCR structure, dynamics, and function. Physiology (Bethesda) 25, 293-303

26. Shraga-Levine, Z., and Sokolovsky, M. (2000) Functional coupling of G proteins to endothelin receptors is ligand and receptor subtype specific. Cellular and molecular neurobiology 20, 305-317

27. Bremnes, T., et al. (2000) Regulation and intracellular trafficking pathways of the endothelin receptors. J Biol Chem 275, 17596-17604

28. Morris, G.E., et al. (2010) Endothelin signalling in arterial smooth muscle is tightly regulated by $\mathrm{G}$ protein-coupled receptor kinase 2. Cardiovasc Res $85,424-433$

29. Maguire, J.J., et al. (2012) Comparison of human ETA and ETB receptor signalling via G-protein and beta-arrestin pathways. Life Sci 91, 544-549

30. Lefkowitz, R.J. (2004) Historical review: a brief history and personal retrospective of seven-transmembrane receptors. Trends Pharmacol Sci 25, 413-422

31. Adner, M., et al. (2001) Evidence that ET-1, but not ET-3 and S6b, ET(A)-receptor mediated contractions in isolated rat mesenteric arteries are modulated by coactivation of $\mathrm{ET}(\mathrm{B})$ receptors. Br J Pharmacol 133, 927-935

32. Hilal-Dandan, R., et al. (1997) The quasi-irreversible nature of endothelin binding and $\mathrm{G}$ protein-linked signaling in cardiac myocytes. J Pharmacol Exp Ther 281, 267-273 
33. Fecteau, M.H., et al. (2005) Endothelin-1 (1-31) is an intermediate in the production of endothelin-1 after big endothelin-1 administration in vivo. Hypertension 46, 87-92

34. Tam, J.P., et al. (1994) Alanine scan of endothelin: importance of aromatic residues. Peptides 15, 703-708

35. Nakajima, K., et al. (1989) Structure-activity relationship of endothelin: importance of charged groups. Biochem Biophys Res Commun 163, 424-429

36. Bigaud, M., and Pelton, J.T. (1992) Discrimination between ETA- and ETBreceptor-mediated effects of endothelin-1 and [Ala1,3,11,15]endothelin-1 by BQ123 in the anaesthetized rat. Br J Pharmacol 107, 912-918

37. Saeki, T., et al. (1991) [Ala1,3,11,15]endothelin-1 analogs with ETB agonistic activity. Biochem Biophys Res Commun 179, 286-292

38. Lattig, J., et al. (2009) Structural determinants for selective recognition of peptide ligands for endothelin receptor subtypes ETA and ETB. J Pept Sci 15, 479-491

39. Sakamoto, A., et al. (1993) The ligand-receptor interactions of the endothelin systems are mediated by distinct "message" and "address" domains. J Cardiovasc Pharmacol 22 Suppl 8, S113-116

40. Breu, V., et al. (1995) Separable binding sites for the natural agonist endothelin-1 and the non-peptide antagonist bosentan on human endothelin-A receptors. Eur J Biochem 231, 266-270

41. Orry, A.J., and Wallace, B.A. (2000) Modeling and docking the endothelin G-protein-coupled receptor. Biophysical journal 79, 3083-3094

42. Webb, M.L., et al. (1996) Mutational analysis of the endothelin type A receptor (ETA): interactions and model of selective ETA antagonist BMS-182874 with putative ETA receptor binding cavity. Biochemistry 35, 2548-2556

43. Masaki, T., et al. (1999) Structural basis of the function of endothelin receptor. Mol Cell Biochem 190, 153-156

44. Kenakin, T. (2004) Principles: receptor theory in pharmacology. Trends Pharmacol Sci 25, 186-192

45. Blandin, V., et al. (2000) Allosteric inhibition of endothelin ETA receptors by 3 , 5-dibromosalicylic acid. Mol Pharmacol 58, 1461-1469

46. Talbodec, A., et al. (2000) Aspirin and sodium salicylate inhibit endothelin ETA receptors by an allosteric type of mechanism. Mol Pharmacol 57, 797-804

47. Neubig, R.R., et al. (2003) International Union of Pharmacology Committee on Receptor Nomenclature and Drug Classification. XXXVIII. Update on terms and symbols in quantitative pharmacology. Pharmacol Rev 55, 597-606

48. Vauquelin, G., and Van Liefde, I. (2006) Slow antagonist dissociation and longlasting in vivo receptor protection. Trends Pharmacol Sci 27, 356-359 
49. Hirata, Y., et al. (1993) Endothelin receptor subtype B mediates synthesis of nitric oxide by cultured bovine endothelial cells. J Clin Invest 91, 1367-1373

50. Plant, T.D., et al. (2007) Endothelin potentiates TRPV1 via ETA receptormediated activation of protein kinase $\mathrm{C}$. Molecular pain 3, 35

51. Wang, Y., and Wang, D.H. (2004) Prevention of endothelin-1-induced increases in blood pressure: role of endogenous CGRP. Am J Physiol Heart Circ Physiol 287, H1868-1874

52. Christopoulos, A., et al. (2004) G-protein-coupled receptor allosterism: the promise and the problem(s). Biochem Soc Trans 32, 873-877

53. Bindslev, N. (2013) Allosteric transition. A comparison of two models. BMC pharmacology \& toxicology 14,4

54. Kenakin, T., and Miller, L.J. (2010) Seven transmembrane receptors as shapeshifting proteins: the impact of allosteric modulation and functional selectivity on new drug discovery. Pharmacol Rev 62, 265-304

55. Hynynen, M.M., and Khalil, R.A. (2006) The vascular endothelin system in hypertension--recent patents and discoveries. Recent patents on cardiovascular drug discovery 1, 95-108

56. Kirkby, N.S., et al. (2008) The endothelin system as a therapeutic target in cardiovascular disease: great expectations or bleak house? $\mathrm{Br} \mathrm{J}$ Pharmacol $153,1105-1119$

57. Ihara, M., et al. (1992) Biological profiles of highly potent novel endothelin antagonists selective for the ETA receptor. Life Sci 50, 247-255

58. Clozel, M., et al. (1994) Pharmacological characterization of bosentan, a new potent orally active nonpeptide endothelin receptor antagonist. J Pharmacol Exp Ther 270, 228-235

59. Doherty, A.M., et al. (1993) Structure-activity relationships of C-terminal endothelin hexapeptide antagonists. J Med Chem 36, 2585-2594

60. Sogabe, K., et al. (1993) Pharmacological profile of FR139317, a novel, potent endothelin ETA receptor antagonist. J Pharmacol Exp Ther 264, 1040-1046

61. Patt, W.C., et al. (1997) Structure-activity relationships in a series of orally active gamma-hydroxy butenolide endothelin antagonists. J Med Chem 40, 1063-1074

62. Saad, D., et al. (1998) The effects of endothelin-A receptor blockade during the progression of pacing-induced congestive heart failure. Journal of the American College of Cardiology 32, 1779-1786

63. Palmer, M.J. (2009) Endothelin receptor antagonists: status and learning 20 years on. Prog Med Chem 47, 203-237

64. Kohan, D.E., et al. (2012) Clinical trials with endothelin receptor antagonists: what went wrong and where can we improve? Life Sci 91, 528-539 
65. Nelissen, J., et al. (2012) Pharmacokinetic and pharmacodynamic properties of SOL1: a novel dual inhibitor of neutral endopeptidase and endothelin converting enzyme. Life Sci 91, 587-592

66. Abassi, Z.A., et al. (1992) Role of neutral endopeptidase in the metabolism of endothelin. Hypertension 20, 89-95

67. Channick, R.N., et al. (2001) Effects of the dual endothelin-receptor antagonist bosentan in patients with pulmonary hypertension: a randomised placebocontrolled study. Lancet 358, 1119-1123

68. Galie, N., et al. (2008) Ambrisentan for the treatment of pulmonary arterial hypertension: results of the ambrisentan in pulmonary arterial hypertension, randomized, double-blind, placebo-controlled, multicenter, efficacy (ARIES) study 1 and 2. Circulation 117, 3010-3019

69. Bagnato, A., and Rosano, L. (2008) The endothelin axis in cancer. Int J Biochem Cell Biol 40, 1443-1451

70. Peters, C.M., et al. (2004) Endothelin and the tumorigenic component of bone cancer pain. Neuroscience 126, 1043-1052

71. Khodorova, A., et al. (2009) Endothelin receptors and pain. J Pain 10, 4-28

72. Xu, S., et al. (1998) Endothelins: effect on matrix biosynthesis and proliferation in normal and scleroderma fibroblasts. J Cardiovasc Pharmacol 31 Suppl 1, S360-363

73. Meens, M.J., et al. (2009) Calcitonin gene-related peptide selectively relaxes contractile responses to endothelin-1 in rat mesenteric resistance arteries. $J$ Pharmacol Exp Ther 331, 87-95

74. Christopoulos, A., and Kenakin, T. (2002) G protein-coupled receptor allosterism and complexing. Pharmacol Rev 54, 323-374

75. Keov, P., et al. (2011) Allosteric modulation of $G$ protein-coupled receptors: a pharmacological perspective. Neuropharmacology 60, 24-35 


\section{Chapter 2}

Stimuli of Sensory-Motor Nerves Terminate Arterial Contractile EFFeCts of ENDOthelin-1 by CGRP and DisSOCIATION of ET-1/ET A RECEPTOR COMPLEXES

Merlijn JPMT Meens, Matthijs G Compeer, Tilman M Hackeng, Marc A van Zandvoort, Ben Ja Janssen, Jo GR De Mey PLOS ONE 2010 JUN 1;5(6):E10917 


\begin{abstract}
Endothelin-1 (ET-1), a long-acting paracrine mediator, is implicated in cardiovascular diseases but clinical trials with ET-receptor antagonists were not successful in some areas. We tested whether the quasi-irreversible receptor-binding of ET-1 (i) limits reversing effects of the antagonists and (ii) can be selectively dissociated by an endogenous counterbalancing mechanism.

In isolated rat mesenteric resistance arteries, $\mathrm{ET}_{\mathrm{A}}$-antagonists, endothelium-derived relaxing factors and synthetic vasodilators transiently reduced contractile effects of ET-1 but did not prevent persistent effects of the peptide. Stimuli of peri-vascular vasodilator sensory-motor nerves such as capsaicin not only reduced but also terminated long-lasting effects of ET-1. This was prevented by CGRP-receptor antagonists and was mimicked by exogenous calcitonin gene-related peptide (CGRP). Using 2-photon laser scanning microscopy in vital intact arteries, capsaicin and CGRP, but not $\mathrm{ET}_{\mathrm{A}}$-antagonism, were observed to promote dissociation of preexisting $\mathrm{ET}-1 / \mathrm{ET}_{\mathrm{A}}$-receptor complexes.

Irreversible binding and activation of $\mathrm{ET}_{\mathrm{A}}$-receptors by $\mathrm{ET}$-1 (i) occur at an antagonistinsensitive site of the receptor and (ii) are selectively terminated by endogenously released CGRP. Hence, natural stimuli of sensory-motor nerves that stimulate release of endogenous CGRP can be considered for therapy of diseases involving ET-1.
\end{abstract}




\section{Introduction}

Prototypic G-protein coupled receptors (GPCR) are characterized by tight agonist concentration-response relationships on the short run and by tolerance on the long run. For instance, acute $\beta_{2}$-adrenoceptor stimulated cAMP production and the resulting smooth muscle relaxation are readily reversible as a result of rapid dissociation of the agonist-receptor complexes. This property underlies the therapeutic applicability of drugs that inhibit the synthesis or the receptor-binding of endogenous GPCR-agonists. During prolonged exposure to agonists, $\beta_{2}$-adrenergic effects fade as a result of phosphorylation, desensitization, uncoupling from the G-proteins and internalization of the receptors (for review see [1]).

In sharp contrast, the GPCR-agonist endothelin-1 (ET-1) causes long-lasting effects. Its in vitro arterial contractile effects persist after thorough washout of the agonist [2]. Its in vivo vasopressor effects are maintained long after clearance of the peptide from the circulation by the lungs and the kidneys [3]. The 21 amino acid bicyclic peptide, that is constitutively expressed by the endothelium and that can be induced in several other cell types $[4,5]$, is implicated in several cardiovascular diseases $[4,6,7]$, cancers [8] and pain [9]. Its vasoconstrictor, pro-inflammatory, oxidative and mitogenic effects are mediated by $\mathrm{ET}_{\mathrm{A}}$ receptors $[4,6,7]$ while more beneficial effects such as endothelium-dependent vasodilatation and scavenging of circulating ET-1 are mediated by distantly related $\mathrm{ET}_{\mathrm{B}}$ receptors $[4-7,10] . \mathrm{ET}_{\mathrm{B}}$ agonism can be mimicked by short C-terminal fragments of ET-1 [11-13] but high affinity $E_{A}$ agonism requires the full length, both disulfide bonds and distinct amino acids in the $\mathrm{N}$-terminal loop of the peptide [12, 14-18]. This suggests that distinct parts of ET-1 have different functions in binding and activation of $\mathrm{ET}_{\mathrm{A}}$ receptors. Several classes of low molecular weight $\mathrm{ET}_{\mathrm{A}}$ selective or mixed $\mathrm{ET}$-receptor antagonists have been developed primarily on the basis of prevention of the binding of ET-1 to its receptors [4-6, 19-21]. These compounds are thought to compete with the C-terminal tail of the agonist. They can prevent ET-1-induced effects in vitro (for review see [2]) and in animal studies $[4,6,19]$. They are, however, less effective in reversing the effects of ET-1 in vitro [2], in animal studies [22] and in clinical trials [6, 23]. This may be due to the atypical properties of $\mathrm{ET}_{\mathrm{A}}$ receptors.

Irreversible agonism by ET-1 is incompatible with homeostasis unless counterbalancing systems exist. ET-1 can stimulate NO release from the endothelium [24]. NO reduces ET-1 synthesis [25] and counteracts vasoconstriction initiated by $\mathrm{ET}_{\mathrm{A}}$ receptors on smooth muscle cells $[4,7,26]$. ET-1 can also promote activity of transient receptor potential (TRP) cation channels that stimulate release of 
vasodilator neurotransmitters from peri-arterial sensory-motor nerves (SMN) [27, 28]. Hence, in cardiovascular diseases characterized by reduced bioavailability of endothelium-derived NO, ET-1 and $\mathrm{ET}_{\mathrm{A}}$ effects are upregulated [4] and can be tempered by counterbalancing effects of SMN [29-31]. Whether the latter involves functional antagonism or a selective effect on $\mathrm{ET}_{\mathrm{A}}$ receptors has not been addressed.

In this study, we hypothesized that polyvalent agonist-receptor binding by ET-1 limits reversing effects of ET-receptor antagonists and used physiological reasoning to search for a superior inhibitor. For these purposes we studied rat mesenteric arteries in which $\mathrm{ET}_{\mathrm{A}}$ and $\mathrm{ET}_{\mathrm{B}}$ receptors are expressed by several cell types [31-33]. We discovered that calcitonin-gene related peptide (CGRP) released from peri-arterial SMN terminates long-lasting vasoconstrictor effects of ET by promoting dissociation of $E T-1 / E_{A}$ receptor complexes.

\section{Results}

Key role of smooth muscle $E T_{A}$ receptors in long-lasting arterial contractile responses to $E T-1$

In isolated rat mesenteric resistance arteries, the $\mathrm{ET}_{\mathrm{B}}$ selective agonist $\mathrm{Ala}^{1,3,11,15} \mathrm{ET}-1$ [10] (1 nM-1 $\mu \mathrm{M})$ caused neither contraction (Table 1) nor relaxation (data not shown). In contrast, the non-selective agonist ET-1 [10] potently stimulated contractions (Fig. 2.1A, table 2.1). The concentration-response relationship was steep and the responses were quasi-irreversible $\left(T_{1 / 2}>20 \mathrm{~min}\right.$ versus $T_{1 / 2} \approx 30 \mathrm{sec}$ for similarly strong contractile responses to norepinephrine (NE) (Fig. 2.1A/B). Contractile effects

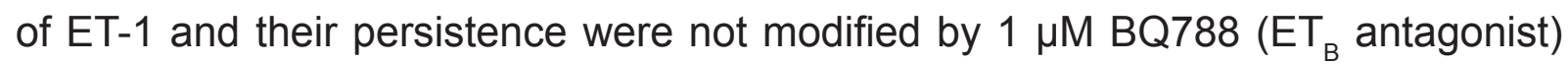
[10, 34], $100 \mu \mathrm{M}$ L-NAME and $10 \mu \mathrm{M}$ indomethacin (which reduce endothelial influences), nor by pre-treatment with capsaicin ( $1 \mu \mathrm{M}$ during $20 \mathrm{~min}$, which reduces effects of SMN) (Fig. 2.1A and table 2.1). Mechanical removal of the endothelium resulted in a small increase in the sensitivity for ET-1 (Table 2.1). The sensitivity to ET-1 was reduced in presence of the $\mathrm{ET}_{\mathrm{A}}$ antagonists BQ123 [10], [35] $(1 \mu \mathrm{M})$, SB234551 [10, 21] $(10 \mathrm{nM})$ or bosentan [10, 19] $(3 \mu \mathrm{M}$ studied in presence of $1 \mu \mathrm{M}$ $\mathrm{BQ788}$ to focus on $\mathrm{ET}_{\mathrm{A}}$ antagonism by bosentan, a mixed $\mathrm{ET}_{\mathrm{AB}}$ receptor antagonist) (Fig. 2.1A, Suppl. Fig. 2.1.1A).

Partial and transient reversing effects of $E T_{A}$ antagonists

Although BQ123, SB234551 and bosentan prevented contractile responses to up to 
Table 2.1. Arterial effects of ET-1 and two analogues.

\begin{tabular}{|c|c|c|c|c|}
\hline Agonist & Condition & $\mathrm{EC}_{50}(\mathrm{nM})$ & $E_{\max }\left(\% \mathrm{NE}_{\max }\right)$ & $\begin{array}{l}\text { Tension (\%NE }{ }_{\max } ; 8 \mathrm{~min} \text { after agonist } \\
\text { removal) }\end{array}$ \\
\hline \multirow[t]{4}{*}{$\mathrm{ET}-1$} & - & $4.9 \pm 0.8$ & $88.5 \pm 4.0$ & $80.9 \pm 3.5$ \\
\hline & Denuded & $2.1 \pm 0.2^{*}$ & $100.1 \pm 6.2$ & $82.54 \pm 5.4$ \\
\hline & L-NAME + INDO & $3.5 \pm 0.5$ & $100.4 \pm 5.0$ & $79.2 \pm 3.3$ \\
\hline & CAPS + L-NAME + INDO & $3.6 \pm 0.3$ & $104.0 \pm 4.0$ & $84.5 \pm 14.0$ \\
\hline Rh-ET-1 & CAPS + L-NAME + INDO & $4.1 \pm 0.3$ & $102.0 \pm 10.0$ & $80.6 \pm 14.6$ \\
\hline $\mathrm{Ala}^{1,3,11,15}$-ET-1 & CAPS + L-NAME + INDO & $>1 \mu \mathrm{M}$ & 0 & 0 \\
\hline
\end{tabular}

Potency, efficacy and persistence (response remaining at $8 \mathrm{~min}$ after agonist removal) are shown for arteries without and with pre-treatment with capsaicin (1 $\mu \mathrm{M}$, $20 \mathrm{~min} ;$ CAPS $)$ and presence of L-NAME $(100 \mu \mathrm{M})$ and indomethacin $(10 \mu \mathrm{M} ; \mathrm{INDO})$ and for denuded arteries. $n=6-10 . * 0<0.05$ vs control.

Figure 2.1. Partial and reversible A reversing effect of ET-receptor antagonists on arterial contractile responses to ET-1 and their persistence. Isolated rat mesenteric resistance arteries were studied after treatment with capsaicin and in continuous presence of L-NAME $(100 \mu \mathrm{M})$ and indomethacin $(10 \mu \mathrm{M}) . \mathrm{A}$, responses to $0.25-16 \mathrm{nM}$ $\mathrm{ET}-1$ in absence (black) and presence $\mathrm{C}$ of BQ123 $(1 \mu \mathrm{M}$, red), BQ788 $(1 \mu \mathrm{M}$, grey) or bosentan $(3 \mu \mathrm{M}$ in presence of $1 \mu \mathrm{M} \mathrm{BQ788,} \mathrm{blue).} \mathrm{BQ123} \mathrm{and}$ bosentan prevented responses to up to $8 \mathrm{nM} \mathrm{ET-1.} \mathrm{B,} \mathrm{vasomotor} \mathrm{tone} \mathrm{after}$ removal of free agonist and antagonist. $C$, effects of BQ123 and bosentan $(0.1-3.0 \mu \mathrm{M})$ in the presence of $8 \mathrm{nM}_{\mathrm{E}}$ ET-1. D, vasomotor tone after removal of free agonist and antagonist. E, effect of BQ123 $(1 \mu \mathrm{M})$ and bosentan $(3 \mu \mathrm{M})$ on contractile responses initiated by 8 nM ET-1 that persisted in absence of the peptide. $F$, vasomotor tone after removal of free antagonist. $n=6-20$. *, $\mathrm{P}<0.05$ vs. control.
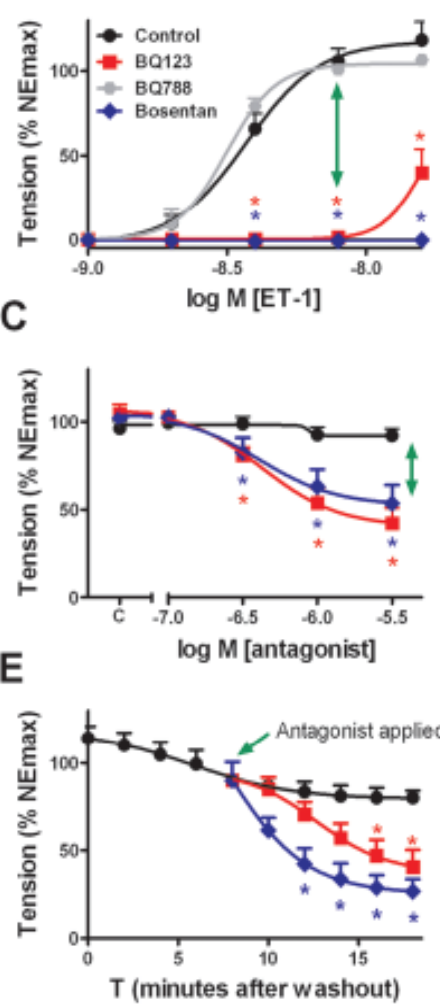

B

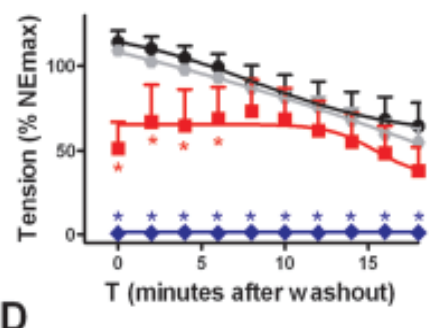

D
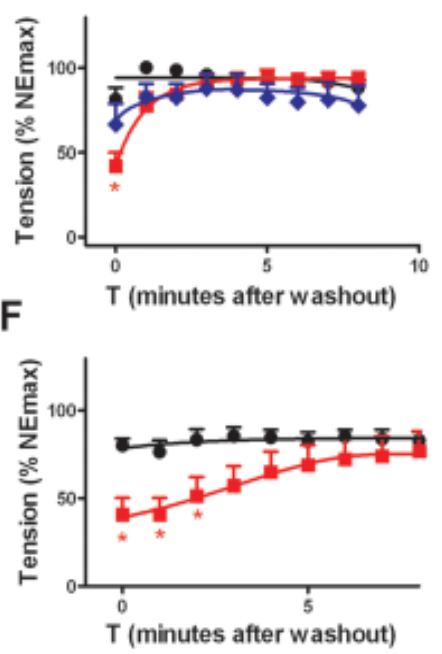

$8 \mathrm{nM}$ ET-1, the antagonists could only partly ( $\approx 50 \%)$ reverse contractile responses initiated by $8 \mathrm{nM}$ ET-1 (Fig. 2.1C, Suppl. Fig. 2.1.1C). The relaxing effect of the antagonists was reversible, i.e. vasomotor tone rapidly recovered after washout of the ET-receptor ligands (Fig. 2.1D, Suppl. Fig. 2.1.1D). This indicates irreversible agonism and reversible antagonism. In addition, contractile effects of ET-1 that persisted in absence of free agonist were partly and transiently reduced by the antagonists (Fig. 2.1E/F, Suppl. Fig. 2.1.1E/F).

\section{Transient reversing effects of endothelium-derived and exogenous vasodilators}

In contrast to ET-antagonists, several vasodilator stimuli fully reversed contractile responses to ET-1 (Fig. 2.2A). This was the case for acetylcholine (endotheliumdependent vasodilator), forskolin (direct activator of adenylyl cyclase), isoproterenol 
(beta-adrenergic stimulus of adenylyl cyclase), Na-nitroprusside (NO-donor) and pinacidil (activator of $\mathrm{K}_{\mathrm{ATP}}$-channels) (Fig. 2.2C). However, vasomotor tone rapidly recovered in absence of vasodilators and ET-1 (Fig. 2.2D). Moreover, contractions remaining after exposure to ET-1 could be relaxed by for instance acetylcholine (Fig. 2.3B) but again this inhibitory effect was reversible (Fig. 2.3C).

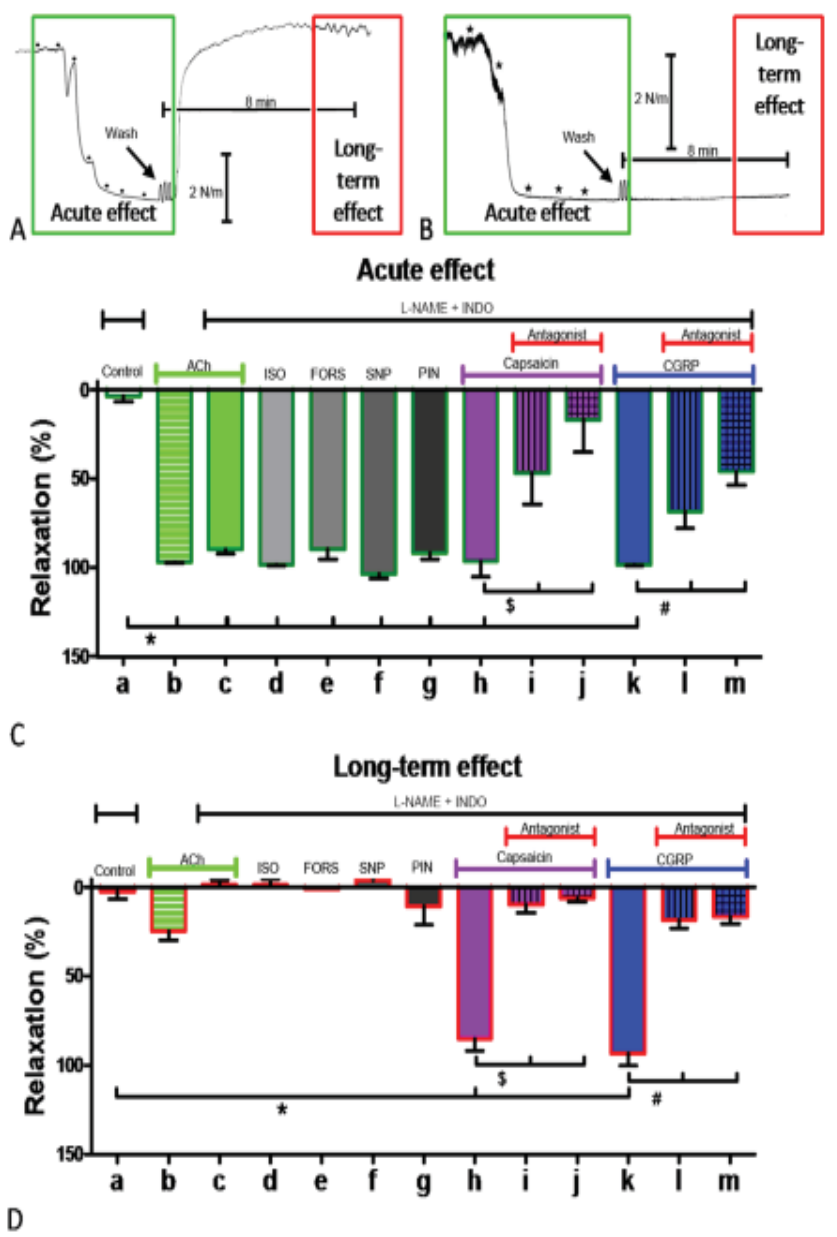

\section{Effects of TRP-channel activators and CGRP}

Figure 2.2. Capsaicin and CGRP relax endothelinergic arterial contraction and prevent the persistent contractile effect of ET-1.

Isolated rat mesenteric resistance arteries were studied in presence of L-NAME (100 $\mu \mathrm{M})$ and indomethacin $(10 \mu \mathrm{M})$ (as indicated) and were contracted with ET-1 (16 nM). Increasing vasodilator concentrations were administered until a maximal effect was observed. Thereafter vasoconstrictor and vasodilator stimuli were removed from the organ chamber while the recording of active wall tension continued for $>10 \mathrm{~min}$. $A$ and $B$, typical tracings of active wall tension (WT) versus time $(\mathrm{t})$ illustrating acute relaxing effects (green box) of acetylcholine (A; 0.01-10 $\mu \mathrm{M})$ and capsaicin (B; 0.01-1 $\mu \mathrm{M})$ and rapid recovery of contraction after removal of the vasodilator (long-term effect, red box) in the case of acetylcholine (A) but not capsaicin (B). C, maximal acute relaxing effects of various dilators. $D$, long-term effects of various dilators. a, time control; b and $c$, acetylcholine; $d$, isoproterenol; e, forskolin; $f$, Na-nitroprusside; g, pinacidil; $\mathrm{h}-\mathrm{j}$, capsaicin in the absence $(\mathrm{h})$ and presence of $\mathrm{CGRP}_{8-37}$ (i) or BIBN4096BS (j); k - m, CGRP in the absence (k) and presence of $\mathrm{CGRP}_{8-37}(\mathrm{l})$ or BIBN4096BS $(\mathrm{m})$. For concentrations of vasodilators see "Methods" section. $n=6-8$. *, $\$$ and \#: $P<0.05$ vs. control, capsaicin or CGRP, respectively.

In contrast to these vasodilators, capsaicin relaxed ET-1-induced contractions (Fig. 2.2B/C) and prevented their recovery (Fig. 2.2B/D). This was also observed with rutaecarpine and with allyl isothiocyanate (Fig. 2.4A/B). In the case of rutaecarpine these effects were endothelium independent (Suppl. Fig. 2.1.2). Capsaicin, rutaecarpine and allyl isothiocyanate stimulate release of several neurotransmitters from SMN [27, 36-40]. The CGRP-receptor antagonists CGRP ${ }_{37}[41](1 \mu \mathrm{M})$ and BIBN4096BS [42] $\left.(20 \mathrm{nM})\right)$ reduced both the relaxation and the prevention of persistent effects of ET-1 by the SMN stimuli (Fig. 2.2C/D, Fig. 2.4A/B). Moreover, exogenous CGRP relaxed ET-1-induced contractions (Fig. 2.2C), prevented recovery of contractions initiated by ET-1 (Fig. 2.2D) and 
Figure 2.3. Capsaicin, CGRP and acetylcholine relax endothelinergic arterial contraction that remained after removal of ET-1 from its biophase but only capsaicin and CGRP prevent the persistent contractile effect of ET-1.

A, schematic tracings of active wall tension (WT) versus time (t) illustrating i) ET-1-induced $A$ contractions that are not reversed upon agonist removal (W), ii) acute effects of various dilators and iii) prevention of long-term ET-1 effects by capsaicin (purple) and CGRP (blue) but not acetylcholine (grey). $B$, maximal acute relaxing effects of acetylcholine (b), capsaicin (c) or CGRP (d). C, long-term effects B

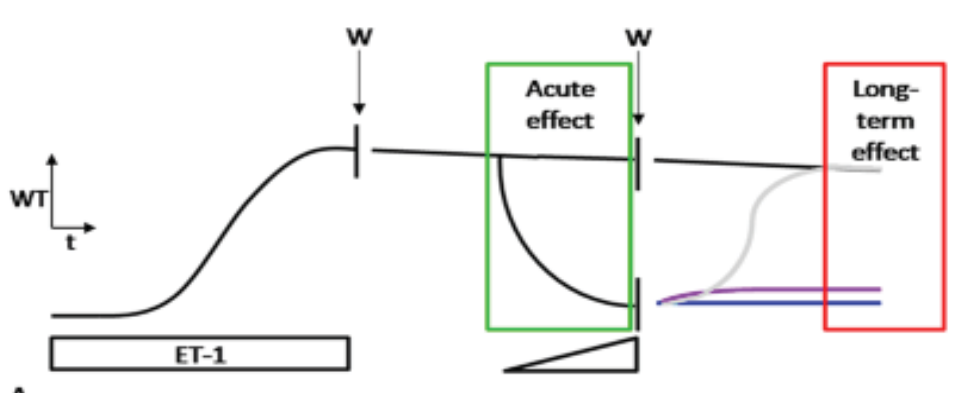
of acetylcholine (b), capsaicin (c) or CGRP (d). For concentrations of vasodilators see "Methods" section. $n=6-8$. *: $P<0.05$ vs. control.

caused long-lasting inhibition of the persistent effects initiated by ET-1 (Fig. 2.3A/B). These effects were endothelium independent (Suppl. Fig. 2.1.2) and were reduced by CGRP-receptor antagonists (Fig. 2.2C/D). The contraction that persisted after exposure to ET-1 and that was transiently inhibited by ET-receptor antagonists (Fig. 2.1E/F) or by acetylcholine (Fig. 2.3B/C), was terminated by capsaicin and by CGRP (Fig. 2.3B/C).

Figure 2.4. Stimuli of SMN, like rutaecarpine and allyl isothiocyanate, relax endothelinergic arterial contraction and prevent the persistent contractile effect of ET-1. Isolated rat mesenteric resistance arteries were precontracted with 16 nM ET-1. Increasing concentrations of vasodilator compounds were administered until a maximal effect was observed. Thereafter vasoactive stimuli were removed from the organ chamber while the recording of active wall tension continued for $>10 \mathrm{~min}$. A, maximal acute relaxing effects of rutaecarpine and allyl isothiocyanate. B, longterm effects of rutaecarpine and allyl isothiocyanate. a, time control; $\mathrm{b}$, rutaecarpine; $\mathrm{c}$, rutaecarpine in presence of BIBN4096BS; d, allyl isothiocyanate; e, allyl isothiocyanate in presence of BIBN4096BS. For concentrations of vasodilators see "Methods" section. $\mathrm{n}=6-8 .{ }^{*}, \$$ and \#: $\mathrm{P}<0.05$ vs. control, rutaecarpine and allyl isothiocyanate, respectively.

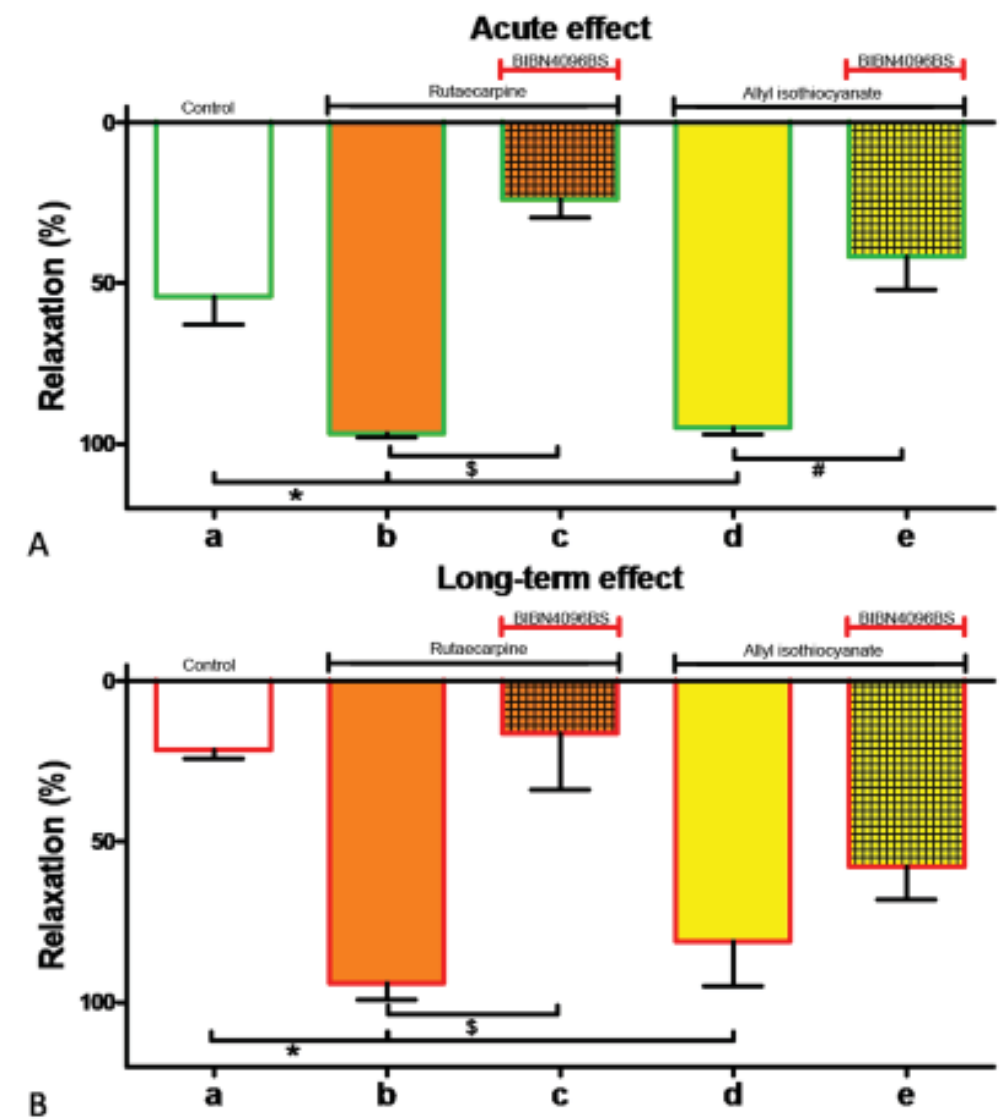


When arteries were transiently exposed to a high concentration of CGRP (100 nM; Fig. 2.5A) or to ET-1 (16 nM) and then to CGRP (100 nM; Fig. 2.5B), exogenous ET-1 (1-16 nM; applied after removing other vasoactive compound from the organ bath) caused contractions with a potency and an efficacy that deviate only marginally from those observed in controls (Fig. 2.5C/D). This suggests that CGRP does not induce a long-lasting relaxing effect (Fig. 2.5C) but rather promotes dissociation of previously established $\mathrm{ET}-1 / \mathrm{ET}_{\mathrm{A}}$ receptor complexes allowing re-application of ET-1 to again induced contractile responses (Fig. 2.5D).
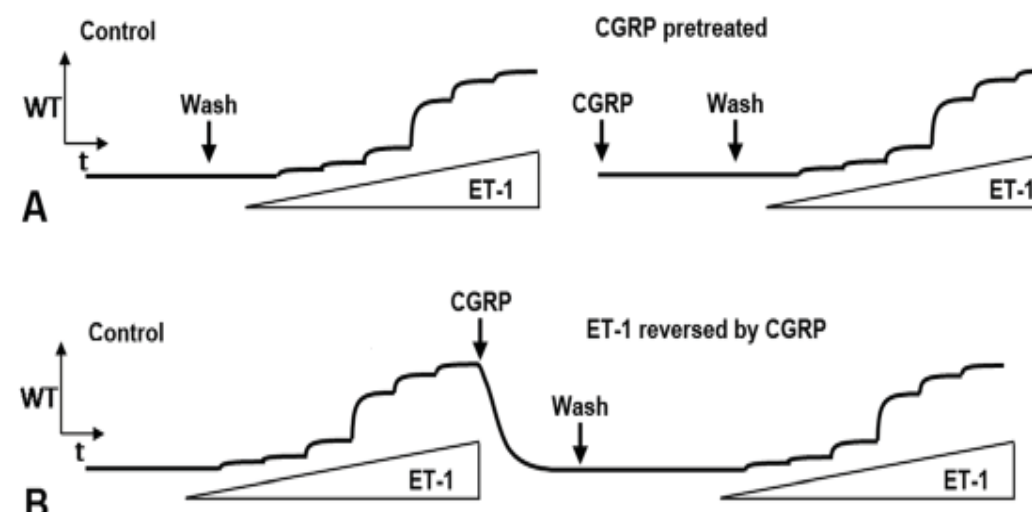

B
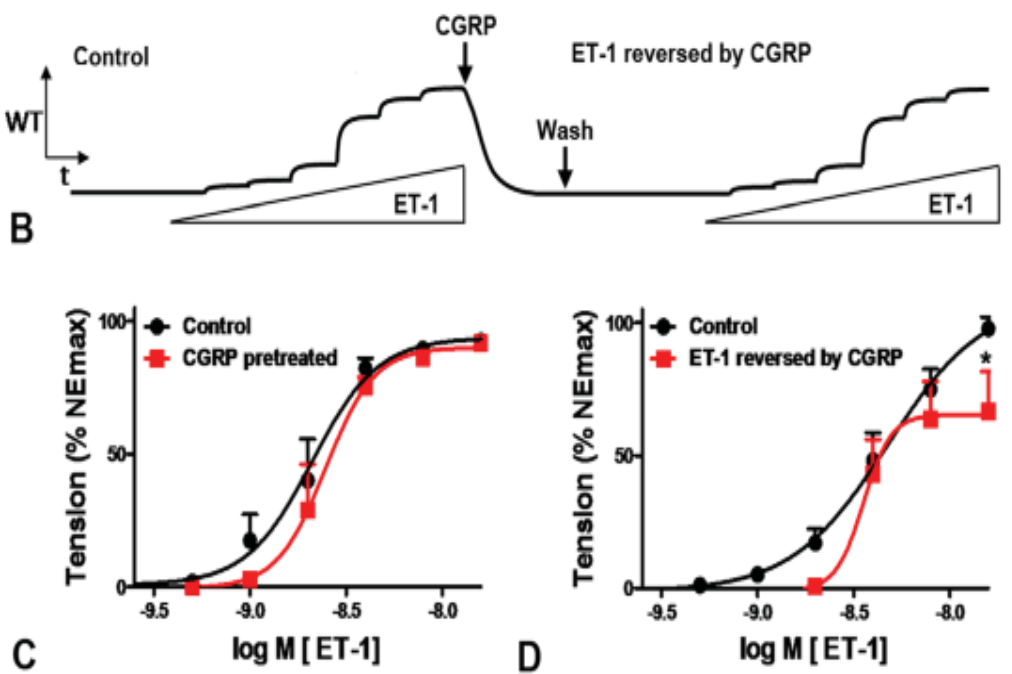

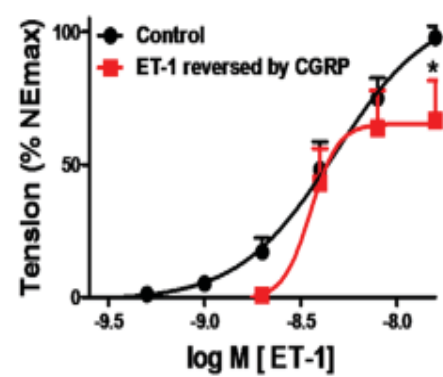

Figure 2.5. Unaltered arterial contractile responses to ET-1 $(0.25-16 \mathrm{nM})$ following exposure to CGRP.

A, schematic tracings of active wall tension (WT) versus time (t) illustrating contractile reponses to ET-1 $(0.25-16 \mathrm{nM})$ in arteries transiently treated with (right) or without (left) CGRP (100 nM). $B$, schematic tracing of active wall tension (WT) versus time (t) illustrating initial ET-1 effects which were reversed by CGRP before a second concentration response curve was generated. C: Effect of ET-1 (0.25-16 nM) in arteries pre-treated with CGRP (100 nM, during $16 \mathrm{~min})$. D: Effect of ET-1 $(0.25-16 \mathrm{nM})$ in arteries in which ET-1-induced contractions were reversed by CGRP $(100 \mathrm{nM}) . \mathrm{n}=6$. *: $p<0.05$ vs control.

Modulation of ET-1/ET $T_{A}$ receptor binding

We used rhodamine-labeled ET-1 (Rh-ET-1) and two-photon laser scanning microscopy (TPLSM) focusing on the tunica media, to visualize binding of ET-1 to the smooth muscle. Contractile properties did not differ between Rh-ET-1 and ET-1 (Table 2.1). Binding of Rh-ET-1 (16 nM) to smooth muscle (Fig. 2.6D) was reduced by BQ788 $(1 \mu \mathrm{M}$; Fig. 2.6E) and was prevented by presence of either ET-1 (16 $\mathrm{nM})$ or of both BQ788 $(1 \mu \mathrm{M})$ and BQ123 $(1 \mu \mathrm{M})$ [2] indicating selective binding to $E_{A}$ and $E T_{B}$ receptors. Once established, binding of Rh-ET-1 persisted after washout of free Rh-ET-1 and was not reversed by BQ123 (1 $\mu \mathrm{M}$; Fig. 2.6F) indicating quasi-irreversible receptor-binding of the agonist. In contrast, capsaicin $(1 \mu \mathrm{M})$ and exogenous CGRP (100 nM; investigated in presence and absence (not shown) of 1 $\mu \mathrm{M} B \mathrm{~B} 788$ ), reversed the binding of Rh-ET-1 to smooth muscle that remained after exposure to Rh-ET-1 (Fig. 2.6I/M). Thereafter, Rh-ET-1 could again label the arterial smooth muscle (Fig. 2.6J/N). 

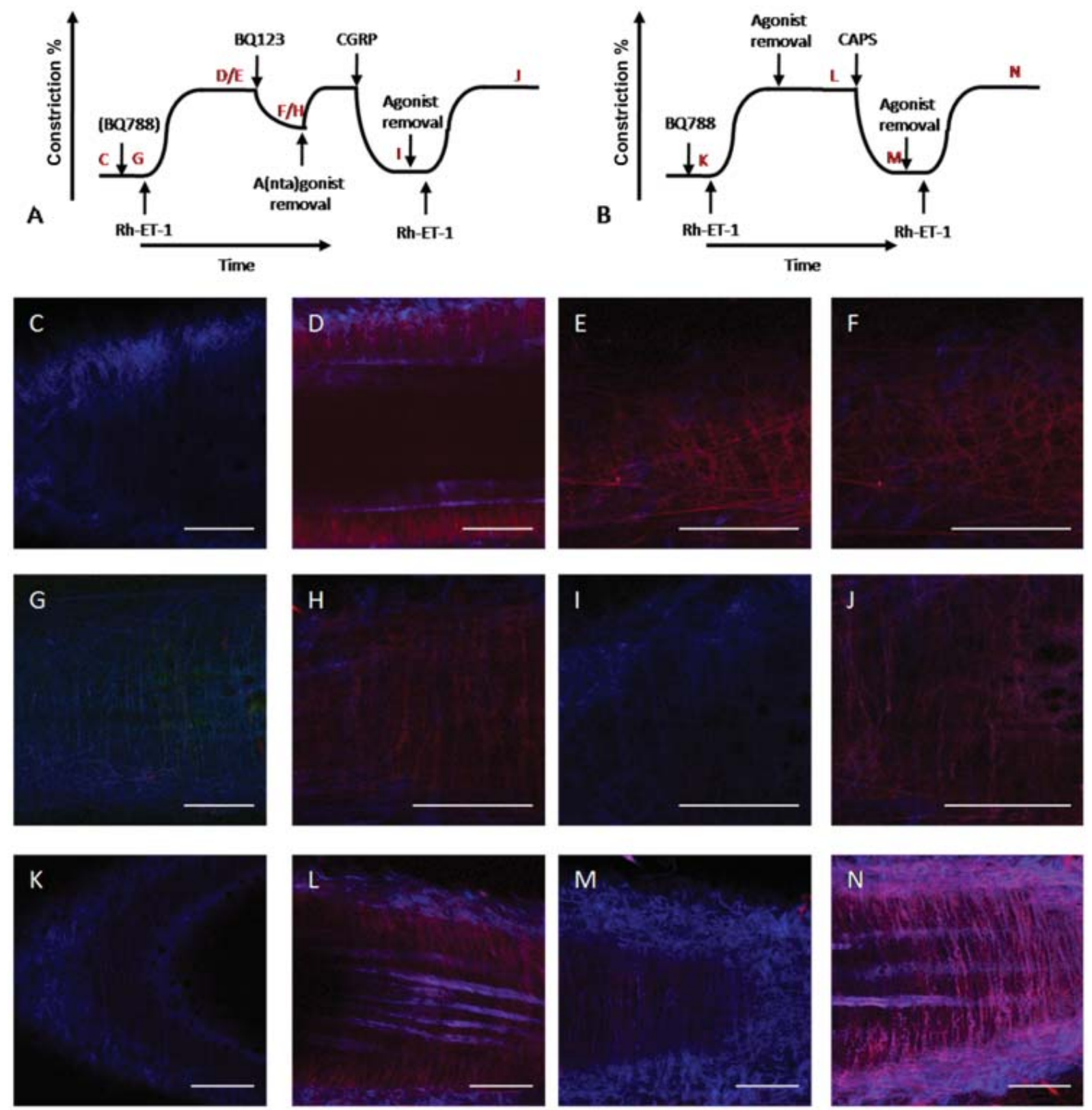

Figure 2.6. Binding of ET-1 is not reversed by ET-receptor antagonists (C-F) but can be reversed by CGRP (G-J) and by capsaicin (K-N).

Isolated rat mesenteric arteries were canullated, pressurized and mounted under a 2-photon laser scanning microscope. Analyses focussed on the smooth muscle layer (bordered by the autofluorescent (blue) internal and elastic laminae) $(\mathrm{C}, \mathrm{G}, \mathrm{H})$ ). Experiments were performed in continuous presence of BQ788 $(1 \mu \mathrm{M})$ except panels $\mathrm{C}$ and $\mathrm{D}$. A and B illustrate schematic tracings of active wall tension versus time illustrating the order of (i) administration of rhodamine-labeled ET-1 (Rh-ET-1, $16 \mathrm{nM}$ ), (ii) application of pharmacological agents and (iii) removal of agonists and antagonists. C, autofluoresence. $D$ - F, labeling of vascular smooth muscle (D, red) observed in presence of Rh-ET-1 is not noticeably affected by administration of BQ788 (E, $1 \mu \mathrm{M})$ and BQ123 (F, $1 \mu \mathrm{M})$. G, autofluorescence. $\mathrm{H}-\mathrm{J}$, labeling induced by exposure to Rh-ET-1 (16 nM) persists in absence of free label and is resistant to ET-receptor antagonists $(\mathrm{H})$ but is rapidly abolished $(\mathrm{I})$ by exposure of the artery to CGRP $(100 \mathrm{nM})$; thereafter labeling of smooth muscle can be re-established by exposure to Rh-ET-1 $(16 \mathrm{nM})(\mathrm{J})$. K, autofluoresence. $\mathrm{L}-\mathrm{N}$, largely similar experiment using capsaicin (CAPS, $1 \mu \mathrm{M}$ ). Labeling induced by exposure to Rh-ET-1 (16 $n M)$ that persists in absence of free label (L) is abolished (M) by exposure of the artery to CAPS $(1 \mu M)$; thereafter labeling of smooth muscle can be re-established by exposure to Rh-ET-1 (16 nM) (N). Scale bars: $50 \mu \mathrm{m}$. Findings are representative for 4 arteries of 3 rats. 


\section{Discussion}

The novel finding of our work is that while ET-receptor antagonists partly and transiently reduce endothelinergic vasoconstriction as a result of bitopic and irreversible agonist-receptor binding, stimuli of SMN can terminate effects initiated by ET-1 through CGRP-receptors that promote dissociation of $E T-1 / E_{A}$ receptor complexes. This may lead to novel therapies of diseases involving ET-1.

We compared effects and mechanisms of action of competitive and physiological antagonists of ET-1 in isolated rat mesenteric resistance arteries. In these vessels, which influence local blood flow and total peripheral resistance and contribute to the development of hypertension [43], ET-receptor subtypes are expressed by several cell types [31-33]. However, a selective $\mathrm{ET}_{\mathrm{B}}$ agonist did not modify vasomotor tone. Contractile effects of ET-1 were not modified by an $\mathrm{ET}_{\mathrm{B}}$ antagonist, pre-treatment with capsaicin or inhibition of NO-synthases and cyclo-oxygenases. Thus, initiation and maintenance of contractile responses to ET-1 were dominated by smooth muscle $\mathrm{ET}_{\mathrm{A}}$ receptors and were hardly affected by basal or endothelinergic influences of SMN or the endothelium.

Ligand-binding studies and analyses of structure-affinity and structure-selectivity relationships previously indicated quasi-irreversible and polyvalent binding of ET-1 to $\mathrm{ET}_{\mathrm{A}}$ receptors $[2,5,15,17,44,45]$. The high affinity of $E T-1$ for $\mathrm{ET}_{\mathrm{A}}$ receptors is due to slow dissociation of the agonist-receptor complexes [2]. ET-1 requires the C-terminal $\operatorname{Trp}^{21}$, both disulphide bonds and distinct amino acids in the $\mathrm{N}$-terminal loop for high affinity binding to $\mathrm{ET}_{\mathrm{A}}$ receptors $[2,5,12-15,18]$. It has therefore been proposed that several parts of ET-1 interact with distinct sites on the $\mathrm{ET}_{\mathrm{A}}$ receptor $[15,17]$. To the best of our knowledge, the consequences of this polyvalent and irreversible binding of ET-1 to $\mathrm{ET}_{\mathrm{A}}$ receptors for signaling have not been addressed before. We show that $\mathrm{ET}_{\mathrm{A}}$ antagonists can prevent binding and contractile effects of ET-1 but that they are less effective in reversing effects induced by ET-1. This discrepancy has also been observed in vivo (e.g. [22]) and was even more marked in an in vitro study using another $\mathrm{ET}_{\mathrm{A}}$ antagonist [46]. In addition, we report that ET-receptor antagonists reduce not only responses in presence of ET-1 but also responses that had been initiated by ET-1 and that persisted in absence of free agonist. These findings combined with earlier models of $\mathrm{ET}_{\mathrm{A}}$ receptor function [15, 17] can be integrated into a model regarding $E T-1 / E T_{A}$ interactions and $E T_{A}$ mediated signaling as depicted in Fig. 2.7. A part of ET-1, and the low molecular weight antagonists, binds with high affinity to one binding site on the receptor (site $\mathrm{H}$ ). Thereafter another part of the ET-1 molecule binds to a second distinct binding-site 
Figure 2.7. Schemes illustrating the interaction of ET-1 with arterial smooth muscle $E T_{A}$ receptors (A - D) and the influences of vasodilators.

A, Initially, a part of ET-1 binds to a high affinity binding site $(\mathrm{H})$ on an $\mathrm{ET}_{\mathrm{A}}$ receptor. $B$, next, another part of ET-1 binds to a low affinity binding site (L) of the receptor. Signaling is triggered by the occupied site $L$ and reinforced by the occupied site H. C, while binding of ET-1 to site $L$ is quasi-irreversible, the binding of ET-1 to site $\mathrm{H}$ remains dynamic and can be competed off by low molecular weight antagonists such as BQ123. $D$, binding of antagonists is readily reversible after which bivalent binding of ET-1 to the $\mathrm{ET}_{\mathrm{A}}$ receptor and cooperative signaling can be re-established. E, schematic representation of the endothelium (red), arterial smooth muscle (blue) and peri-arterial SMN (green). Endotheliumderived relaxing factors such as nitric oxide (NO),
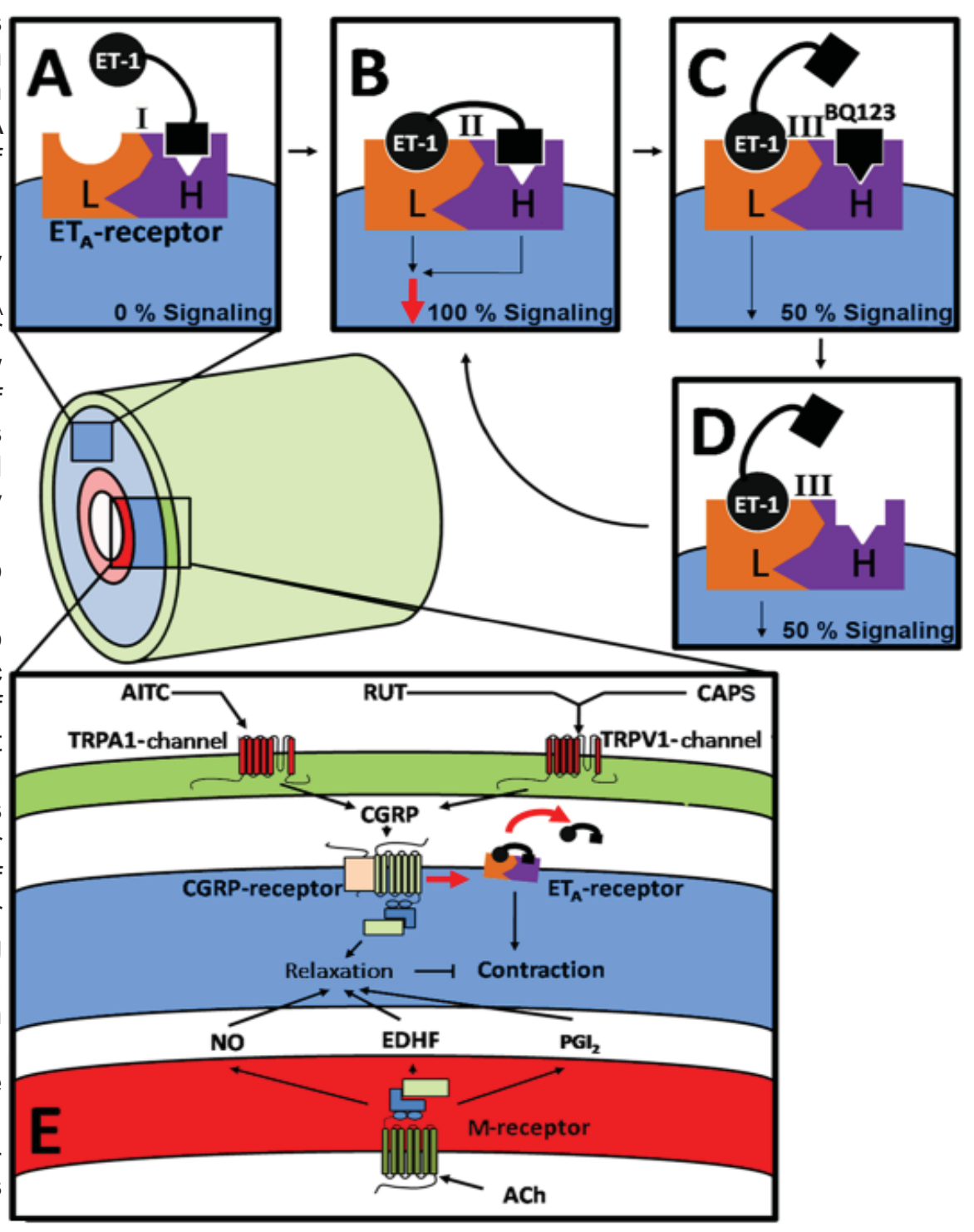

endothelium-derived hyperpolarizing factor (EDHF) and prostacyclin $\left(\mathrm{PGI}_{2}\right)$ released upon stimulation of e.g. endothelial muscarinic receptors $(M)$ by acetylcholine (ACh), counteract the $E T-1 / E_{A}$ contractile effect by their relaxing effect (functional antagonism). Stimulation of TRPA1-channels by allyl isothiocyanate (AITC) or of TRPV1-channels by capsaicin (CAPS) or rutaecarpine (RUT) leads to release of CGRP. In addition to functional antagonism, stimulation of post junctional CGRP-receptors causes dissociation of ET-1/ET $T_{A}$ receptor complexes resulting in termination of thepersistent vasoconstrictor effect of ET-1.

on the receptor (site L). Binding of ET-1 at site $\mathrm{H}$ is dynamic and remains susceptible to competition by the low molecular weight antagonists. It precedes and is required for binding at site $L$ which (i) is insensitive to antagonists, (ii) triggers signalling and (iii) binds the agonist quasi-irreversibly. This model explains the lower potency than affinity and the steepness of the concentration-effect relationships of ET-1 when signaling by $\mathrm{ET}_{\mathrm{A}}$ receptors is enhanced by cooperativity between the two binding sites of ET-1. In addition, it takes into account the flexibility of ET-1 as indicated by X-ray crystallography and NMR spectroscopy studies [47, 48] and displays similarities to the "address and message domain model" proposed for other GPCR agonists $[49,50]$. Because similar findings were obtained with BQ123, SB234551 
and bosentan which represent i) hydrophilic and lipophilic antagonists and ii) $\mathrm{ET}_{\mathrm{A}}$ selective and mixed antagonists, internalization and heterodimerization of receptors do not seem to be involved.

Our model predicts that compounds which accelerate dissociation of ET-1/ $\mathrm{ET}_{\mathrm{A}}$ receptor complexes have a larger and more long-lasting inhibitory effect on responses initiated by ET-1 compared to neutral competitive antagonists. Aspirin-like molecules were reported to display such an allosteric inhibitory effect at millimolar concentrations $[45,51]$. We focused on the endothelium and on SMN, two structures

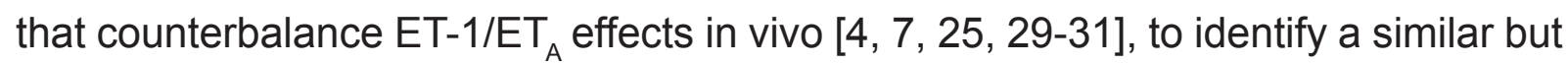
more potent mechanism. The endothelium-dependent vasodilator acetylcholine and several directly acting vasodilators fully relaxed ET-1-induced contractions. However, these relaxations were transient and did not inhibit the persistent contractile effect initiated by ET-1. This indicates mere functional antagonism. In contrast, stimuli of SMN not only reversed ET-1-induced contractions but also prevented their recovery. This was observed with capsaicin (pungent vanilloid TRPV1-stimulus of Capsicum Spec [40]), rutaecarpine (an alkaloid TRPV1-agonist from the chinese traditional medicinal herb Evodia Rutaecarpa [39]) and with allyl isothiocyanate (an organosulfur TRPA1-channel activator of Allium and Brassica [37]). For rutaecarpine the effects were not modified by removal of the endothelium excluding a role for endothelial TRPV1-channels [52]. The effects of SMN-stimuli were reduced by CGRP-receptor antagonists and mimicked by exogenous CGRP, a neurotransmitter that can be released from peri-arterial SMN [27, 36, 40]. However, they could not be reproduced by agents that stimulate adenylyl cyclase (forskolin and isoproterenol), generate NO (Na-nitroprusside) or open $\mathrm{K}_{\text {ATP }}$-channels (pinacidil) and thus activate components of the classical signal-transduction mechanism triggered by CGRP-receptors (for review see [53]). Furthermore, the contractile potency and efficacy of ET-1 were hardly modified by pre-exposure to capsaicin or CGRP or after "termination" of the persistent effect of ET-1 by CGRP. This suggests that the CAMP-independent effect of CGRP against ET-1 involves dissociation of ET-1/ET $\mathrm{A}_{\mathrm{A}}$ receptor complexes and not a long-lasting relaxing effect.

Clearly, this invites for further investigations into the molecular mechanism(s) induced by CGRP in this setting. These studies should focus on possibilities like i) heterodimers between $\mathrm{ET}_{\mathrm{A}}$ and CGRP-receptors, ii) rapid phosphorylation followed by desensitization of $\mathrm{ET}_{\mathrm{A}}$ receptors mediated by e.g. $\mathrm{G}$ protein receptor kinases [54], which can be activated by CGRP-receptor stimulation [55] and iii) possible interactions between the different subunits of CGRP receptors, most notably receptor activity modifying protein 1 , and $\mathrm{ET}_{\mathrm{A}}$ receptors. 
We used imaging to study the effects of CGRP-receptor activation on binding of $\mathrm{ET}-1$ to arterial smooth muscle $\mathrm{ET}_{\mathrm{A}}$ receptors. In line with earlier findings, fluorescent labeling of ET-1 at Lys9 did not modify the pharmacology of the agonist [2], [56], [57]. We observed intense staining of intact vascular smooth muscle which could be prevented by ET-1 and by combined $\mathrm{ET}_{\mathrm{A}}$ and $\mathrm{ET}_{\mathrm{B}}$ antagonism ([2] and this study). Thus, we show that ET-1 agonist-receptor binding can be visualised in a vital tissue without the need for supra-physiological receptor densities. Compared to conventional radioligand binding experiments with microsomes or intact arteries (e.g. [58] it has the added value that (i) small tissue samples can be used efficiently without the need for large numbers of arteries and animals, (ii) dissociation of ET-1/ $\mathrm{ET}_{\mathrm{A}}$ complexes can be monitored in real-time and (iii) effects of second messengers and endogenously released mediators (e.g. neurotransmitters) can be registered. In line with the model that we propose, labeling of vascular smooth muscle persisted after removal of free label. In addition, labeling was not reversed by BQ123 in the presence of BQ788. In contrast, capsaicin and CGRP each abolished pre-existing labeling. Thereafter, Rh-ET-1 could again label the smooth muscle with comparable intensity. This strengthens the conclusion that CGRP-receptor stimulation promotes dissociation of the agonist ET-1 from contractile $\mathrm{ET}_{\mathrm{A}}$ receptors.

In summary (Fig. 2.7), CGRP released from SMN promotes the dissociation of the $E T-1 / E_{A}$ receptor complexes that are responsible for the long-lasting effects of the peptide. Hence CGRP can be more suited to inhibit vascular effects of ET-1 compared to functional antagonists and competitive antagonists. We could not demonstrate that this mechanism acts as a negative feedback under normal conditions because desensitization of SMN and presence of CGRP-receptor antagonists do not alter the sensitivity to ET-1 ([33] and this study). This is in line with observations that ET-1 does not directly stimulate but modulates effects of TRP channel activators [27, 28]. The negative feedback may become operative during ischemia and inflammation which stimulate SMN activity. Several other aspects remain to be addressed to validate CGRP-receptor agonism and SMN as valid targets for therapy of ET-1-related diseases. These include effects of SMN and CGRP against endogenously produced ET-1 in other vessels and other species. In the mean time it may be worthwhile to consider how widely available natural and orally active stimuli of SMN could be applied in diseases that involve ET-1 but in which clinical efficacy of ET-receptor antagonists has been hard to prove [6, 23]. 


\section{Materials and Methods}

Experimental protocols were approved by the Ethics Committee on Experimental Animal Welfare of Maastricht University.

\section{Solutions and Drugs}

Bosentan [19], BIBN4096BS [42] and SB-234551 [21] were obtained from Actelion Pharmaceuticals (Allschwill, CH), Boehringer Ingelheim Pharma KG (Biberach, D) and GlaxoSmithKline (Stevenage, UK) respectively, and dissolved in DMSO. Allyl isothiocyanate [37], capsaicin [38, 40], forskolin and indomethacin were purchased from Sigma Aldrich (Zwijndrecht, NL) and dissolved in ethanol. Acetylcholine, isoproterenol, L-NAME ( $\mathrm{N} \omega(\mathrm{G})$-nitro-L- arginine methyl ester), Na-nitroprusside, norepinephrine, and isoproterenol were purchased from Sigma Aldrich (Zwijndrecht, $\mathrm{NL}$ ) and dissolved in Krebs-Ringer bicarbonate (KRB) solution. Pinacidil was obtained from Sigma Aldrich (Zwijndrecht, NL) and dissolved in DMSO. BQ123 [20] and BQ788 [34] were obtained from Bachem (Weil am Rhein, D) and dissolved in DMSO. Human CGRP, CGRP ${ }_{8-37}$ [41], ET-1 and Ala ${ }^{1,3,11,15} \mathrm{ET}-1$ [10] were obtained from Bachem (Weil am Rhein, D) and dissolved in KRB solution. Rutaecarpine [39] was a kind gift from Prof. Yu Huang (Chinese University of Hong Kong, China) and was dissolved in DMSO. The maximal concentrations of the solvents never exceeded $0.1 \%$ and did not alter arterial reactivity.

\section{Tissue Preparation}

16 weeks old male WKY rats (Charles River, Maastricht, NL) were euthanized by $\mathrm{CO}_{2}$ inhalation. Second-order side branches of the superior mesenteric artery were isolated, and either mounted in a wire-myograph and stretched as previously described [33, 59] or mounted in a pressure-myograph and pressurized at $80 \mathrm{~mm} \mathrm{Hg}$ $[27,60]$. In some arteries, the endothelium was mechanically removed[27, 33, 59].

\section{Vasomotor responses}

At optimal diameter $(340 \pm 6 \mu \mathrm{m})$ the contractile response to $10 \mu \mathrm{M}$ NE averaged $4.1 \pm 0.2 \mathrm{~N} / \mathrm{m}$. The relaxing responses to acetylcholine $(10 \mu \mathrm{M})$ during this precontraction averaged $93.7 \pm 0.7 \%$ and was absent in denuded arteries. 
Effects of ET-receptor antagonists.

The effect of the $\mathrm{ET}_{\mathrm{A}}$ antagonists BQ123 [20] $(1 \mu \mathrm{M})$, bosentan [19] $(3 \mu \mathrm{M}$, in presence of BQ788 $(1 \mu \mathrm{M}))$ or SB234551 [21] $(10 \mathrm{nM})$ was assessed when applied $20 \mathrm{~min}$. before ET-1 induced contractions $(0.25-16 \mathrm{nM})$. In addition, the effect of increasing concentrations $(0.1-3 \mu \mathrm{M})$ of $\mathrm{BQ} 123$ and bosentan was assessed during contractions induced by $8 \mathrm{nM}$ ET-1. Also, the effect of SB234551 (10 nM) during ET1 -induced contraction $(8 \mathrm{nM})$ was determined. Finally, the effect of the antagonists was determined during contractions that remained after removal of ET-1 from its biophase. Before these experiments, peri-arterial SMN were desensitized [33, 38, 40]. In addition, L-NAME $(100 \mu \mathrm{M})$ and indomethacin $(10 \mu \mathrm{M})$ were continuously present.

Effects of candidate functional antagonists.

During ET-1-induced contractions (16 $\mathrm{nM}$ ), and during contractions that remained after removal of ET-1 $(16 \mathrm{nM})$ from its biophase, arterial relaxing responses to increasing concentrations acetylcholine $(0.01-10 \mu \mathrm{M})$, capsaicin $(0.01-1.0 \mu \mathrm{M})$, CGRP $(0.1-100 \mathrm{nM})$, Na-nitroprusside $(0.01-10 \mu \mathrm{M})$, rutaecarpine $(0.1-10 \mu \mathrm{M})$, allyl isothiocyanate $(0.01-10 \mu \mathrm{M})$, forskolin $(0.1-3 \mu \mathrm{M})$, isoproterenol $(0.01-3 \mu \mathrm{M})$ or pinacidil $(0.01-10 \mu \mathrm{M})$ were assessed. These experiments were performed in absence of pharmacological inhibitors and were repeated in presence of L-NAME $(100 \mu \mathrm{M})$ and indomethacin $(10 \mu \mathrm{M})$ and in presence of CGRP-receptor antagonists (BIBN4096BS [42] $(20 \mathrm{nM})$ or $\left.\mathrm{aCGRP}_{8-37}[41](1 \mu \mathrm{M})\right)$. Some of these experiments were repeated in denuded arteries.

Synthesis of fluorescently labeled ET-1

$0.35 \mathrm{mg} \mathrm{ET}-1(0.14 \mu \mathrm{mol})$ was dissolved in $50 \mu \mathrm{L}$ dimethylformamide $+1 \mu \mathrm{L} \mathrm{N}, \mathrm{N}$ diisopropylethylamine. $50 \mu \mathrm{L}$ Rhodamine-succinimidyl ester (Rh-SE) stock solution $(6.3 \mu \mathrm{mol} / \mu \mathrm{l} 33 \%$ acetonitril/ $67 \%$ methanol) was added and left overnight for coupling. After 16 hours HPLC and MALDI-TOF analyses showed that $>90 \%$ of ET-1 was mono-labeled. Rh-ET-1 was purified using semi-preparative reversed-phase HPLC using a Vydac C-18 column $(250 \times 10 \mathrm{~mm}, 10 \mu \mathrm{m})$. A lineair gradient of acetonitrile in water $/ 0.1 \%$ TFA (flow rate $5 \mathrm{ml} / \mathrm{min} ; 0.5 \% \mathrm{~B} / \mathrm{min}$ ) was applied to elute peptides. RhET-1 was lyophilized and stored at $-20^{\circ} \mathrm{C}$ until use. 
After isolating and pressurizing the arteries, TPLSM was performed as previously described [27, 60]. In short, tissue samples were excited with Tsunami Ti:sapphire laser (Spectra-Physics), which was pumped by a Millennia Vs $5 \mathrm{~W}$ pump laser (Spectra-Physics) and mode locked at $840 \mathrm{~nm}$, with a $82.5 \mathrm{MHz}$ repetition rate and $100 \mathrm{fs}$ pulse width. Autofluoresence was visualized at 400 to $450 \mathrm{~nm}$ and focal planes were positioned within the tunica media. Arteries were incubated with RhET-1 (16 nM) and labeling of structures in the vessel wall was assessed at 620 to 660 $\mathrm{nM}$. Subsequently, the effect of preincubation with BQ123 $(1 \mu \mathrm{M}), \mathrm{BQ} 123(1 \mu \mathrm{M})+$ BQ788 $(1 \mu \mathrm{M})$ on labeling was determined. Labeling of arterial smooth muscle in the arterial wall by Rh-ET-1 (16 nM) can be prevented by ET-1 (16 nM) [2]. Finally, the effects of BQ123 $(1 \mu \mathrm{M})$, removal of free label and antagonist and of administration of either CGRP $(100 \mathrm{nM})$ or of capsaicin $(1 \mu \mathrm{M})$ on labeling were determined. These experiments were performed in presence of BQ788 $(1 \mu \mathrm{M})[2]$.

\section{Data and Statistical Analysis}

Contractile responses are expressed as percentage of the maximal contractile response to $10 \mu \mathrm{M} \mathrm{NE}$ in absence of pharmacological inhibitors (NEmax). Relaxing responses are expressed as percentage reduction of the level of pre-contraction. Concentration-response curves (CRC) were fitted to a non-linear sigmoid regression curve (Graphpad Prism 5.0). All data are shown as mean \pm SEM. Statistical significance was assessed using either one-way ANOVA (comparison of $E_{50}$ and $E_{\max }$ ) or two-way ANOVA (comparison of CRCs). Bonferroni's post-hoc test was used to compare multiple groups. A P value $<0.05$ was considered statistically significant.

\section{Acknowledgments}

We thank Dennis Suylen for technical assistance. 


\section{References}

1. Pierce, K.L., et al. (2002) Seven-transmembrane receptors. Nature reviews. Molecular cell biology 3, 639-650

2. De Mey, J., et al. (2009) Endothelin-1, an Endogenous Irreversible Agonist in Search of an Allosteric Inhibitor. Molecular and Cellular Pharmacology 1, 246

3. Yanagisawa, M., et al. (1988) A novel potent vasoconstrictor peptide produced by vascular endothelial cells. Nature 332, 411-415

4. Hynynen, M.M., and Khalil, R.A. (2006) The vascular endothelin system in hypertension--recent patents and discoveries. Recent patents on cardiovascular drug discovery 1, 95-108

5. Masaki, T. (2004) Historical review: Endothelin. Trends Pharmacol Sci 25, 219224

6. Kirkby, N.S., et al. (2008) The endothelin system as a therapeutic target in cardiovascular disease: great expectations or bleak house? $\mathrm{Br} \mathrm{J}$ Pharmacol 153, 1105-1119

7. Schneider, M.P., et al. (2007) Contrasting actions of endothelin ET(A) and ET(B) receptors in cardiovascular disease. Annu Rev Pharmacol Toxicol 47, 731-759

8. Bagnato, A., et al. (2008) The endothelin axis in cancer: the promise and the challenges of molecularly targeted therapy. Can J Physiol Pharmacol 86, 473484

9. Khodorova, A., et al. (2003) Endothelin-B receptor activation triggers an endogenous analgesic cascade at sites of peripheral injury. Nature medicine 9 , 1055-1061

10. Davenport, A.P. (2002) International Union of Pharmacology. XXIX. Update on endothelin receptor nomenclature. Pharmacol Rev 54, 219-226

11. Maggi, C.A., et al. (1989) The C-terminal hexapeptide, endothelin-(16-21), discriminates between different endothelin receptors. Eur J Pharmacol 166, 121-122

12. Saeki, T., et al. (1991) [Ala1,3,11,15]endothelin-1 analogs with ETB agonistic activity. Biochem Biophys Res Commun 179, 286-292

13. Takai, M., et al. (1992) A potent and specific agonist, Suc-[Glu9,Ala11,15]endothelin-1(8-21), IRL 1620, for the ETB receptor. Biochem Biophys Res Commun 184, 953-959

14. Kimura, S., et al. (1988) Structure-activity relationships of endothelin: importance of the C-terminal moiety. Biochem Biophys Res Commun 156, 1182-1186

15. Lattig, J., et al. (2009) Structural determinants for selective recognition of peptide ligands for endothelin receptor subtypes ETA and ETB. J Pept Sci 15, 479-491 
16. Randall, M.D., et al. (1989) Vascular activities of endothelin-1 and some alanyl substituted analogues in resistance beds of the rat. $\mathrm{Br} \mathrm{J}$ Pharmacol 98, 685-699

17. Sakamoto, A., et al. (1993) Distinct subdomains of human endothelin receptors determine their selectivity to endothelinA-selective antagonist and endothelinBselective agonists. J Biol Chem 268, 8547-8553

18. Tam, J.P., et al. (1994) Alanine scan of endothelin: importance of aromatic residues. Peptides 15, 703-708

19. Clozel, M., et al. (1994) Pharmacological characterization of bosentan, a new potent orally active nonpeptide endothelin receptor antagonist. J Pharmacol Exp Ther 270, 228-235

20. Ihara, M., et al. (1992) In vitro biological profile of a highly potent novel endothelin (ET) antagonist BQ-123 selective for the ETA receptor. J Cardiovasc Pharmacol 20 Suppl 12, S11-14

21. Ohlstein, E.H., et al. (1998) Nonpeptide endothelin receptor antagonists. XI. Pharmacological characterization of SB 234551, a high-affinity and selective nonpeptide ETA receptor antagonist. J Pharmacol Exp Ther 286, 650-656

22. Sabaa, N., et al. (2008) Endothelin receptor antagonism prevents hypoxiainduced mortality and morbidity in a mouse model of sickle-cell disease. J Clin Invest 118, 1924-1933

23. McMurray, J.J., et al. (2007) Effects of tezosentan on symptoms and clinical outcomes in patients with acute heart failure: the VERITAS randomized controlled trials. JAMA : the journal of the American Medical Association 298, 2009-2019

24. Hirata, Y., et al. (1993) Endothelin receptor subtype B mediates synthesis of nitric oxide by cultured bovine endothelial cells. J Clin Invest 91, 1367-1373

25. Boulanger, C., and Luscher, T.F. (1990) Release of endothelin from the porcine aorta. Inhibition by endothelium-derived nitric oxide. J Clin Invest 85, 587-590

26. Vanhoutte, P.M. (2000) Say NO to ET. Journal of the autonomic nervous system 81, 271-277

27. De Mey, J.G., et al. (2008) Functional antagonism between endogenous neuropeptide $Y$ and calcitonin gene-related peptide in mesenteric resistance arteries. J Pharmacol Exp Ther 324, 930-937

28. Plant, T.D., et al. (2007) Endothelin potentiates TRPV1 via ETA receptormediated activation of protein kinase $\mathrm{C}$. Molecular pain 3, 35

29. Xie, C., and Wang, D.H. (2009) Ablation of transient receptor potential vanilloid 1 abolishes endothelin-induced increases in afferent renal nerve activity: mechanisms and functional significance. Hypertension 54, 1298-1305

30. Supowit, S.C., et al. (1997) Calcitonin gene-related peptide is a depressor of deoxycorticosterone-salt hypertension in the rat. Hypertension 29, 945-950 
31. Wang, Y., and Wang, D.H. (2004) Prevention of endothelin-1-induced increases in blood pressure: role of endogenous CGRP. Am J Physiol Heart Circ Physiol 287, $\mathrm{H} 1868-1874$

32. Molero, M.M., et al. (2002) Decreased endothelin binding and [Ca2+]i signaling in microvessels of DOCA-salt hypertensive rats. J Hypertens 20, 1799-1805

33. Meens, M.J., et al. (2009) Calcitonin gene-related peptide selectively relaxes contractile responses to endothelin-1 in rat mesenteric resistance arteries. $J$ Pharmacol Exp Ther 331, 87-95

34. Ishikawa, K., et al. (1994) Biochemical and pharmacological profile of a potent and selective endothelin B-receptor antagonist, BQ-788. Proc Natl Acad Sci U S A 91, 4892-4896

35. Ihara, M., et al. (1992) Biological profiles of highly potent novel endothelin antagonists selective for the ETA receptor. Life Sci 50, 247-255

36. Burnstock, G. (2009) Autonomic neurotransmission: 60 years since sir Henry Dale. Annu Rev Pharmacol Toxicol 49, 1-30

37. Bautista, D.M., et al. (2005) Pungent products from garlic activate the sensory ion channel TRPA1. Proc Natl Acad Sci U S A 102, 12248-12252

38. Caterina, M.J., et al. (1997) The capsaicin receptor: a heat-activated ion channel in the pain pathway. Nature $389,816-824$

39. Deng, P.Y., et al. (2004) Stimulation of calcitonin gene-related peptide synthesis and release: mechanisms for a novel antihypertensive drug, rutaecarpine. J Hypertens 22, 1819-1829

40. Szallasi, A., and Blumberg, P.M. (1999) Vanilloid (Capsaicin) receptors and mechanisms. Pharmacol Rev 51, 159-212

41. Chiba, T., et al. (1989) Calcitonin gene-related peptide receptor antagonist human CGRP-(8-37). Am J Physiol 256, E331-335

42. Doods, H., et al. (2000) Pharmacological profile of BIBN4096BS, the first selective small molecule CGRP antagonist. Br J Pharmacol 129, 420-423

43. Mulvany, M.J., and Aalkjaer, C. (1990) Structure and function of small arteries. Physiol Rev 70, 921-961

44. Hilal-Dandan, R., et al. (1997) The quasi-irreversible nature of endothelin binding and $G$ protein-linked signaling in cardiac myocytes. J Pharmacol Exp Ther 281, 267-273

45. Talbodec, A., et al. (2000) Aspirin and sodium salicylate inhibit endothelin ETA receptors by an allosteric type of mechanism. Mol Pharmacol 57, 797-804

46. Adner, M., et al. (2001) Evidence that ET-1, but not ET-3 and S6b, ET(A)-receptor mediated contractions in isolated rat mesenteric arteries are modulated by coactivation of ET(B) receptors. Br J Pharmacol 133, 927-935 
47. Aumelas, A., et al. (1998) Formation of native disulfide bonds in endothelin-1. Structural evidence for the involvement of a highly specific salt bridge between the prosequence and the endothelin-1 sequence. Biochemistry 37, 5220-5230

48. Hewage, C.M., et al. (1999) Solution structure of a novel ETB receptor selective agonist ET1-21 [Cys(Acm)1,15, Aib3,11, Leu7] by nuclear magnetic resonance spectroscopy and molecular modelling. The journal of peptide research : official journal of the American Peptide Society 53, 223-233

49. Conner, A.C., et al. (2007) Ligand binding and activation of the CGRP receptor. Biochem Soc Trans 35, 729-732

50. Peng, X., et al. (2007) Pharmacological properties of bivalent ligands containing butorphan linked to nalbuphine, naltrexone, and naloxone at mu, delta, and kappa opioid receptors. J Med Chem 50, 2254-2258

51. Blandin, V., et al. (2000) Allosteric inhibition of endothelin ETA receptors by 3 , 5-dibromosalicylic acid. Mol Pharmacol 58, 1461-1469

52. Nilius, B., et al. (2007) Transient receptor potential cation channels in disease. Physiol Rev 87, 165-217

53. Brain, S.D., and Grant, A.D. (2004) Vascular actions of calcitonin gene-related peptide and adrenomedullin. Physiol Rev 84, 903-934

54. Morris, G.E., et al. (2010) Endothelin signalling in arterial smooth muscle is tightly regulated by $\mathrm{G}$ protein-coupled receptor kinase 2 . Cardiovasc Res $85,424-433$

55. Aiyar, N., et al. (2000) Involvement of G protein-coupled receptor kinase-6 in desensitization of CGRP receptors. Eur J Pharmacol 403, 1-7

56. Oksche, A., et al. (2000) Late endosomal/lysosomal targeting and lack of recycling of the ligand-occupied endothelin B receptor. Mol Pharmacol 57, 11041113

57. Zemanova, L., et al. (2004) Endothelin receptor in virus-like particles: ligand binding observed by fluorescence fluctuation spectroscopy. Biochemistry 43 , 9021-9028

58. Stassen, F.R., et al. (1998) A positive and reversible relationship between adrenergic nerves and alpha-1A adrenoceptors in rat arteries. J Pharmacol Exp Ther 284, 399-405

59. Hilgers, R.H., and De Mey, J.G. (2009) Myoendothelial coupling in the mesenteric arterial bed; segmental differences and interplay between nitric oxide and endothelin-1. Br J Pharmacol 156, 1239-1247

60. Megens, R.T., et al. (2007) Two-photon microscopy of vital murine elastic and muscular arteries. Combined structural and functional imaging with subcellular resolution. Journal of vascular research 44 , 87-98 


\section{Chapter 2.1}

Supplementary Data concerning Chapter 2 
A

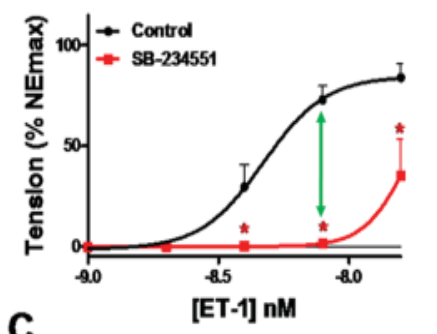

C
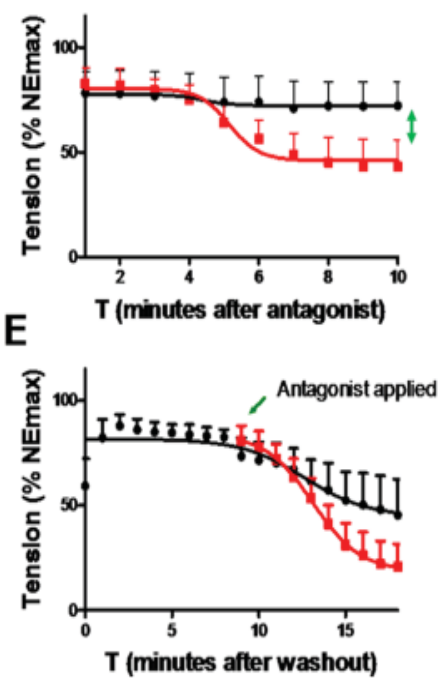

B

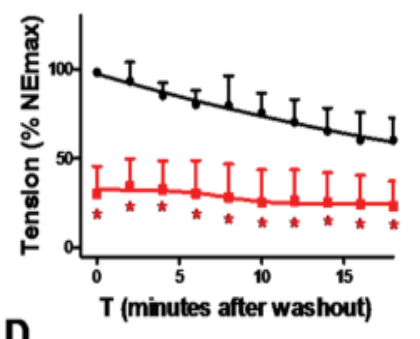

D

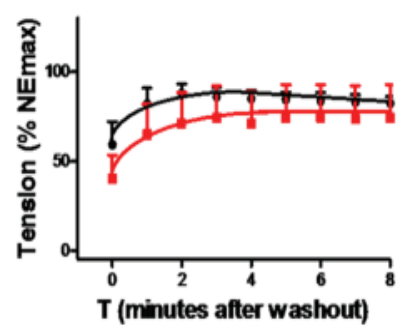

\section{on}

ET-1 and persisting in the absence of the peptide. F, vasomotor tone after removal of free antagonist. Data are expressed as \% of the maximal response to norepinephrine (NEmax) prior to exposure to any drug, and are shown as mean \pm SEM $(n=6)$. *, the difference from control is statistically significant $(P<0.05)$. reversible reversing effect of the $\mathrm{ET}_{\mathrm{A}}$ receptor antagonist SB234551 on arterial contractile responses to ET-1 and their persistence. Isolated rat mesenteric resistance arteries were studied after treatment with capsaicin (1 $\mu \mathrm{M}$ during $20 \mathrm{~min}$.) in the continuous presence of L-NAME $(100 \mu \mathrm{M})$ and indomethacin $(10 \mu \mathrm{M})$. A, responses to 0.25-16 nM ET-1 in the absence (black) and presence of SB234551 (10 nM, red). Note that SB234551 prevented responses to up to $8 \mathrm{nM} \mathrm{ET-1.} \mathrm{B,} \mathrm{vasomotor} \mathrm{tone} \mathrm{after}$ removal of free agonist and antagonist. C, effects of SB234552 (10 nM) on contractile responses to $8 \mathrm{nM}$ ET-1. D, vasomotor tone after removal of free agonist and antagonist. E, effect of SB234551 (10 nM) on the contractile response initiated by $8 \mathrm{nM}$
Supplementary Figure 2.1.2. Effects of CGRP and rutaecarpine are endothelium-independent. Isolated, denuded rat arteries were studied in presence of L-NAME $(100 \mu \mathrm{M})$ and indomethacin $(10 \mu \mathrm{M})$ as indicated. Arteries were precontracted with 16 nM ET-1. Next, increasing concentrations of vasodilator compounds were administered until a maximal effect was observed. Thereafter vasoactive stimuli were removed from the organ chamber while the recording of active wall tension continued for $>10 \mathrm{~min}$. A, maximal acute relaxing effects of CGRP and rutaecarpine. B, long-term effects of CGRP and rutaecarpine. a, time control; b, CGRP; c, rutaecarpine.
Supplementary Figure 2.1.1. Partial and

\section{Acute effect}
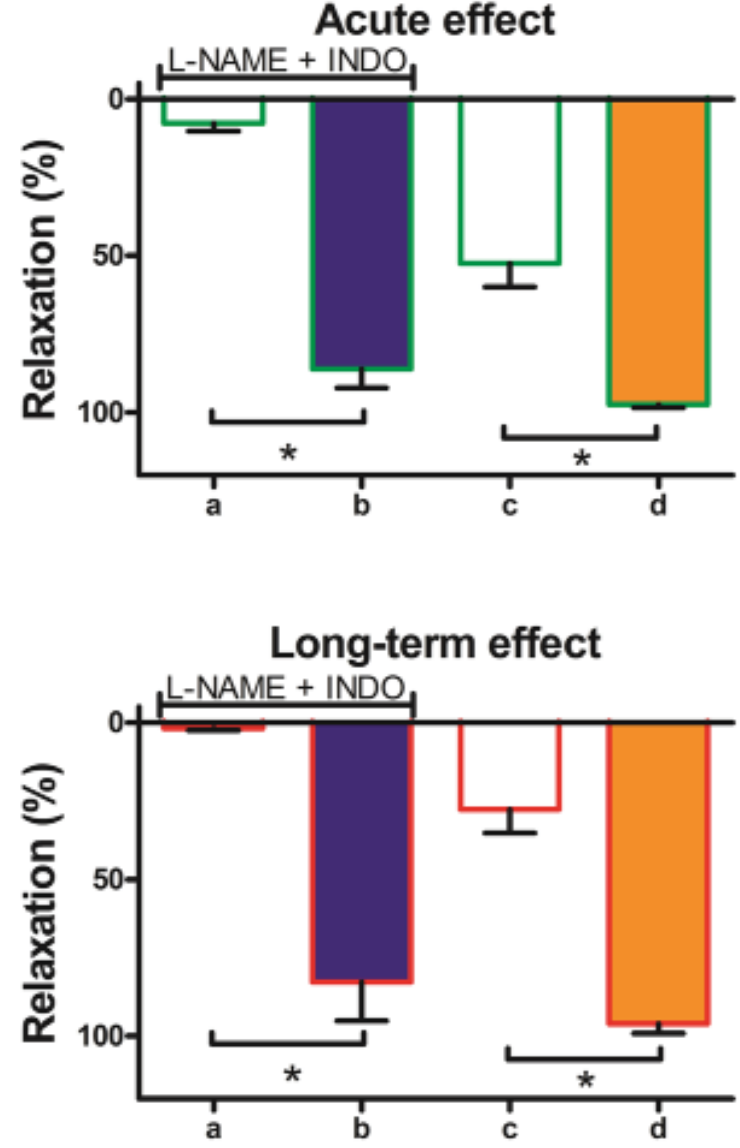


\section{Chapter 3}

Endothelin-1 And -2:Two Amino Acids Matter

Matthijs G Compeer, Dennis PL Suylen, Tilman M Hackeng, Jo GR De Mey LIFE SCI. 2012 OCT 15;91(13-14):607-12 


\begin{abstract}
Endothelin-1 (ET-1) and endothelin-2 (ET-2; Trp ${ }^{6}$ Leu $^{7}$ ET-1) are expressed by different cell types, but are considered to display identical pharmacological properties on endothelin receptors. We studied agonist-dependent aspects of endothelin ${ }_{A}\left(E T_{A}\right)$ receptor function and the importance of amino acids 6 and 7 of ET-1 and ET-2 in this respect.
\end{abstract}

We used isolated rat mesenteric resistance arteries in wire myographs, in a setting that minimizes influences of endothelium and sensorimotor nerves, to study arterial smooth muscle $\mathrm{ET}_{\mathrm{A}}$ receptor-mediated vasomotor responses, to ET-1, ET-2 and chimeras thereof (Trp ${ }^{6} \mathrm{ET}-1$ and Leu $\left.{ }^{7} \mathrm{ET}-1\right)$.

ET-1 and ET-2 cause arterial contractions with comparable sensitivities and maximal responses. $\mathrm{BQ123}$ ( $E \mathrm{~T}_{\mathrm{A}}$ antagonist) reduces sensitivity to $\mathrm{ET}-1$ more potently than that to $\mathrm{ET}-2\left(\mathrm{pK}_{\mathrm{B}}: 7.1 \pm 0.2\right.$ versus $\left.5.6 \pm 0.4\right)$. However, $1 \mu \mathrm{M}$ BQ123 relaxes maximal contractile responses to ET-2 more markedly than those to ET-1. Leu ET-1 is a contractile agonist with lower potency and similar maximal effect compared to ET-1 and greater sensitivity to BQ123 than ET-2. Up to $256 \mathrm{nM}$ Trp $^{6} \mathrm{ET}-1$ did not cause contraction and did not antagonize arterial responses to ET-1.

Arterial smooth muscle $\mathrm{ET}_{\mathrm{A}}$ receptor function displays agonist-dependent aspects. This involves roles of amino acids on position 6 and 7 of the endothelin sequence. Agonist-dependent pathologies may benefit from the design of specific, agonistselective ET receptor antagonists. 


\section{Introduction}

Evolution left homo sapiens with three distinct potent vasoactive members of the endothelin family; endothelin-1 (ET-1), endothelin-2 (ET-2) and endothelin-3 (ET-3) $[1,2]$. The biological effects of these 21 amino acid bicyclic peptides are mediated by two distantly related 7 transmembrane domain receptors (7TMRs): endothelin $\left(E T_{A}\right)$ and endotheli $n_{B}\left(E T_{B}\right)$ receptors [1-3]. Binding to $E T_{B}$ receptors requires the 6 amino acid C-terminus, which is identical for all three ETs, making them equipotent at this receptor [4]. The 15 amino acid $\mathrm{N}$-terminal loop, with disulfide bonds between Cys ${ }^{1}$ and $\mathrm{Cys}^{15}$ and between $\mathrm{Cys}^{3}$ and $\mathrm{Cys}^{11}$, determines selectivity for the $\mathrm{ET}_{\mathrm{A}}$ receptor [5]. Compared to ET-1 and ET-2, ET-3 differs in 6 amino acids within the N-terminal loop, distinguishing $\mathrm{ET}-3$ as an $\mathrm{ET}_{\mathrm{B}}$ selective ligand $[3,6]$.

ET-1 and ET-2 were reported to be non-selective ET receptor agonists. Their amino acid sequences differ only at positions 6 and 7 within the N-terminal loop. They bind to $\mathrm{ET}_{\mathrm{A}}$ and $\mathrm{ET}_{\mathrm{B}}$ with equal affinities and their pharmacological properties were proposed to be identical [2, 3]. However, ET-1 and ET-2 are expressed by different cell types, restricting their paracrine and autocrine function to distinct tissues [7]. ET-1 is mainly found in the cardiovascular system where it causes, amongst other effects, long-lasting vasoconstriction mediated by tight binding to $\mathrm{ET}_{\mathrm{A}}$ receptors [811]. ET-2 is mainly found in the gastrointestinal tract and the urogenital system [7]. Via $\mathrm{ET}_{\mathrm{A}}$ receptors, ET-2 can modulate immune cell function [12] and ovulation [13]. ET-1 and ET-2 are expressed at different developmental stages in the embryo and in different cell types and organ systems in the adult [1]. While ET-1 is intimately involved in the cardiovascular system [8], ET-2 seems to have selective functions in for instance the ovaries [13, 14]. The pharmacological properties of ET-1 and ET-2 have been considered to be identical [2]. This may be surprising because during the course of evolution other endothelin isoforms were lost [1]. We therefore compared both peptides beyond apparent affinities and efficacies.

Here we tested the hypothesis that ET-1 and ET-2 display distinct $\mathrm{ET}_{\mathrm{A}}$ receptor mediated pharmacological properties. We studied inhibitory effects of an antagonist of $\mathrm{ET}_{\mathrm{A}}$ receptors (BQ123, [15]) on arterial responses to the two endogenous agonists. In addition, we evaluated the arterial effects of two newly synthesized ET-1/ET-2 chimeras, one in which we substituted Leu ${ }^{6}$ of ET-1 for Trp ${ }^{6}$ of ET-2 (Trp ${ }^{6}$ ET-1 (or Met $\left.{ }^{7} E T-2\right)$ ) and another one in which we substituted Met $^{7}$ of ET-1 for Leu ${ }^{7}$ of ET-2 (Leu ${ }^{7}$ TT-1 (or Leu ${ }^{6}$ ET-2)). Our observations indicate agonist-dependent modulation of $\mathrm{ET}_{\mathrm{A}}$ receptor function and marked effects of amino acids 6 and 7 of the endothelin sequence in this respect. 


\section{Materials and methods}

Experiments were performed in accordance with institutional guidelines and were approved by the Ethics Committee on Experimental Animal Welfare of the Maastricht University.

\section{Solutions and compounds}

BQ123 (SigmaAldrich, Zwijndrecht, NL) and BQ788 (Peptides International, Louisville, USA) were dissolved in DMSO. Capsaicin (CAPS) and indomethacin (INDO) (Sigma Aldrich, Zwijndrecht, NL) were dissolved in ethanol. Human ET-1, human ET-2, 4AlaET-1, Sarafotoxin 6c (S6c) (Bachem, Weil am Rhein, D), noradrenaline (NA) and $\mathrm{N} \omega(\mathrm{G})$-nitro-L- arginine methyl ester (L-NAME) (Sigma Aldrich, Zwijndrecht, NL) were dissolved in Krebs Ringer bicarbonate buffer (KRB) containing (in $\mathrm{mM}$ ): $\mathrm{NaCl}$ : 118.5; KCl: $4.7 ; \mathrm{CaCl}_{2}: 2.5 ; \mathrm{MgSO}_{4}: 1.2 ; \mathrm{KH}_{2} \mathrm{PO}_{4}: 1.2 ; \mathrm{NaHCO}_{3}: 25.0$; glucose: 5.5. The maximal solvent concentration never exceeded $0.1 \%$ and did not significantly modify arterial vasomotor responses.

De novo synthesis of $\operatorname{Trp}^{6} E T-1$ and Leu ${ }^{7} E T-1$

Single batches of $\operatorname{Trp}^{6} \mathrm{ET}-1$ and Leu ${ }^{7} \mathrm{ET}-1$ were synthesized by manual solidphase peptide synthesis on 4-methylbenzhydrylamine (MBHA) resin using the in situ neutralization/activation procedure for tBoc-peptide synthesis as described [16], but using O-(6-Chlorobenzotriazol-1-yl)-N,N,N',N'-tetramethyluronium hexafluorophosphate (HCTU) instead of O-(Benzotriazol-1-yl)-N,N,N',N'tetramethyluronium hexafluorophosphate (HBTU) as a coupling reagent. To allow controlled $\mathrm{Cys}^{3}-$ Cys $^{11}$ and Cys $^{1}-$ Cys $^{15}$ disulfide formation within ET peptides, two acetamidomethyl (Acm)-protected cysteines $(1 ; 15)$ were used that could selectively be deprotected during folding, ensuring the correct folding of the N-terminal loop of the peptide. The peptides were cleaved from the resin by treatment with anhydrous hydrofluoric acid for $1 \mathrm{~h}$ at $0{ }^{\circ} \mathrm{C}$, using $4 \mathrm{v}$-\% p-cresol as a scavenger. Following cleavage, the peptides were purified by preparative high-performance liquid chromatography (HPLC). Fractions containing the desired product were identified by electrospray ionization mass spectrometry, pooled and lyophilized.

\section{Peptide Folding}

The peptides were folded by a two-step protocol. The first disulfide bond was formed stirring the purified peptide in $0.05 \mathrm{M}$ Tris buffer $\mathrm{pH} 8.0,3 \mathrm{M} \mathrm{Gn} . \mathrm{HCl}(0.2 \mathrm{mg} / \mathrm{ml})$ for 
$72 \mathrm{~h}$ at $4^{\circ} \mathrm{C}$. For the second disulfide bond the solution was adjusted to $10 \% \mathrm{AcOH}$, purged with nitrogen, and Acm groups were removed by addition of 2 equivalents of iodine ( $0.12 \mathrm{M}$ in methanol). Reaction progress was monitored by analytical HPLC and ESI-MS. Products were purified by semi-preparative HPLC and lyophilized. Presence of two disulfide bonds in the peptides in solution was checked by HPLC after completing the functional experiments.

\section{Recording of vasomotor responses}

Male, 16 weeks old Wistar Kyoto rats (Charles River, Maastricht, The Netherlands) were euthanized by $\mathrm{CO}_{2}$-inhalation. Second-order branches of the superior mesenteric artery were isolated by dissection in $\mathrm{KRB}$ at room temperature. To record isometric tension development, freshly isolated $2 \mathrm{~mm}$ long arterial segments were mounted in wire myographs (DMT, Aarhus, DK) in which $5 \mathrm{~mL}$ KRB was maintained at $37^{\circ} \mathrm{C}$ and aerated with $95 \% \mathrm{O}_{2} / 5 \% \mathrm{CO}_{2}$. The arterial segments were stretched to the diameter at which the largest contractile response to $10 \mu \mathrm{M}$ NA was obtained $[9,17]$. The optimal internal diameter of the segments averaged $306 \pm 8 \mu \mathrm{m}$ and contractile responses to $10 \mu \mathrm{M} \mathrm{NA}$ averaged $3.9 \pm 0.1 \mathrm{~N} / \mathrm{m}$.

Arterial segments were pre-treated with $1 \mu \mathrm{M}$ CAPS for $20 \mathrm{~min}$ and were thereafter studied in the continuous presence of $100 \mu \mathrm{M}$ L-NAME and $10 \mu \mathrm{M}$ INDO. These interventions minimize the effects of sensorimotor nerves and of the endothelium, which we have previously shown to express immunoreactive $E T_{A}$ and $E T_{B}$ receptors $[9,17]$.

\section{Pharmacological protocols}

Increasing concentrations of an endothelin isopeptide (cumulative concentrationresponse curve, CCRC) were administered to resting arteries to record contractile effects. The effect of $E T_{B}$ receptor activation was assessed using the $E T_{B}$ agonists $4^{\mathrm{Ala} E T-1}$ [18] and S6c [19] and the $\mathrm{ET}_{\mathrm{B}}$ antagonist BQ788 [20].

Competition Experiments. Using arterial segments in parallel, CCRCs for a putative agonist were constructed in the absence and in the presence of $1 \mu \mathrm{M}$ of an antagonist. Effects of the antagonist on the position (ratio of $\mathrm{EC}_{50}, \mathrm{pK}_{\mathrm{B}}$ ) and on the height of the agonist CCRC $\left(\mathrm{E}_{\mathrm{MAX}}\right)$ were monitored.

Inhibition Experiments. In arteries made to contract with an ET, we acutely applied the same concentration of the antagonist as we used in the competition experiments. Thereafter, we assessed the effect of removal of the receptor ligands on contractility 
of the arterial segments as a measure for the remaining receptor activation. Because endothelins cause long-lasting arterial contractile effects [9, 11], comparable inhibition experiments were performed on agonist-initiated contractions, where we removed the free agonist before assessing the inhibitory effects of the antagonist.

Only one set of experiments was performed in one set of arterial segments, i.e. distinct pharmacological protocols were not performed in series in the same set of arterial segments. Experiments comparing BQ123-induced inhibition of ET-1- and ET-2-induced contractile effects were analyzed in comparison to control curves within the same rat and not to curves obtained in rats used to compare the various endothelinergic peptides

\section{Data analysis and statistics}

Data are shown as mean \pm SEM. Contractile responses are expressed as percentage of the maximal contractile response to NA observed prior to the administration of any pharmacological inhibitor $\left(N A_{M A X}\right)$. Individual CCRC were fitted to a non-linear regression curve and $\mathrm{ED}_{50}$ and $\mathrm{pK}_{\mathrm{B}}$ values were calculated using GraphPad Prism 5.02. Data were analyzed using one-way ANOVA (comparison of $\mathrm{pD}_{2}, \mathrm{pK}_{\mathrm{B}}$ and $\mathrm{E}_{\max }$ ) or two-way ANOVA (comparison of CCRC). Bonferroni's post-hoc test was used to compare multiple groups. $\mathrm{P}<0.05$ was considered to denote statistical significance.

\section{Results}

Vasomotor responses to ET-1 and ET-2

Nanomolar concentrations of ET-1 and ET-2 caused long-lasting contractions in isolated rat mesenteric resistance arteries. When compared in vessels from the same animals, the potency $\left(\mathrm{pD}_{2}: 8.4 \pm 0.1\right.$ and $8.5 \pm 0.1$, respectively) and the maximal effect $\left(\mathrm{E}_{\mathrm{MAX}}: 102 \pm 5 \%\right.$ vs. $\left.99 \pm 10 \%\right)$ did not differ significantly between both peptides (Fig. 3.1A), in line with earlier findings [21, 22] and in addition their effects were equally persistent (Fig. 3.1D and 3.1F). In contrast, the $\mathrm{ET}_{\mathrm{B}}$ selective agonists S6c [19], found in snake venom, and $4^{\mathrm{Ala} E T-1}$ [18], a linear analogue of ET-1 where the four Cys residues are replaced by Ala, did not contract the isolated arteries at up to $1 \mu \mathrm{M}$ (Fig. 3.1A) [23]. Furthermore, presence of $1 \mu \mathrm{M} 4^{\mathrm{Ala} E T-1}$ or of $1 \mu \mathrm{M} \mathrm{BQ788,}$, an $\mathrm{ET}_{\mathrm{B}}$ selective antagonist [20], tended to alter the sensitivity to ET-1 but this did not reach statistical significance (Fig. 3.1B). These findings indicate that ET-1 and ET-2 cause seemingly similar $\mathrm{ET}_{\mathrm{A}}$ receptor mediated arterial smooth 
muscle contractions, although sensitivity to ET-2 in these $2^{\text {nd }}$ order mesenteric arterial side branches is rather variable in experiments performed in sets of rats within a few weeks interval (Fig. 3.1A and 3.1E).

Figure 3.1. Vasomotor effects of isoforms and analogues of ET-1. ET-1 and ET-2 induce contractions with comparable affinity and efficacy, whereas the selective $\mathrm{ET}_{\mathrm{B}}$ receptor agonists $4^{\mathrm{Ala}} \mathrm{ET}-1$ and $\mathrm{S} 6 \mathrm{C}$ do not induce responses $\mathrm{C}$

A (A). Neither $4{ }^{\text {Ala ET}}$-1 nor the selective $\mathrm{ET}_{\mathrm{B}}$ receptor antagonist BQ788 significantly alter the ET1-induced contractile responses (B). Sensitivity to ET-1-induced contractions (C) and ET-2-induced contractions $(\mathrm{E})$ are reduced in the presence of selective $E_{A}$ antagonist $1 \mu \mathrm{M}$ BQ123. Once full $\mathbf{E}$ contractions are established, they are sustained following removal of BQ123 and ET-1 (D) or ET-2 (F).
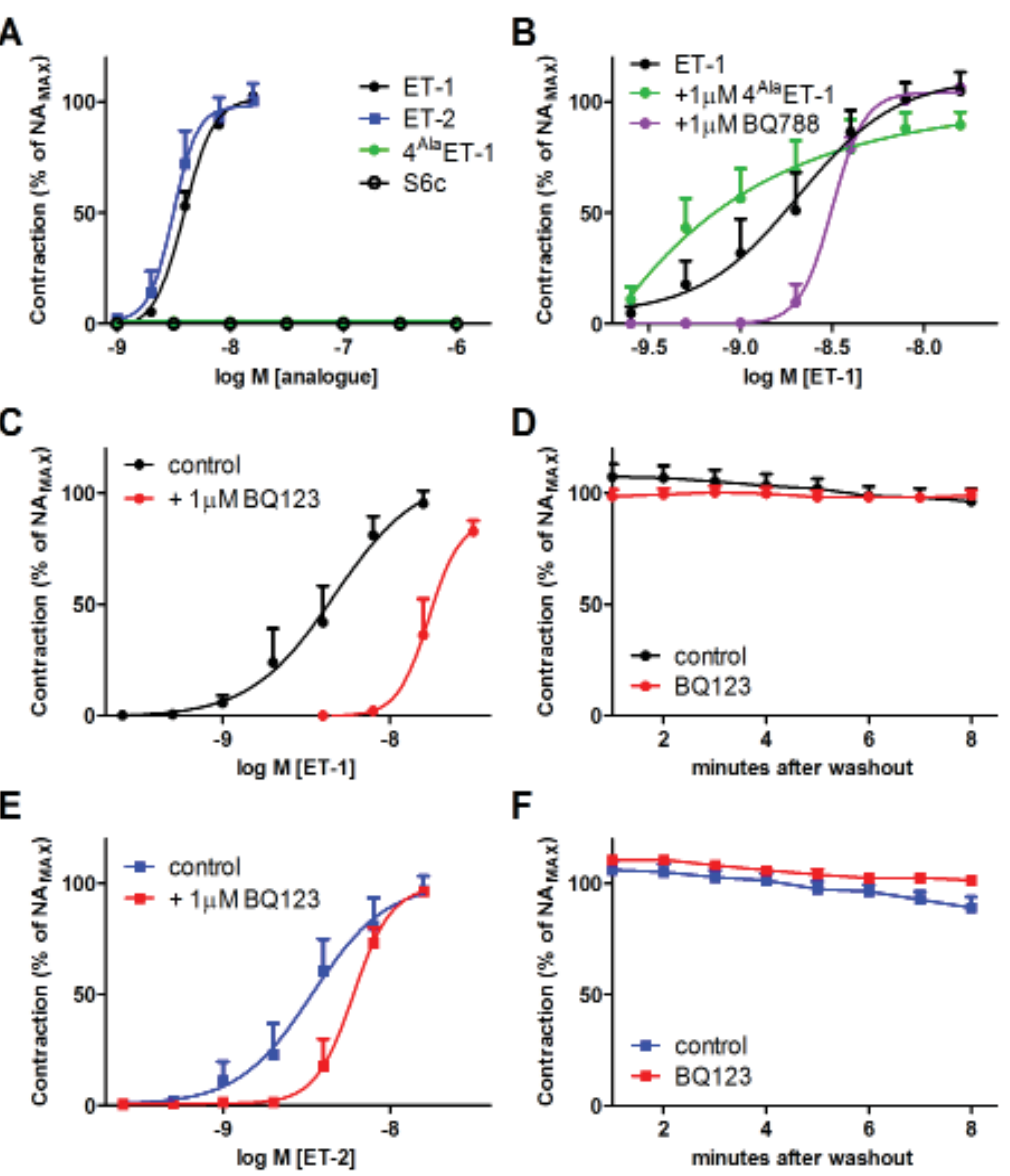

$\mathbf{F}$

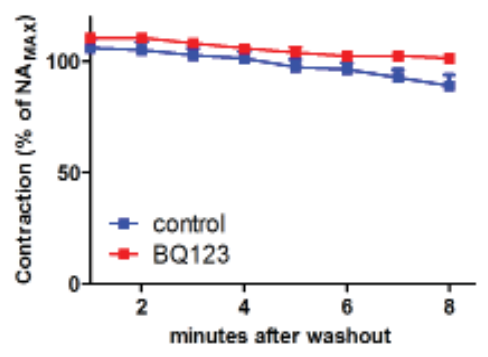

Effects of an $E T_{A}$ antagonist

Presence of $1 \mu \mathrm{M}$ of the $\mathrm{ET}_{\mathrm{A}}$ selective antagonist $\mathrm{BQ123}$ [15] reduced the sensitivities to ET-1 and ET-2 without significant alteration of their maximal contractile effects (Fig. 3.1C and 3.1E). In contrast to earlier reports, where BQ123 inhibited ET-2induced contractions more effective than ET-1-induced contractions in a preparation of either rings of the superior mesenteric artery or the perfused mesenteric arterial bed [24], the effect of the antagonist wasobserved to be more pronounced against ET-1 (11 fold reduction of sensitivity) than against ET-2 (2 fold) in our preparation using $2^{\text {nd }}$ order mesenteric artery side branches and a different pharmacological study protocol. As a consequence, the apparent affinity of BQ123 was 30 times higher against ET-1 ( $\left.\mathrm{pK}_{\mathrm{B}}: 7.1 \pm 0.2\right)$ than against ET-2 $\left(\mathrm{pK}_{\mathrm{B}}: 5.6 \pm 0.4\right)$. Presence of BQ123 did on the other hand not prevent the development of persistent long-lasting contractile effects of ET-1 and ET-2 (Fig. 3.1D and 3.1F). 
Application of $1 \mu \mathrm{M} \mathrm{BQ123}$ during maximal contractile responses to ET-1 or ET-2 of comparable amplitude, resulted in significant relaxation (Fig. 3.2A and 3.2B). BQ123 relaxed ET-1-induced contractions by $43 \pm 7 \%$ but inhibited ET-2-induced effects to a significantly larger extent $(92 \pm 1 \%)$. In both cases, the relaxing effect of BQ123 was rapidly reversible as tonic contractions redeveloped within 1 to $2 \mathrm{~min}$ after flushing both the ET and the antagonist from the organ chamber content (Fig. 3.2A and 3.2B). Similarly, when contractile responses were initiated by an ET and then allowed to proceed in the absence of free agonist, application of $1 \mu \mathrm{M}$ BQ123 caused a reversible relaxation (Fig. 3.2C and 3.2D). Again this relaxing effect was significantly smaller for ET-1- ( $56 \pm 1 \%$, Fig. $3.2 \mathrm{C}$ ) than for ET-2-initiated contractions (90 $\pm 2 \%$; Fig. 3.2D).

\section{A}
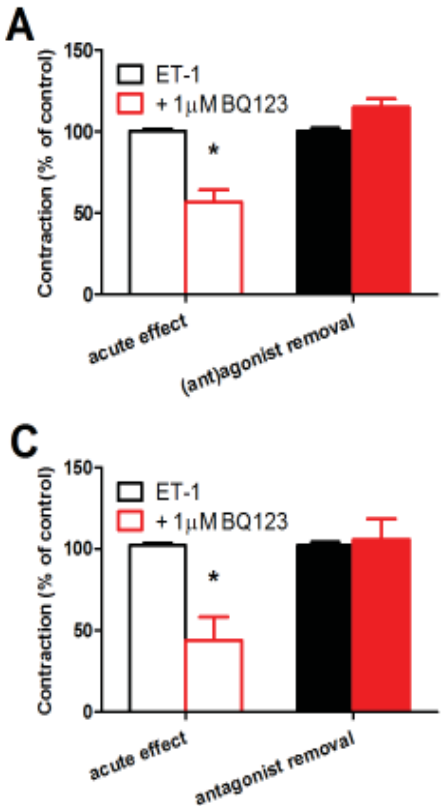

B

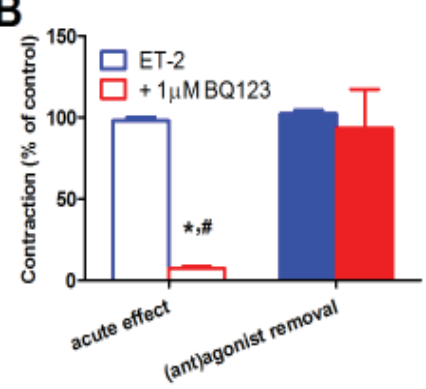

D

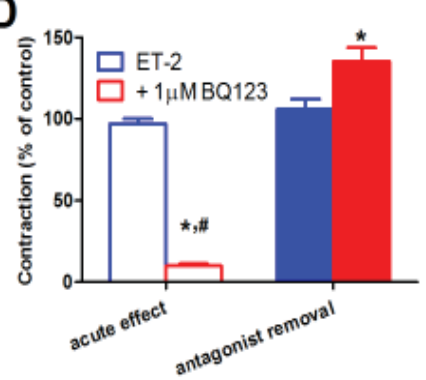

Figure 3.2. Inhibitory effects of BQ123 on sustained and maintained contractions. $1 \mu \mathrm{M}$ BQ123 reduces ET-1-induced contractions by approximately $50 \%$ in presence $(A)$ or following removal $(C)$ of free agonist. The BQ123-induced inhibitions were rapidly reversed upon removal of antagonist and/or agonist. ET-2induced contractions were reduced by $1 \mu \mathrm{M}$ BQ123 by approximately $90 \%$ in presence (B) or following removal (D) of free agonist. Again, these BQ123-induced inhibitions were rapidly reversed upon removal of the ligand(s). ${ }^{*} \mathrm{P}<0.05$ vs control, \# $\mathrm{P}<0.05$ vs $B Q 123$ effect on ET-1.

These observations with BQ123 indicate agonist-dependent modulation of arterial smooth muscle $\mathrm{ET}_{\mathrm{A}}$ receptor function. We next evaluated whether this could be attributed to one of the two amino acids that differ between the sequences of ET-1 and ET-2.

\section{De novo chimera synthesis}

Two chimeras of ET-1/ET-2 were synthesized and studied. The folded Leu'ET-1 (CSCSSL6L7DKECVYFCHLDIIW) had an observed mass of $2472.2 \mathrm{Da}$, fitting well between the calculated monoisotopic mass (2472.1) and the average mass (2473.9) of the folded peptide. The folded Trp ${ }^{6}$ ET-1 (CSCSSW6M7DKECVYFCHLDIIW) peptide had an observed mass of $2563.3 \mathrm{Da}$, fitting well between the calculated monoisotopic mass (2563.0) and the average mass (2565.0) of the folded peptide. An observed mass difference of -144.2 Da between reduced and folded peptide 
a strong response developed rapidly after washout of both ligands (Fig. 3.3D). This indicates tight binding of Leu'ET-1 to $\mathrm{ET}_{\mathrm{A}}$ receptors and inhibition of $\mathrm{ET}_{\mathrm{A}}$ receptor activity by BQ123.

\section{Discussion}

The main findings of this work are that i) not only ET-1, but also ET-2 causes long-lasting arterial contractions, ii) arterial smooth muscle $\mathrm{ET}_{\mathrm{A}}$ receptors display agonist-dependent function, iii) $B Q 123$ acts as a negative allosteric modulator of $E_{A}$ receptors and iv) substitution of a single amino acid in the N-terminal loop of ET-1 can have profound pharmacological consequences. This may lead the way to the development of agonist-selective $\mathrm{ET}_{\mathrm{A}}$ receptor antagonists.

To study $\mathrm{ET}_{\mathrm{A}}$ receptor function we used rat mesenteric resistance arteries, which take part in the regulation of local and total peripheral vascular resistance and in the development of hypertension [25]. We performed all experiments after desensitization of peri-arterial sensorimotor nerves and during continuous inhibition of cyclooxygenases and NO-synthases. The selective $\mathrm{ET}_{\mathrm{B}}$ receptor agonists $4^{\mathrm{Ala}} \mathrm{ET}-1$ and S6c and the $E_{B}$ receptor antagonist BQ788 were without effects, the latter not only versus ET-1-induced contractions but also versus ET-2-induced contractions (data not shown). ET-1 and ET-2 caused contractions and the sensitivity to these nonselective ET receptor agonists was reduced by BQ123. These results indicate that the responses investigated are mediated by smooth muscle $\mathrm{ET}_{\mathrm{A}}$ receptors [3] and are not modulated by endothelium, sensorimotor nerves or $\mathrm{ET}_{\mathrm{B}}$ receptors as we have previously proposed [9].

Not surprisingly, sensitivity and maximal responses to ET-1 and ET-2 did not differ significantly in arteries from the same animals. The responses to both peptides were long-lasting. They persisted after removal of free unbound agonist, in line with earlier findings in different preparations [22], by a procedure that abolishes arterial responses to other contractile stimuli within less than 2 min [9], in line with earlier findings . For ET-1 this has been attributed to tight binding of the peptide to $\mathrm{ET}_{\mathrm{A}}$ receptors $[9,26$, 27]. To us it seems fair to propose that, also for ET-2, the rate of dissociation of the agonist/receptor complexes is particularly slow although estimates of this parameter have not been reported for this isopeptide yet. Our proposal is strengthened by the finding that BQ123 caused reversible relaxations of ET-2-induced and ET-2-initiated contractions as previously reported for ET-1 $[9,10]$. 
The cyclic pentapeptide and $\mathrm{ET}_{\mathrm{A}}$ selective antagonist $\mathrm{BQ} 123$ [15] reduced sensitivity and responses to both endothelins. The antagonist, however, reduced the sensitivity to ET-1 more markedly than that to ET-2. Conversely, the antagonist reduced responses to ET-2 more markedly than those to ET-1. This agonist-dependence and these different effects under resting and activating conditions are not compatible with neutral competitive antagonism but indicative of negative allosteric modulation of $\mathrm{ET}_{\mathrm{A}}$ receptor function $[26,28,29]$. In this view, $\mathrm{BQ123}$ binds to $\mathrm{ET}_{\mathrm{A}}$ receptors at a site that is topographically distinct from the orthosteric binding sites of ET-1 and ET-2. This binding of the modulator changes the conformation of the receptors and thereby alters their affinities for the orthosteric ligands. In addition the bound modulator reduces the intrinsic activity of the agonist/receptor complexes. Activation resulting from tight binding of ET-2 to $\mathrm{ET}_{\mathrm{A}}$ receptors was reduced to a larger extent than that resulting from ET-1. Whether also some of the low molecular weight nonpeptidergic ET receptor antagonists are negative allosteric modulators rather than neutral competitive antagonists [26] largely remains to be established. For bosentan, however, it has been shown that its binding site does not fully coincide with that of $E T-1$ on $E_{A}$ receptors [30] and $A B T-627$ was shown to promote internalization of $E T_{A}$ receptors [31]; an effect that is not compatible with neutral competitive antagonism.

To gain insight in the mechanism of agonist-dependence of $\mathrm{ET}_{\mathrm{A}}$ receptor function, we synthesized chimeras of ET-1 and ET-2. Chemical analyses performed before and after the ex vivo experiments demonstrated that both compounds remained intact and were of the desired molecular weight. Leu'ET-1 behaved as a full $\mathrm{ET}_{\mathrm{A}}$ agonist but was less potent than ET-1 and ET-2. Presence of BQ123 reduced the sensitivity to Leu'ET-1 more markedly than that to ET-2 (Trp ${ }^{6}$ Leu$^{7}$ ET-1). However, BQ123 reduces the intrinsic activity of Leu'ET-1 rather than its affinity for $\mathrm{ET}_{\mathrm{A}}$ receptors. This suggestion is based on the observation that while BQ123 prevented contractile responses to the chimera, the antagonist did not prevent the development of a strong contractile response when both unbound ligands were removed. Apparently, Leu'ET-1 bound tightly to $\mathrm{ET}_{\mathrm{A}}$ receptors even in the presence of BQ123 and the antagonist inhibited the activity of the agonist/receptor complexes. The findings with Leu'ET-1 thus strengthen the notions of agonist-dependence of $\mathrm{ET}_{\mathrm{A}}$ receptor function and the allosteric properties of BQ123.

$\operatorname{Trp}^{6} \mathrm{ET}-1$, on the other hand, displayed neither agonistic nor antagonistic properties at concentrations at which even a low-affinity $\mathrm{ET}_{\mathrm{A}}$ agonist like ET-3 induces contractile responses. It is unlikely that these observations result from a failure of synthesis, as methods of synthesis used were identical to those of the biologically active LeuET-1. In earlier work, replacement in ET-1 of the 
amino acids at positions 6 or 7 by alanine did not modify binding affinity to $\mathrm{ET}_{\mathrm{A}}$ receptors in microsomes [32], nor did these substitutions alter constrictor activity [33]. However, in the current study, Leu ${ }^{6}$ is replaced by a tryptophan, which will have a greater impact on structure-function of a small peptide. While endothelinergic

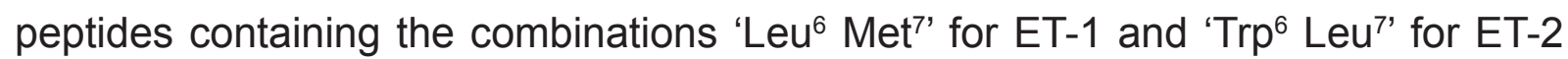
can bind and activate $\mathrm{ET}_{\mathrm{A}}$ receptors, combination of tryptophan on position 6 and methionine on position 7 leads to a marked loss of binding affinity, despite that these substitutions would not alter backbone confirmation [34]. It remains to be determined what the consequences of this combination are for the conformation and flexibility of the agonist molecule [35] leading to the observed loss in biological activity.

Agonist-dependence (or probe-dependence) is one of the main properties of allosteric modulation of receptor function. Further exploration of this mechanism in the endothelin field may ultimately lead to the development of ET receptor antagonists that discriminate between endogenous endothelins (orthosteric agonists) acting in different organs or that become more efficacious with increasing activity of the endothelin axis $[28,29]$.

In conclusion, arterial smooth muscle $\mathrm{ET}_{\mathrm{A}}$ receptors display agonist-dependent properties, involving the roles of amino acids on position 6 and 7 of the endothelin sequence. Agonist-dependent pathologies may benefit from the design of specific, agonist-selective ET receptor antagonists. 


\section{References}

1. Braasch, l., et al. (2009) The endothelin system: evolution of vertebrate-specific ligand-receptor interactions by three rounds of genome duplication. Mol Biol Evol 26, 783-799

2. Masaki, T. (2004) Historical review: Endothelin. Trends Pharmacol Sci 25, 219224

3. Davenport, A.P. (2002) International Union of Pharmacology. XXIX. Update on endothelin receptor nomenclature. Pharmacol Rev 54, 219-226

4. Mihara, S., and Fujimoto, M. (1992) Non-isopeptide-selective endothelin receptors in human Girardi heart cells. Life Sci 50, 219-226

5. Arai, H., et al. (1990) Cloning and expression of a cDNA encoding an endothelin receptor. Nature 348, 730-732

6. Sakurai, T., et al. (1992) Molecular characterization of endothelin receptors. Trends Pharmacol Sci 13, 103-108

7. Levin, E.R. (1995) Endothelins. N Engl J Med 333, 356-363

8. Hynynen, M.M., and Khalil, R.A. (2006) The vascular endothelin system in hypertension--recent patents and discoveries. Recent patents on cardiovascular drug discovery 1, 95-108

9. Meens, M.J., et al. (2010) Stimuli of sensory-motor nerves terminate arterial contractile effects of endothelin-1 by CGRP and dissociation of ET-1/ET(A)receptor complexes. PLoS One 5, e10917

10. Meens, M.J., et al. (2011) Calcitonin gene-related peptide terminates longlasting vasopressor responses to endothelin 1 in vivo. Hypertension 58, 99-106

11. Yanagisawa, M., et al. (1988) A novel potent vasoconstrictor peptide produced by vascular endothelial cells. Nature 332, 411-415

12. Takizawa, S., et al. (2005) Differential expression of endothelin-2 along the mouse intestinal tract. J Mol Endocrinol 35, 201-209

13. Ko, C., et al. (2006) Endothelin-2 in ovarian follicle rupture. Endocrinology 147, 1770-1779

14. Meidan, R., and Levy, N. (2007) The ovarian endothelin network: an evolving story. Trends Endocrinol Metab 18, 379-385

15. Ihara, M., et al. (1992) Biological profiles of highly potent novel endothelin antagonists selective for the ETA receptor. Life Sci 50, 247-255

16. Schnolzer, M., et al. (1992) In situ neutralization in Boc-chemistry solid phase peptide synthesis. Rapid, high yield assembly of difficult sequences. Int J Pept Protein Res 40, 180-193 
17. Meens, M.J., et al. (2009) Calcitonin gene-related peptide selectively relaxes contractile responses to endothelin-1 in rat mesenteric resistance arteries. $J$ Pharmacol Exp Ther 331, 87-95

18. Saeki, T., et al. (1991) [Ala1,3,11,15]endothelin-1 analogs with ETB agonistic activity. Biochem Biophys Res Commun 179, 286-292

19. Deng, L.Y., et al. (1995) Endothelin receptor subtypes in resistance arteries from humans and rats. Cardiovasc Res 29, 532-535

20. Ishikawa, K., et al. (1994) Biochemical and pharmacological profile of a potent and selective endothelin B-receptor antagonist, BQ-788. Proc Natl Acad Sci U S A 91, 4892-4896

21. Bogoni, G., et al. (1996) Characterization of endothelin receptors in the human umbilical artery and vein. Br J Pharmacol 119, 1600-1604

22. Saito, A., et al. (1991) Endothelins: vasoconstrictor effects and localization in canine cerebral arteries. Br J Pharmacol 103, 1129-1135

23. Maguire, J.J., and Davenport, A.P. (1995) ETA receptor-mediated constrictor responses to endothelin peptides in human blood vessels in vitro. $\mathrm{Br} \mathrm{J}$ Pharmacol 115, 191-197

24. Donoso, M.V., et al. (1996) Pharmacological characterization of the ETA receptor in the vascular smooth muscle comparing its analogous distribution in the rat mesenteric artery and in the arterial mesenteric bed. Peptides 17, 1145-1153

25. Mulvany, M.J., and Aalkjaer, C. (1990) Structure and function of small arteries. Physiol Rev 70, 921-961

26. De Mey, J.G., et al. (2011) ETA-receptor antagonists or allosteric modulators? Trends Pharmacol Sci 32, 345-351

27. Hilal-Dandan, R., et al. (1997) The quasi-irreversible nature of endothelin binding and $G$ protein-linked signaling in cardiac myocytes. J Pharmacol Exp Ther 281, 267-273

28. Christopoulos, A., and Kenakin, T. (2002) G protein-coupled receptor allosterism and complexing. Pharmacol Rev 54, 323-374

29. Keov, P., et al. (2011) Allosteric modulation of $G$ protein-coupled receptors: a pharmacological perspective. Neuropharmacology 60, 24-35

30. Breu, V., et al. (1995) Separable binding sites for the natural agonist endothelin-1 and the non-peptide antagonist bosentan on human endothelin-A receptors. Eur J Biochem 231, 266-270

31. Chiou, W.J., et al. (2000) 'Irreversible' endothelin-1 binding does not prohibit ABT-627 from reversing endothelin-1-induced effects. J Cardiovasc Pharmacol $36, \mathrm{~S} 48-52$

32. Tam, J.P., et al. (1994) Alanine scan of endothelin: importance of aromatic residues. Peptides 15, 703-708 
33. Huggins, J.P., et al. (1993) The structure and specificity of endothelin receptors: their importance in physiology and medicine. Pharmacol Ther 59, 55-123

34. Wallace, B.A., and Janes, R.W. (1995) The crystal structure of human endothelin-1 and how it relates to receptor binding. J Cardiovasc Pharmacol 26 Suppl 3, S250-253

35. Lattig, J., et al. (2009) Structural determinants for selective recognition of peptide ligands for endothelin receptor subtypes ETA and ETB. J Pept Sci 15, 479-491 


\section{Chapter 4}

Endothelin-1 and Endothelin-2 Initiate and Maintain Contractile Responses by Different Mechanisms in Rat Mesenteric and Cerebral ARTERIES

Matthijs G Compeer, Ger MJ Janssen, Jo GR De Mey

SUBMITTED 


\begin{abstract}
Endothelin-1 (ET-1) and endothelin-2 (ET-2) cause potent long-lasting vasoconstrictions by tight binding to smooth muscle $\mathrm{ET}_{\mathrm{A}}$ receptors. We tested the hypotheses that different mechanisms mediate initiation and maintenance of arterial contractile responses to ET-1 and ET-2 and that this differs between vascular beds.
\end{abstract}

Segments of rat mesenteric resistance artery (MRA) and basilar artery (BA) were studied in wire myographs with and without functional antagonists.

The sensitivity and maximum of MRA contractile responses to ET-1 were not, or only moderately, reduced by stimuli of soluble guanylate cyclase, adenylate cyclase or $\mathrm{K}^{+}$-channels and by an inhibitor of receptor-operated ion-channels. Yet, each of these reduced the maintenance of ET-1 effects and relaxed ET-1-induced contractions in MRA. A calcium-channel antagonist did not alter sensitivity, maximum and maintenance of ET-1 effects but relaxed ET-1-induced contractions in MRA. A phospholipase $C$ inhibitor prevented contractile responses to ET-1 and ET-2 in MRA and $B A$, and relaxed ET-1- and ET-2-induced responses in MRA and ET-1 effects in BA. A Rho-kinase inhibitor did not modify sensitivity, maximum and maintenance of responses to both peptides in both arteries but relaxed ET-2, but not ET-1, effects in MRA and ET-1 effects in BA.

Phospholipase C plays a key role in arterial contractile responses to ETs but ET-1 and ET-2 initiate and maintain vasoconstriction by different mechanisms and these differ between rat mesenteric and basilar arteries. Selected functional antagonism may be considered for agonist- and vascular bed selective pharmacotherapy of ETrelated diseases. 


\section{Introduction}

Endothelins (ETs) are bicyclic 21 amino acid peptidergic paracrine mediators [1, 2] involved in the cardiovascular system [3], chronic pain [4] and cancers [5]. In mammalian species, the ET family consists of three members, endothelin-1 (ET-1), endothelin-2 (ET-2) and endothelin-3 (ET-3), the former being most prevalent in the cardiovascular system as a regulator of vascular tone [6]. After release from the endothelium, ET-1 causes contraction of vascular smooth muscle cells (VSMCs) via endothelin $\mathrm{ET}_{\mathrm{A}}$ receptors [7]. In most ex vivo settings of freshly isolated arteries, there is no observable effect of endothelial or smooth muscle $E T_{B}$ receptors on vasomotor tone $[8,9]$. Activated $\mathrm{ET}_{\mathrm{A}}$ receptors can stimulate several signal-transduction pathways including NADPH-oxidases, phospholipases, Rho-kinase and cellularinflux of calcium ions $[6,10,11]$. For several other vasoconstrictor agonists it has been established that transient stimulation of calcium-influx is followed by calciumsensitization resulting from Rho-kinase mediated inhibition of myosin light-chain phosphatase illustrating different molecular mechanisms underlying the initiation and maintenance of vasoconstrictor responses [12-14].

ET-1 binds tightly to $\mathrm{ET}_{\mathrm{A}}$ receptors [9, 15], causing arterial contractions followed by long-lasting vasospasms that are refractory to inhibition by ET-receptor antagonists $[2,9,16-18]$. This might explain why ET-receptor antagonists are rather ineffective in treating ET-related diseases in clinical trials $[3,19,20]$. In view of the tight agonist binding, functional antagonists may be better suited for therapeutic purposes than receptor antagonists.

The endogenous ET-2 (Trp6 Leu ET-1) has binding affinities and efficacies at ET-receptors that are seemingly similar to those of ET-1 and has therefore been considered to display identical pharmacological properties [21]. Recently however we reported quantitative differences between the effects of $\mathrm{ET}_{\mathrm{A}}$ antagonists on arterial responses to ET-1 and ET-2 $[8,22]$ and an elegant review of the literature identified several differences in the functions of ET-1 and ET-2 in the cardiovascular system, ovaries, immunology and cancer [23].

Here we tested the hypotheses that i) different mechanisms mediate ET-induced contractions and vasospasms and ii) that these mechanisms display agonist- and system dependence. For the latter we focused on differences between ET-1 and ET-2 and between mesenteric and cerebral arteries. 


\section{Methods}

Experiments were performed in accordance with the institutional guidelines and were approved by the Ethics Committee on Experimental Animal Welfare of the Maastricht University.

\section{Solutions and compounds}

Bay412272 and Bay602770 were a kind gift from Dr. JP Stasch (Bayer Healthcare, Wuppertal, D) and were dissolved in DMSO. Felodipine, Staurosporine (Sigma Aldrich, Zwijndrecht, NL), Chelerythrine chloride, Pyr3, OH-fasudil, Ro318220 and U73122 (Tocris Bioscience, Bristol, UK), were also dissolved in DMSO, the latter by heating to $70^{\circ} \mathrm{C}$ for $2 \mathrm{~h}$. Indomethacin (INDO, cyclooxygenase-inhibitor) (Sigma Aldrich, Zwijndrecht, NL) was dissolved in 100\% ethanol. Human ET-1 and human ET-2 (Bachem, Weil am Rhein, D), noradrenaline (NA), phenylephrine (PHE), acetylcholine (ACh), pinacidil, isoproterenol, forskolin and L-NAME (NO synthaseinhibitor) (Sigma Aldrich, Zwijndrecht, NL) were dissolved in Krebs Ringer bicarbonate buffer (KRB) containing, in $\mathrm{mM}: \mathrm{NaCl}: 118.5 ; \mathrm{KCl}: 4.7 ; \mathrm{CaCl}_{2}: 2.5 ; \mathrm{MgSO}_{4}: 1.2$; $\mathrm{KH}_{2} \mathrm{PO}_{4}: 1.2 ; \mathrm{NaHCO}_{3}: 25.0$; glucose: 5.5 . $\mathrm{K}^{+}-\mathrm{KRB}$ was $\mathrm{KRB}$ in which all $\mathrm{NaCl}$ was replaced by $\mathrm{KCl}$. Buffers with intermediate $\mathrm{K}^{+}$-concentration were prepared by mixing appropriate volumes of KRB and $\mathrm{K}^{+}-\mathrm{KRB}$. The maximal solvent concentrations did not exceed $0.1 \%$ and did not significantly modify vascular reactivity.

Recording of vasomotor responses

16 weeks old male Wistar Kyoto rats (Charles River, Maastricht, NL) were euthanized by $\mathrm{CO}_{2}$-inhalation. The basilar artery and $2^{\text {nd }}$-order branches of the superior mesenteric artery were isolated by dissection in KRB at room temperature. To record isometric tension development, $2 \mathrm{~mm}$ long freshly isolated arterial segments were mounted in wire myographs (DMT, Aarhus, DK) in which the segments were kept in $\mathrm{KRB}$ at $37^{\circ} \mathrm{C}$ and aerated with $95 \% \mathrm{O}_{2} / 5 \% \mathrm{CO}_{2}$. The mesenteric resistance artery segments were progressively stretched to the diameter at which the largest contractile response to $10 \mu \mathrm{M}$ NA was observed [24]. The optimal internal diameter of the segments averaged $311 \pm 7 \mu \mathrm{m}$ and contractile responses to $10 \mu \mathrm{M} N A$ and to $40 \mathrm{mM} \mathrm{K}^{+}$averaged $4.7 \pm 0.2 \mathrm{~N} / \mathrm{m}$ and $4.1 \pm 0.3 \mathrm{~N} / \mathrm{m}$, respectively. The basilar artery segments were distended to a diameter corresponding to $90 \%$ of the diameter at a transmural pressure of $100 \mathrm{mmHg}\left(0.9 \mathrm{D}_{100}\right)$. The internal diameter of these segments averaged $385 \pm 13 \mu \mathrm{m}$ and contractile responses to $40 \mathrm{mM} \mathrm{K}^{+}$averaged $2.5 \pm 0.2 \mathrm{~N} / \mathrm{m}$. 
The arterial segments were treated with $1 \mu \mathrm{M}$ CAPS for 20 min during contraction induced by, $40 \mathrm{mM} \mathrm{K}^{+}$, to desensitize peri-arterial sensory motor-nerves. The segments were thereafter studied in the continuous presence of INDO $(10 \mu \mathrm{M})$ and L-NAME $(100 \mu \mathrm{M})$ to inhibit prostaglandin- and NO-synthesis, respectively. This approach allowed focusing on vascular smooth muscle function, minimizing the effect of the endothelium and sensory motor-nerves [25].

Due to the quasi-irreversible nature of ET-induced contractions, a single set of experiments was performed in one set of arterial segments, i.e. distinct pharmacological protocols were performed in parallel rather than in series. Also, arteries from different rats were used to monitor anti-ET effects of different putative functional antagonists.

\section{Pharmacological protocols}

To determine workable concentrations of putative functional antagonists, we recorded contractile responses to $40 \mathrm{mM} \mathrm{K}^{+}$and $10 \mu \mathrm{M}$ PHE in the presence of increasing concentrations of the compounds. The lowest concentration with the maximal inhibitory effect was then selected for further experiments. The reversibility of these effects was tested after 10 min. repeatedly rinsing the organ chamber with compound-free buffer. Stimuli of relaxing mechanisms and the calcium-antagonist were tested versus $\mathrm{K}^{+}$-induced contractions while inhibitors of receptor-activated mechanisms were evaluated versus PHE-induced contractions. Effects of the putative functional antagonists on i) the apparent potency, ii) the maximal effect and iii) the maintenance of ET-induced arterial contractions were determined by constructing cumulative concentration-response curves (CCRC) to ET-1 or ET-2 in the absence (Fig. 4.1A) and in the continuous presence of the pre-determined concentration of the compound administered $15 \mathrm{~min}$ before the peptide (Fig. 4.1B). In addition, the relaxing effect of the antagonist was determined by first inducing contraction with increasing concentrations of the ET and subsequently administering the compound in the presence of the peptide (Fig. 4.1C). The three CCRCs for the ET were performed in arterial segments from the same rats. They started at $0.25 \mathrm{nM}$ and the concentration of the peptide was doubled at 5 min interval until $16 \mathrm{nM}$ was reached. This concentration was left in contact with the tissues for 15 min allowing the first segment, which was not exposed to antagonist (Fig. 1A), to be used as a time-control for the maintenance and relaxation parts of the protocol (Fig. 4.1B and 4.1C). Ultimately, the peptide and compound were rinsed from the organ chamber contents and tension was recorded for 8 more min to monitor reversibility of the ETinduced contraction and of the antagonist effects. 

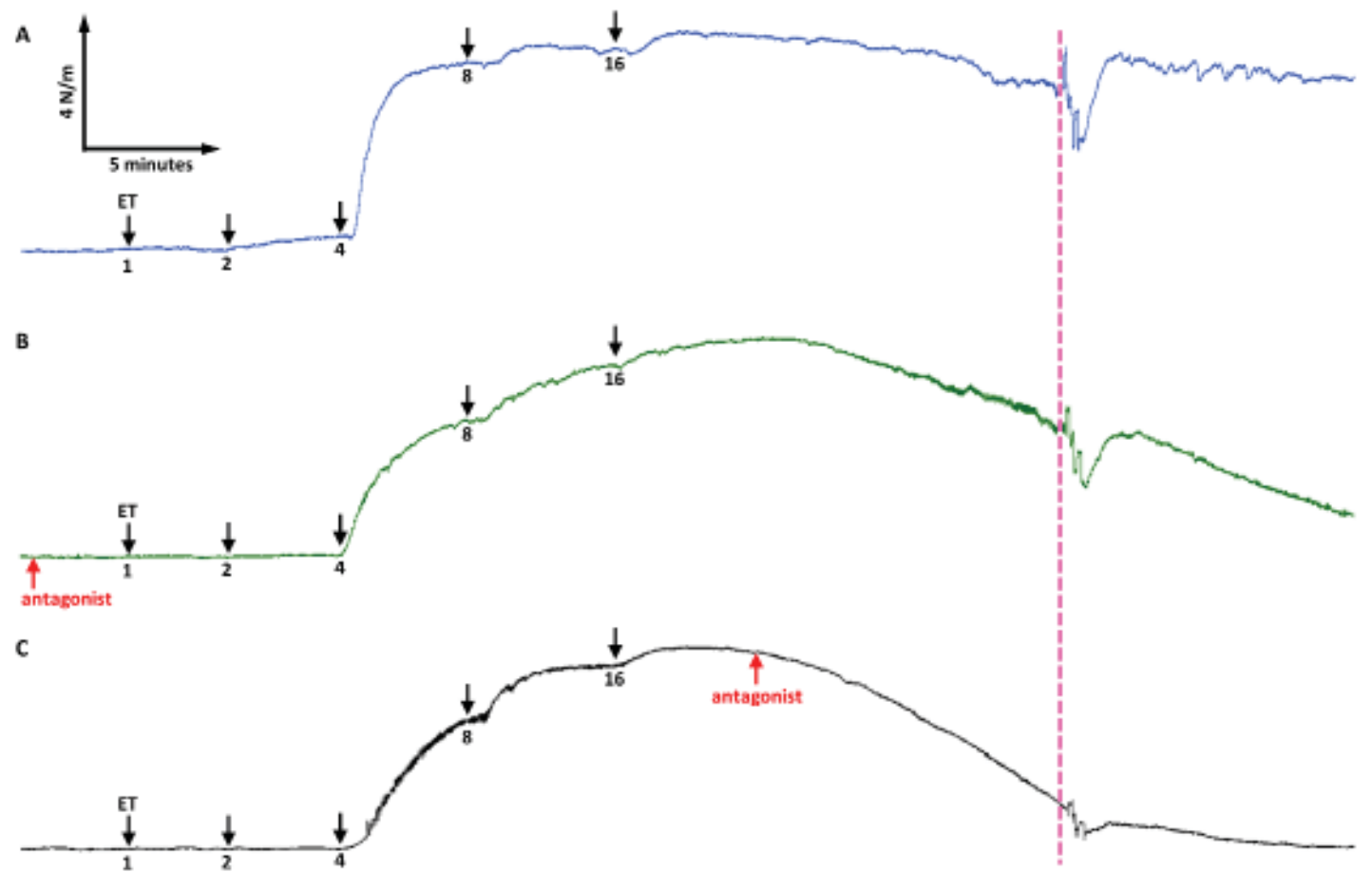

Fig. 4.1. Original tracings of active wall tension as a function of time, illustrating the pharmacological protocols. A. Contractile responses to increasing concentrations of ET-1 or ET-2 and the vasospasm and persistence thereof were recorded. The red dashed line indicates washout of compounds from the organ chamber content. B. Effects of a putative functional antagonist on the potency and maximal effect of the ET and its maintenance was recorded in another arterial segment in parallel. C. In a third arterial segment, the relaxing effect of the putative functional antagonist was recorded during ET-induced vasospasm.

Data analysis and statistics

Data are shown as mean \pm SEM with $n \geq 6$ for each observation. Contractile responses are expressed as percentage of the maximal contractile response to $10 \mu \mathrm{MNA}\left(\mathrm{NA}_{\mathrm{MAX}}\right)$ or $40 \mathrm{mM} \mathrm{K}^{+}$observed prior to the administration of any pharmacological inhibitor for mesenteric and basilar artery preparations, respectively. Individual CCRC were fitted to a non-linear regression curve and $\mathrm{ED}_{50}$ values were calculated using GraphPad Prism 5.02. Data were analyzed using one-way ANOVA (comparison of $E_{50}$ and $\mathrm{E}_{\text {MAX }}$ ) or two-way ANOVA (comparison of CCRC). Bonferroni's post-hoc test was used to compare multiple groups.

\section{Results}

General effects of functional antagonists

Fig. 4.2 summarizes mesenteric resistance artery contractile responses to $40 \mathrm{mM} \mathrm{K}^{+}$and to $10 \mu \mathrm{M} \mathrm{PHE}$ in the presence of functional antagonists. Maximal reduction of $\mathrm{K}^{+}$-induced responses was observed with $1 \mathrm{nM}$ felodipine 
Fig. 4.2. Effects of functional antagonists on contractile responses to $40 \mathrm{mM} \mathrm{K}^{+}$(top) and 10 $\mu \mathrm{M}$ PHE (bottom). The reversibility of the effects of the vasodilator compounds ( $B$ and $D)$ was evaluated at 10 minutes after flushing the antagonist from the organ chamber. Findings were expressed as \% of the contractile response to $40 \mathrm{mM} \mathrm{K}^{+}$or to $10 \mu \mathrm{M} \mathrm{PHE}$ $\left(\mathrm{PHE}_{\mathrm{MAX}}\right)$ and are shown as means \pm SEM $(n=6-8)$. ${ }^{* *} \mathrm{P}<0.01,{ }^{* * *} \mathrm{P}<0.001$
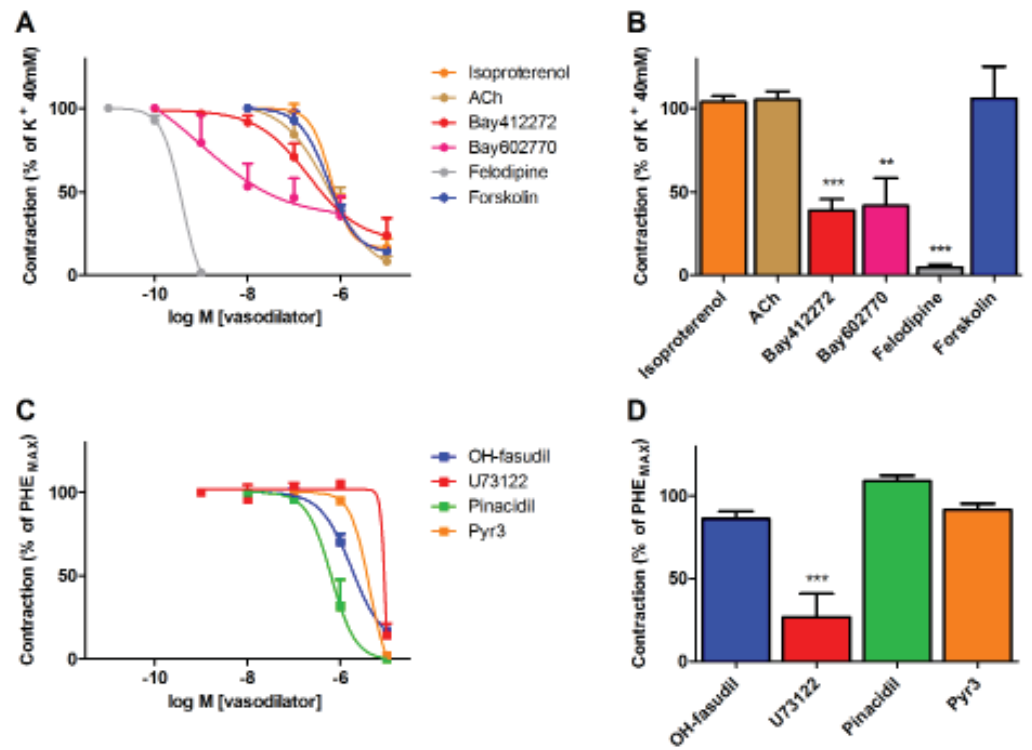

(inhibitor of L-type voltage-operated $\mathrm{Ca}^{2+}$-channels, L-VOCC [26]), $1 \mu \mathrm{M}$ Bay602770 (haem-independent activator of sGC [27]) and with $10 \mu \mathrm{M}$ of each acetylcholine (endothelium-dependent vasodilator [28]), Bay412272 (haem-dependent stimulator of sGC [29]), forskolin (direct stimulus of AC [30]), and isoproterenol ( $\beta$-adrenoceptor agonist [31]) (Fig. 4.2A). Responses to PHE were reduced more than $80 \%$ in the presence of $10 \mu \mathrm{M}$ of each pinacidil (opener of ATP-sensitive $\mathrm{K}^{+}$-channels [32]), U73122 (inhibitor of PLC [33]), OH-fasudil (inhibitor of Rho-kinase [34]) and Pyr3 (inhibitor of receptor-operated $\mathrm{Ca}^{2+}$-channels [35]) (Fig. 4.2B). $1 \mathrm{nM}$ felodipine did not significantly modify contractile responses to PHE, and both $10 \mu \mathrm{M}$ U73122 and $10 \mu \mathrm{M} \mathrm{OH}$-fasudil did not significantly modify $\mathrm{K}+$-induced contraction (data not shown), as expected. Conflicting results were obtained with candidate inhibitors of protein kinase $\mathrm{C}$. They either had no effect on contractile responses at up to $10 \mu \mathrm{M}$ (Ro318220) or they reduced responses to $\mathrm{K}^{+}$and PHE to the same extent (staurosporine and chelerythrine chloride; data not shown). Inhibitory effects of acetylcholine, forskolin, isoproterenol, $\mathrm{OH}$-fasudil, pinacidil and Pyr3 were abolished within 10 min of washout of the compounds while inhibitory effects of Bay412272, Bay602770, U73122 and especially felodipine were only poorly reversible (Fig. 4.2C and 4.2D).

Mesenteric resistance artery response to $E T-1$

After sensorimotor nerve desensitization and in the presence of L-NAME and indomethacin, mesenteric resistance arteries responded to ET-1 with concentrationdependent contractions (Fig. 4.1, 4.3 and 4.4). The maximal response was well maintained in the presence of $16 \mathrm{nM} \mathrm{ET-1}$ and long-lasting after washout of free unbound peptide (Fig. 4.1A, 4.3B and 4.4B). 

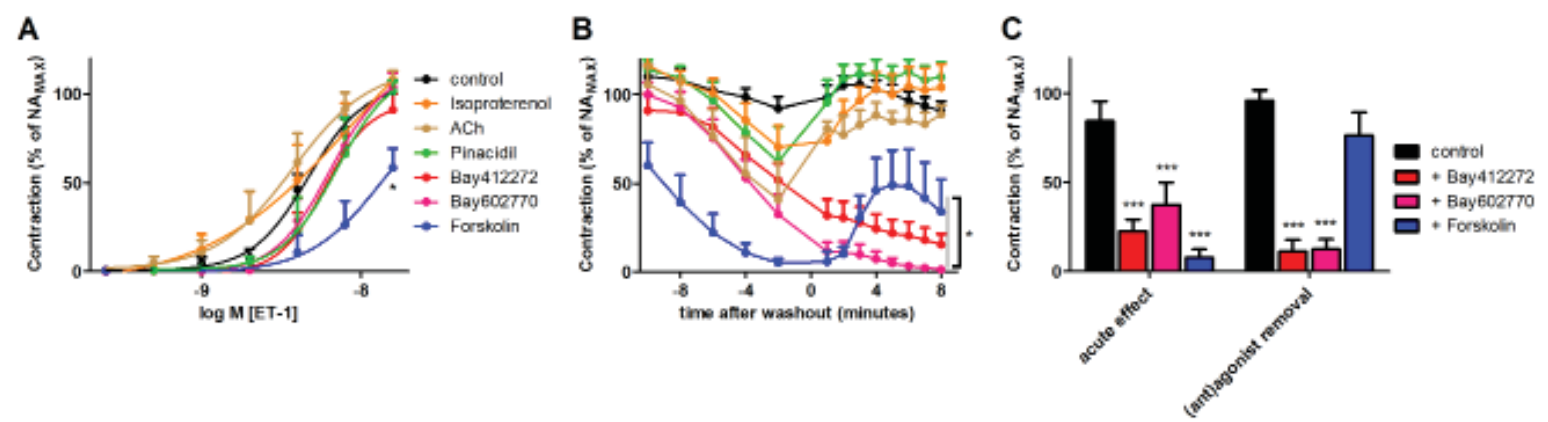

Fig. 4.3. Effects of the antagonists on sensitivity and maximal contractile responses to ET-1 (A) and their effects on the persistent ET-1-induced vasospasm before and after removal of free compounds from the tissue (washout) (B). C: The acute relaxing effect of the antagonists on ET-1-induced vasospasms and reversibility of the relaxation when the agonist and antagonist were removed. Findings were expressed as $\%$ of the contractile response to $10 \mu \mathrm{M}$ noradrenaline $\left(\mathrm{NA}_{\text {MAX }}\right)$ and are shown as means \pm SEM $(n=$ $6-8) .{ }^{*} \mathrm{P}<0.05,{ }^{* * *} \mathrm{P}<0.001$.

Presence of most of the functional antagonists at concentrations that inhibited $\mathrm{K}^{+}$- or PHE-induced contraction, did not significantly modify sensitivity or maximal responses to ET-1. This was the case for acetylcholine, Bay412272, Bay602779, felodipine, isoproterenol, OH-fasudil, pinacidil and Pyr3 (Fig. 4.3A and 4.4A). Forskolin moderately reduced the sensitivity to ET-1 (Fig. 4.3A) and U73122 markedly attenuated the initiation of contraction by 0.25 to $16 \mathrm{nM} \mathrm{ET-1}$ (Fig. 4.4A). Despite lack of effect on sensitivity and maximal responsiveness to ET-1, presence of several
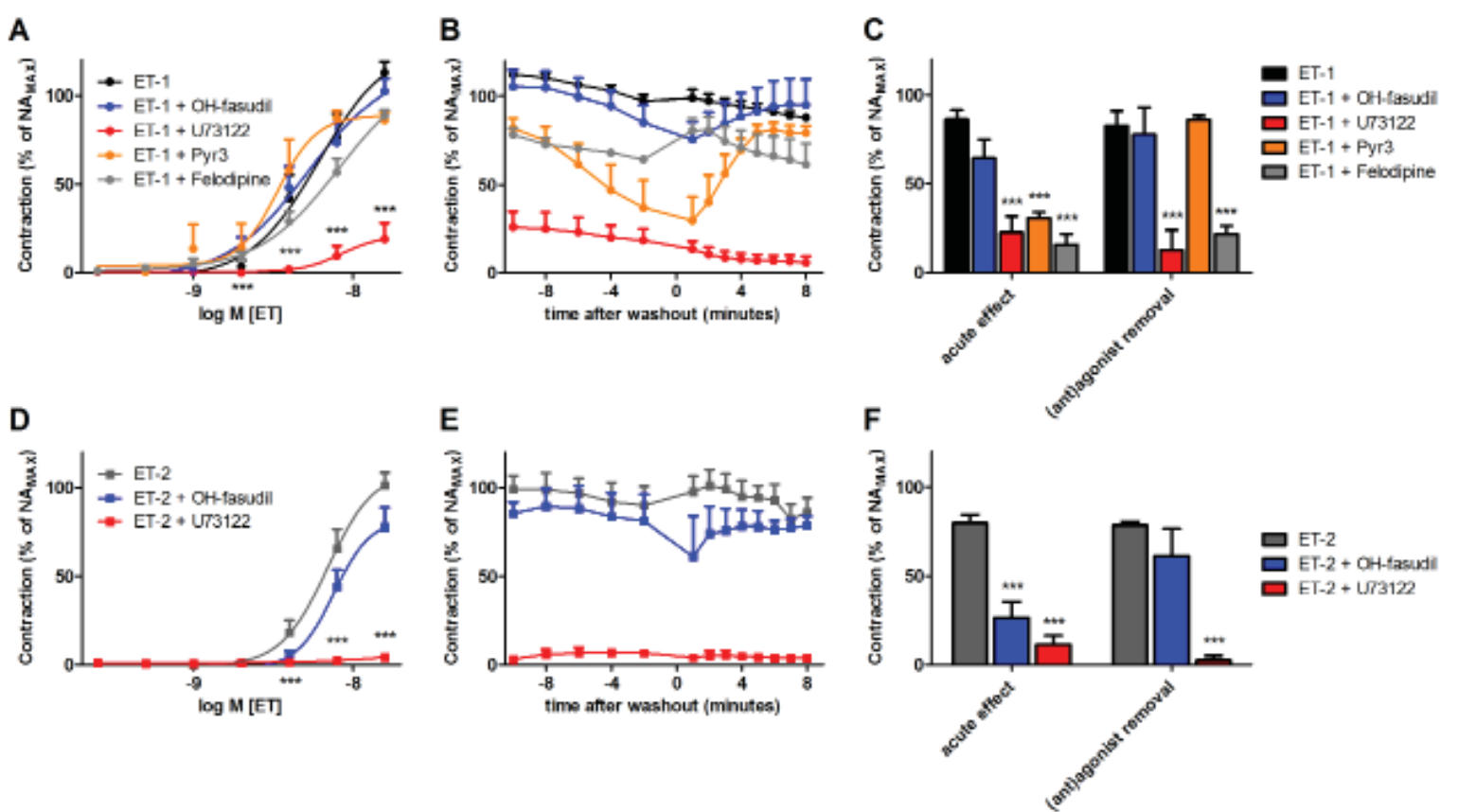

Fig. 4.4. Top: effects of felodipine, Pyr3, OH-fasudil and U73122 on ET-1-induced contractions (A) and persistence of vasospasms before and after washout $(B)$, and the acute relaxing effect of the felodipine, Pyr3, OH-fasudil and U73122 on ET-1-induced vasospasms and reversibility of the relaxation when the agonist and antagonist were removed (C). Bottom: effects of OH-fasudil and U73122 on ET-2-induced contractions (D) and persistence of vasospasms (E), and the acute relaxing effect of $\mathrm{OH}$-fasudil and U73122 on ET-2-induced vasospasms and reversibility of this effect $(F)$. Findings were expressed as \% of the contractile response to $10 \mu \mathrm{M}$ noradrenaline $\left(\mathrm{NA}_{\mathrm{MAX}}\right)$ and are shown as means $\pm \operatorname{SEM}(n=6)$. ${ }^{* *}$ $P<0.001$. 
types of functional antagonists reduced the maintenance of the contractile response to the peptide (Fig. 4.3B and 4.4B). 10 min after reaching the maximal response to ET-1, the level of contraction was significantly lower than in the time control in preparations exposed to $10 \mu \mathrm{M}$ isoproterenol, $10 \mu \mathrm{M}$ acetylcholine, $10 \mu \mathrm{M}$ pinacidil, $10 \mu \mathrm{M}$ Bay412272, $1 \mu \mathrm{M}$ Bay602770, $10 \mu \mathrm{M}$ forskolin (Fig. 3B), or $10 \mu \mathrm{M}$ Pyr3 (Fig. 4.4B). In contrast, presence of $1 \mathrm{nM}$ felodipine and $10 \mu \mathrm{M} \mathrm{OH}$-fasudil did not significantly alter the maintenance of mesenteric resistance artery responses to ET-1 (Fig. 4.4B).

In view of the different findings on initiation and maintenance of contraction we determined whether the functional antagonists could relax ET-1-induced contractions. In an earlier study we demonstrated this for isoproterenol, acetylcholine and pinacidil [9]. Here we observed marked relaxation with stimuli of soluble guanylate cyclase or adenylate cyclase which was long-lasting for both Bay412272 and Bay602770 and readily reversible for forskolin (Fig. 4.3C). Also U73122, Pyr3 and felodipine, but not $\mathrm{OH}$-fasudil, markedly relaxed ET-1-induced contraction (Fig. 4.4C). While the effects of the PLC inhibitor and the L-VOCC blocker (felodipine) were longlasting that of the inhibitor of receptor-operated calcium-channels (Pyr3) was readily reversible. It is noteworthy that felodipine which did not alter the potency, maximal effect and maintenance of ET-1-induced contracting did induce a marked relaxation of the response to peptide (Fig. 4.4).

\section{Mesenteric resistance artery responses to $E T-2$}

The potency and maximal contractile effects of ET-2 and their maintenance and persistence did not differ from those of ET-1 (Fig. 4.4). Presence of U73122 largely prevented contractile responses to ET-2 and the PLC inhibitor markedly relaxed ET-2-induced contraction. Presence of $\mathrm{OH}$-fasudil did not significantly modify the sensitivity and the maximum and maintenance of responses to ET-2. These findings are very similar to those with ET-1 (Fig. 4.4). However, unlike ET-1-induced contractions (Fig. 4.4C), ET-2-induced contractions could be significantly relaxed by OH-fasudil (Fig. 4.4F).

\section{Basilar artery responses to ET-1and ET-2}

The cerebral arteries were somewhat more sensitive to ET-1 and ET-2 than the mesenteric resistance arteries and also in these vessels the contractile responses to the peptides were maintained and long-lasting (Fig. 4.4 and 4.5). As was the case for the mesenteric vessels, presence of U73122 largely suppressed basilar artery 

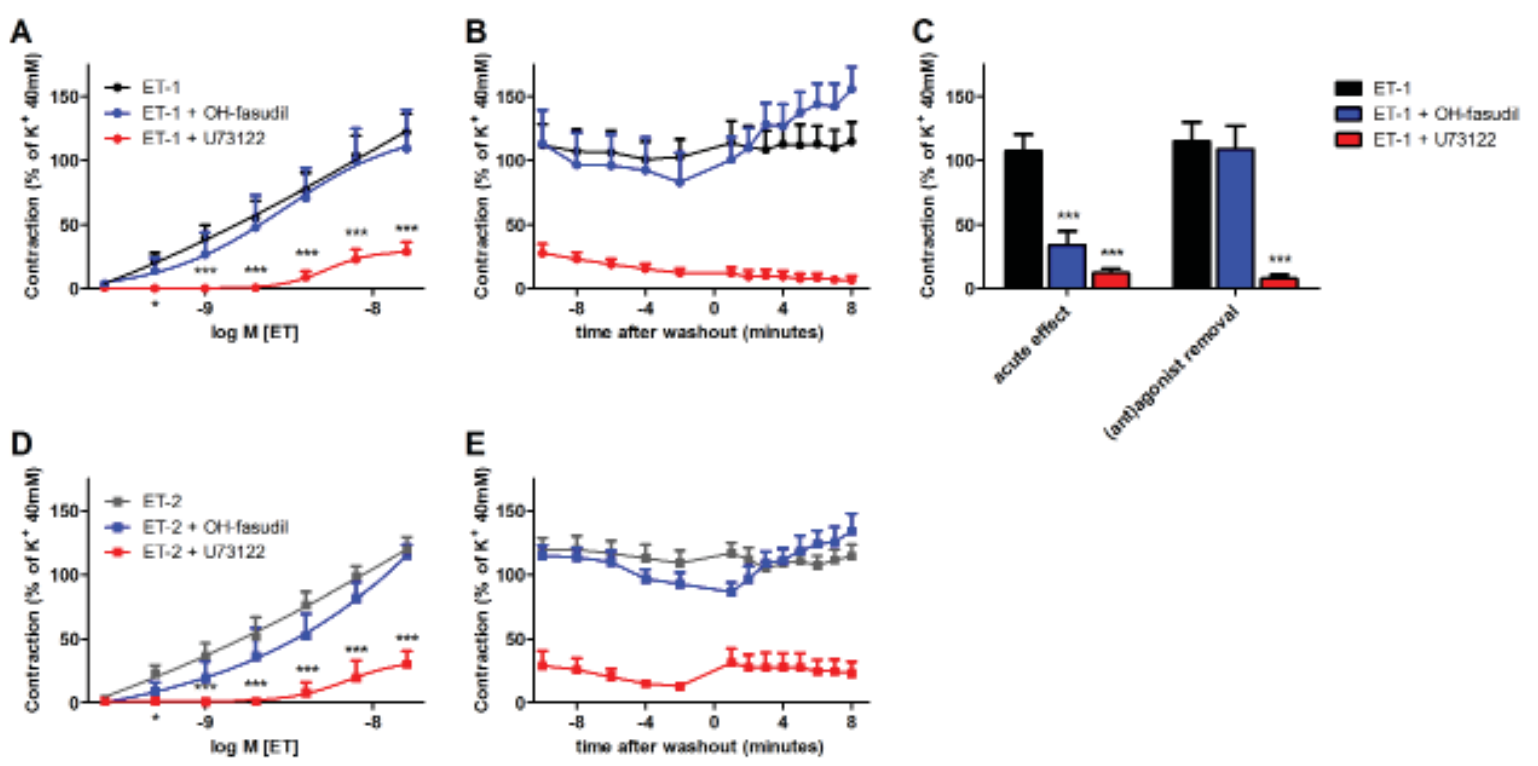

Fig. 4.5. Effects of $\mathrm{U} 73122$ and $\mathrm{OH}$-fasudil, in the basilar artery, on sensitivity and maximal contractile responses to ET-1 (A) and ET-2 (D), on the persistence of the vasospasms before and after washout $(B, E)$, and on the acute relaxing effect of $\mathrm{U} 73122$ and $\mathrm{OH}$-fasudil on ET-1- induced vasospasms and reversibility of the relaxation $(\mathrm{C})$. Findings were expressed as \% of the contractile response to $40 \mathrm{mM} \mathrm{K}^{+}$ and are shown as means $\pm \operatorname{SEM}(n=6) .{ }^{*} P<0.05,{ }^{* *} P<0.01,{ }^{* * *} P<0.001$.

contractile responses to ET-1 and ET-2 (Fig. 4.5A, 4.5D) and the PLC inhibitor markedly relaxed contractile responses to ET-1 (Fig. 4.5C). While presence of $\mathrm{OH}$ fasudil did not modify sensitivity, maximum and maintenance of responses to ET-1, this RhoK-inhibitor markedly relaxed ET-1-induced contractions in rat basilar arteries (Fig. $4.5 \mathrm{C}$ ). This is noteworthy because $\mathrm{OH}$-fasudil had no statistically significant effects on responses to ET-1 in rat mesenteric resistance arteries (Fig. 4.4C).

\section{Discussion}

The main findings of this work are that several functional antagonists reduce the maintenance of ET-induced arterial contractions more markedly than their initiation and that this differs between ET-1 and ET-2 and between rat mesenteric resistance and basilar arteries.

Rat small artery vasomotor responses to ETs are mediated by smooth muscle $\mathrm{ET}_{\mathrm{A}}$ receptors [7]. The peptides bind tightly to these receptors leading to long-lasting contractions that are refractory to reversal by $\mathrm{ET}_{\mathrm{A}}$ antagonists $[2,9,16-18]$. This is even more marked in rat cerebral arteries than mesenteric resistance arteries [36] and invites to consider other types of inhibitors such as a "physiological" antagonist like CGRP [9, 37], negative allosteric modulators of receptor function [8, 15, 22] and functional antagonists. Here we concentrated on anti-endothelinergic effects of 
inhibitors of contractile mechanisms and of stimuli of relaxing mechanisms. We verified the selectivity of these pharmacological tools by analyses of their effects on $\mathrm{K}^{+}$-induced and $\alpha_{1}$-adrenergic contractions.

The molecular mechanisms of vasoconstriction induced by agonists that activate 7 transmembrane domain receptors are still only partly understood. A widely held view suggests differences during initiation and maintenance of smooth muscle contraction. The agonists would stimulate PLC and cause an initial transient marked increase in cytoplasmic calcium-concentration that is followed by increased calciumsensitivity of the contractile apparatus resulting from RhoK-mediated inhibition of myosin light chain phosphatase [12-14]. Most of the uncertainties remain in the origin of the calcium ions, in the nature of the channels involved in intracellular calciumrelease and -influx over the sarcolemma and in the transition to RhoK-dependent mechanisms. In general, $\mathrm{ET}_{\mathrm{A}}$ receptors have been shown to stimulate among others several G-proteins, PLC activity, a transient increase in intracellular calciumconcentration and RhoK activity $[10,11,13,38]$ and most of these were confirmed in smooth muscle cells from rat mesenteric resistance arteries [39, 40]. However, the distinct roles of these processes in the initiation and maintenance of ET-induced contractions are much less clear. Here, we observed that different mechanisms are involved in the initiation and maintenance of $\mathrm{ET}_{\mathrm{A}}$ mediated arterial contractions but found no evidence for involvement of RhoK herein. We rather obtained the first indications that this displays agonist- and system-dependence.

The widely used PLC inhibitor U73122, at a concentration that did not reduce $\mathrm{K}^{+}$induced responses, largely prevented and reversed contractile effects of ET-1 and ET-2 in both mesenteric arteries and to ET-1 in basilar arteries. This suggests a major overall role for $\mathrm{PLC}$ in arterial $\mathrm{ET}_{\mathrm{A}}$ mediated contractions. The precise isoenzymes were proposed to differ from PLC- $\delta 1$ involved in sustained $\alpha_{1}$-adrenergic arterial contraction [39]. The use of U73122 as a selective general inhibitor of phospholipases has recently been challenged [41] but there is no valid pharmacological alternative available yet. A for this study potentially serious additional effect is potent PLCindependent inhibition of plasmalemmal calcium-channels reported in one study [42]. PLC synthesizes inositol trisphosphate that stimulates intracellular calciumrelease and diacylglycerol that stimulates PKC which can among others promote calcium-influx. The former is in line with a strong but transient mesenteric resistance artery contractile response to ET-1 in the absence of extracellular calcium [43]. The roles of the latter could not be investigated because putative inhibitors were either ineffective or lacked the desired selectivity. 
In contrast to U73122, the dihydropyridine inhibitor of L-VOCC felodipine and the RhoK-inhibitor $\mathrm{OH}$-fasudil, at concentrations that inhibited $\mathrm{K}^{+}$-induced and $\alpha_{1}$-adrenergic responses, respectively, did not significantly modify sensitivity, maximum and maintenance of mesenteric artery responses to ET-1. This invited to consider involvement of receptor-operated calcium channels with the use of Pyr3. This pyrazole compound was recently reported to selectively inhibit transient receptor potential canonical channels (TRPC3) and Orai1, a component of storeoperated calcium channels [35, 44]. Pyr3 did not alter initiation of mesenteric artery responses to ET-1 but reversibly inhibited their maintenance and reversibly relaxed ET-1-induced contractions in this tissue. Because TRPC3 and Orai1 functions are modulated by diacylglycerol, either directly or via PKC [45-47], these channels might be linked to ET-1 induced PLC activation and involved in the sustained mesenteric artery responses to the peptide.

Stimuli of relaxing mechanisms that act via hyperpolarization, AC or SGC did not alter sensitivity or maximal responses to ET-1 but could relax ET-1-induced vasospasms. These results indicate different intracellular mechanisms involved in initiation and maintenance of smooth muscle contractions. It is noteworthy that we did not observe a marked difference between the effects of a haem-dependent stimulator of sGC (Bay412272) and a haem-independent activator of sGC (Bay602770) [48] although $\mathrm{ET}-1$ potently stimulates NADPH oxidase activity via $\mathrm{ET}_{\mathrm{A}}$ receptors [49]. The stimuli that produced non-reversible relaxation of ET-1-induced vasospasms were those that were characterized, based on their effects on $\mathrm{K}^{+}$-induced and $\alpha_{1}$-adrenergic contractions, as poorly reversible, and likely did not alter binding of ET-1 to $\mathrm{ET}_{\mathrm{A}}$ receptors. The effects of stimuli of relaxing mechanisms and of the inhibitors of contractile mechanisms are presented in Fig. 6, in which the proposed mechanisms for the initial contraction and subsequent vasospasms are summarized.

As previously described, effects of $\mathrm{ET}_{\mathrm{A}}$ receptor antagonists are agonist-dependent, i.e. the extent of the modulation by these receptor antagonists depends on which agonist is used to activate $\mathrm{ET}_{\mathrm{A}}$ receptors [8, 22]. We therefore aimed to determine if such agonist-dependence also applied to functional antagonists and we found that RhoK-inhibition, in contrast to ET-1-induced vasospasms, reversibly relaxed ET2-induced vasospasms. Because the Rho/RhoK-mediated pathway is a signaling pathway parallel of PLC [13] and the effects of the PLC-inhibitor did not differ between ET-1- and ET-2-induced responses, ET-1 and ET-2 display a functional selectivity and could be considered as biased agonists [50]. ET-1 selectively activates PLC signaling, whereas ET-2 is more biased to a non-selective, parallel activation of PLC and Rho/RhoK pathways. This is worth some consideration when functionally 


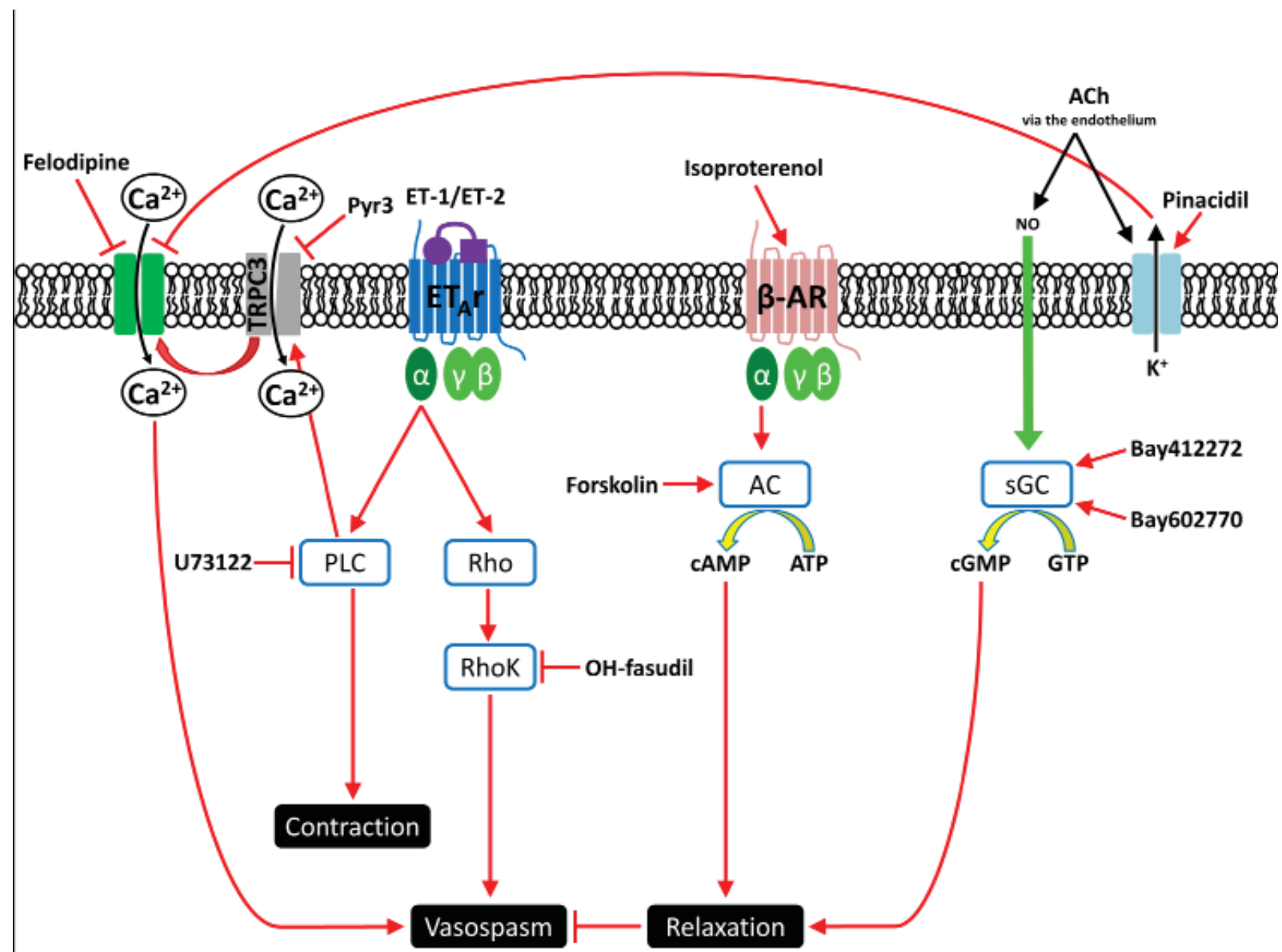

Fig. 6. The intracellular signaling pathway leading to $E T_{A}$ mediated contractions and vasospasms and targets to inhibit these pathways. U73122, the PLC- inhibitor, is the only compound that inhibits both contractions and vasospasms and is therefore likely to be the main mediator of the initiating contraction. $\alpha$ : G-protein $\alpha$ subunit; $\beta$ : G-protein $\beta$ subunit; $\beta$-AR: $\beta$-adrenoceptor; $\gamma$ : G-protein $\gamma$ subunit; AC: adenylate cyclase; ACh: acetylcholine; ATP: adenosine triphosphate: Bay412272: sCG stimulator; Bay602770: sCG activator; cAMP: cyclic adenosine monophosphate; cGMP: cyclic guanosine monophosphate; ET-1: endothelin-1; $E T-2$ : endothelin-2; $\mathrm{ET}_{\mathrm{A}}$ r: endothelin ${ }_{A}$ receptor; felodipine: calcium channel blocker; forskolin; AC activator; GTP: guanosine triphosphate; isoproterenol: $\beta$-adrenoceptor agonist; NO: nitric oxide; $\mathrm{OH}$ fasudil: RhoK-inhibitor; pinacidil: ATP-sensitive potassium channel opener; PLC: phospholipase C; Pyr3: TRPC3-blocker; RhoK: Rho-kinase; sGC: soluble guanylate cyclase; TRPC3: Transient receptor potential cation channel 3; U73122: PLC -inhibitor.

antagonizing $\mathrm{ET}_{\mathrm{A}}$ mediated signaling, as agonist-dependence, one of the indicators of allosterism [50,51] at a receptor level, is now also found as an intracellular occurrence.

To further explore allosteric modulation, we addressed another criterion; systemdependence [52]. To this end, we compared mesenteric arteries with basilar arteries, a system that is resistant to $\mathrm{ET}_{\mathrm{A}}$ receptor antagonist and to the physiological antagonist CGRP [36]. Like in mesenteric arteries, the PLC-inhibitor U73122 largely prevented and reversed contractile effects of ET-1. But OH-fasudil, the RhoK-inhibitor, induced a reversible relaxation of ET-1-induced vasospasms in basilar arteries, in contrast to its (lack of) effect in mesenteric arteries. This suggests a functional selectivity of 
ET-1 towards a biased, PLC-mediated response in mesenteric arteries and a nonselective, non-biased parallel PLC- and Rho/RhoK-mediated response.

In conclusion, the intracellular signaling mechanism of $\mathrm{ET}_{\mathrm{A}}$ mediated contractile responses not only changes during sustained receptor activation but is also dependent on which agonist activates $\mathrm{ET}_{\mathrm{A}}$ receptors. Unlike Rho/RhoK, PLC is involved in contractions as well as vasospasms induced by ET-1 or ET-2 in rat mesenteric arteries. The initiation and maintenance of ET-induced contractile responses are mediated by different mechanisms, downstream of PLC. Additionally, the intracellular signaling mechanism is not only agonist-dependent but also system-dependent, as $\mathrm{Rho/RhoK} \mathrm{signaling} \mathrm{is} \mathrm{involved} \mathrm{in} \mathrm{ET-1-induced} \mathrm{responses} \mathrm{in} \mathrm{basilar} \mathrm{arteries.} \mathrm{When}$ using functional antagonists as a method of pharmacologic intervention in the ET system, both system- and agonist-selectivity of the functional antagonist should be considered. 


\section{References}

1. Wagner, O.F., et al. (1992) Regional effects and clearance of endothelin-1 across pulmonary and splanchnic circulation. Eur J Clin Invest 22, 277-282

2. Yanagisawa, M., et al. (1988) A novel potent vasoconstrictor peptide produced by vascular endothelial cells. Nature $332,411-415$

3. Kirkby, N.S., et al. (2008) The endothelin system as a therapeutic target in cardiovascular disease: great expectations or bleak house? $\mathrm{Br} \mathrm{J}$ Pharmacol $153,1105-1119$

4. Khodorova, A., et al. (2009) Endothelin receptors and pain. J Pain 10, 4-28

5. Buther, K., et al. (2012) Assessment of endothelin-A receptor expression in subcutaneous and orthotopic thyroid carcinoma xenografts in vivo employing optical imaging methods. Endocrinology 153, 2907-2918

6. Masaki, T. (2004) Historical review: Endothelin. Trends Pharmacol Sci 25, 219224

7. Rizzoni, D., et al. (1997) The vasoconstriction induced by endothelin-1 is mediated only by $\mathrm{ET}(\mathrm{A})$ receptors in mesenteric small resistance arteries of spontaneously hypertensive rats and Wistar Kyoto rats. J Hypertens 15, 16531657

8. Compeer, M.G., et al. (2012) Agonist-dependent modulation of arterial endothelinA receptor function. Br J Pharmacol 166, 1833-1845

9. Meens, M.J., et al. (2010) Stimuli of sensory-motor nerves terminate arterial contractile effects of endothelin-1 by CGRP and dissociation of ET-1/ET(A)receptor complexes. PLoS One 5, e10917

10. Badr, K.F., et al. (1989) Mesangial cell, glomerular and renal vascular responses to endothelin in the rat kidney. Elucidation of signal transduction pathways. $J$ Clin Invest 83, 336-342

11. Neylon, C.B. (1999) Vascular biology of endothelin signal transduction. Clinical and experimental pharmacology \& physiology 26, 149-153

12. Loirand, G., et al. (2006) Rho kinases in cardiovascular physiology and pathophysiology. Circ Res 98, 322-334

13. Wynne, B.M., et al. (2009) Vascular Smooth Muscle Cell Signaling Mechanisms for Contraction to Angiotensin II and Endothelin-1. Journal of the American Society of Hypertension : JASH 3, 84-95

14. Somlyo, A.P., and Somlyo, A.V. (2000) Signal transduction by G-proteins, rhokinase and protein phosphatase to smooth muscle and non-muscle myosin II. J Physiol 522 Pt 2, 177-185

15. De Mey, J.G., et al. (2011) ETA-receptor antagonists or allosteric modulators? Trends Pharmacol Sci 32, 345-351 
16. Adner, M., et al. (2001) Evidence that ET-1, but not ET-3 and S6b, ET(A)-receptor mediated contractions in isolated rat mesenteric arteries are modulated by coactivation of $\mathrm{ET}(\mathrm{B})$ receptors. Br J Pharmacol 133, 927-935

17. Inoue, A., et al. (1989) The human endothelin family: three structurally and pharmacologically distinct isopeptides predicted by three separate genes. Proc Natl Acad Sci U S A 86, 2863-2867

18. Hilal-Dandan, R., et al. (1997) The quasi-irreversible nature of endothelin binding and $\mathrm{G}$ protein-linked signaling in cardiac myocytes. J Pharmacol Exp Ther 281, 267-273

19. Kohan, D.E., et al. (2012) Clinical trials with endothelin receptor antagonists: what went wrong and where can we improve? Life Sci 91, 528-539

20. Schneider, M.P., et al. (2007) Contrasting actions of endothelin ET(A) and ET(B) receptors in cardiovascular disease. Annu Rev Pharmacol Toxicol 47, 731-759

21. Davenport, A.P. (2002) International Union of Pharmacology. XXIX. Update on endothelin receptor nomenclature. Pharmacol Rev 54, 219-226

22. Compeer, M.G., et al. (2012) Endothelin-1 and -2: Two amino acids matter. Life Sci $91,607-612$

23. Ling, L., et al. (2013) Endothelin-2, the forgotten isoform: emerging role in the cardiovascular system, ovarian development, immunology and cancer. $\mathrm{Br} J$ Pharmacol 168, 283-295

24. Meens, M.J., et al. (2009) Calcitonin gene-related peptide selectively relaxes contractile responses to endothelin-1 in rat mesenteric resistance arteries. $J$ Pharmacol Exp Ther 331, 87-95

25. De Mey, J.G., et al. (2008) Functional antagonism between endogenous neuropeptide $Y$ and calcitonin gene-related peptide in mesenteric resistance arteries. J Pharmacol Exp Ther 324, 930-937

26. Herlitz, H., et al. (1983) Felodipine, an arteriolar dilator with pronounced antihypertensive effect. Lancet 1, 409-410

27. Pankey, E.A., et al. (2011) Pulmonary and systemic vasodilator responses to the soluble guanylyl cyclase activator, BAY 60-2770, are not dependent on endogenous nitric oxide or reduced heme. Am J Physiol Heart Circ Physiol 300, $\mathrm{H} 792-802$

28. De Mey, J.G., et al. (1982) Endothelium-dependent inhibitory effects of acetylcholine, adenosine triphosphate, thrombin and arachidonic acid in the canine femoral artery. J Pharmacol Exp Ther 222, 166-173

29. Stasch, J.P., et al. (2001) NO-independent regulatory site on soluble guanylate cyclase. Nature 410, 212-215 
30. Seamon, K.B., et al. (1981) Forskolin: unique diterpene activator of adenylate cyclase in membranes and in intact cells. Proc Natl Acad Sci U S A 78, 33633367

31. Aviado, D.M., Jr., et al. (1958) Cardiovascular effects of sympathomimetic bronchodilators; epinephrine, ephedrine, pseudoephedrine, isoproterenol, methoxyphenamine and isoprophenamine. J Pharmacol Exp Ther 122, 406-417

32. Carlsen, J.E., et al. (1983) Pinacidil, a new vasodilator: pharmacokinetics and pharmacodynamics of a new retarded release tablet in essential hypertension. Eur J Clin Pharmacol 25, 557-561

33. Bleasdale, J.E., etal.(1990)Selective inhibition of receptor-coupled phospholipase C-dependent processes in human platelets and polymorphonuclear neutrophils. J Pharmacol Exp Ther 255, 756-768

34. Kandabashi, T., et al. (2002) Involvement of rho-kinase in agonists-induced contractions of arteriosclerotic human arteries. Arterioscler Thromb Vasc Biol 22, 243-248

35. Kiyonaka, S., et al. (2009) Selective and direct inhibition of TRPC3 channels underlies biological activities of a pyrazole compound. Proc Natl Acad Sci U S A 106, 5400-5405

36. Meens, M.J., et al. (2011) Calcitonin gene-related peptide terminates longlasting vasopressor responses to endothelin 1 in vivo. Hypertension 58, 99-106

37. Meens, M.J., et al. (2012) G-protein betagamma subunits in vasorelaxing and anti-endothelinergic effects of calcitonin gene-related peptide. Br J Pharmacol 166, 297-308

38. Saleh, S.N., et al. (2009) Activation of native TRPC1/C5/C6 channels by endothelin-1 is mediated by both PIP3 and PIP2 in rabbit coronary artery myocytes. J Physiol 587, 5361-5375

39. Clarke, C.J., et al. (2008) Phospholipase C-delta1 modulates sustained contraction of rat mesenteric small arteries in response to noradrenaline, but not endothelin-1. Am J Physiol Heart Circ Physiol 295, H826-834

40. Morris, G.E., et al. (2010) Endothelin signalling in arterial smooth muscle is tightly regulated by $\mathrm{G}$ protein-coupled receptor kinase 2. Cardiovasc Res $85,424-433$

41. Klein, R.R., et al. (2011) Direct activation of human phospholipase $C$ by its well known inhibitor u73122. J Biol Chem 286, 12407-12416

42. Pulcinelli, F.M., et al. (1998) Evidence for separate effects of U73122 on phospholipase $\mathrm{C}$ and calcium channels in human platelets. Biochemical pharmacology $56,1481-1484$

43. Boonen, H.C., and De Mey, J.G. (1990) G-proteins are involved in contractile responses of isolated mesenteric resistance arteries to agonists. NaunynSchmiedeberg's archives of pharmacology 342, 462-468 
44. Schleifer, H., et al. (2012) Novel pyrazole compounds for pharmacological discrimination between receptor-operated and store-operated $\mathrm{Ca}(2+)$ entry pathways. Br J Pharmacol 167, 1712-1722

45. Harteneck, C., and Gollasch, M. (2011) Pharmacological modulation of diacylglycerol-sensitive TRPC3/6/7 channels. Current pharmaceutical biotechnology 12, 35-41

46. Vazquez, G., et al. (2010) On the potential role of source and species of diacylglycerol in phospholipase-dependent regulation of TRPC3 channels. Channels (Austin) 4, 232-240

47. Kawasaki, T., et al. (2010) Protein kinase C-induced phosphorylation of Orai1 regulates the intracellular $\mathrm{Ca} 2+$ level via the store-operated $\mathrm{Ca} 2+$ channel. $\mathrm{J}$ Biol Chem 285, 25720-25730

48. Evgenov, O.V., et al. (2006) NO-independent stimulators and activators of soluble guanylate cyclase: discovery and therapeutic potential. Nat Rev Drug Discov 5, 755-768

49. Elmarakby, A.A., et al. (2005) NADPH oxidase inhibition attenuates oxidative stress but not hypertension produced by chronic ET-1. Hypertension 45, 283287

50. Kenakin, T., and Miller, L.J. (2010) Seven transmembrane receptors as shapeshifting proteins: the impact of allosteric modulation and functional selectivity on new drug discovery. Pharmacol Rev 62, 265-304

51. Keov, P., et al. (2011) Allosteric modulation of $G$ protein-coupled receptors: a pharmacological perspective. Neuropharmacology 60, 24-35

52. Christopoulos, A., et al. (2004) G-protein-coupled receptor allosterism: the promise and the problem(s). Biochem Soc Trans 32, 873-877 


\section{Chapter 5}

Agonist-Dependent Modulation of Arterial Endothelin A $_{\text {-Receptor }}$ FUNCTION

Matthijs G Compeer, Merlijn JPMT Meens, Tilman M Hackeng, Witold A Neugebauer, Carsten Höltke, Jo GR De Mey

BR J Pharmacol. 2012 JuL; 166(6):1833-45 


\section{Abstract}

Endothelin-1 (ET-1) causes long-lasting vasoconstrictions. These can be prevented by $E_{A}$ receptor antagonists but are only poorly reversed by these drugs. We tested the hypothesis that endothelin $\mathrm{ET}_{\mathrm{A}}$ receptors are susceptible to allosteric modulation by endogenous agonists and exogenous ligands.

Isolated rat mesenteric resistance arteries were pretreated with capsaicin and studied in wire myographs, in the presence of L-NAME and indomethacin to concentrate on arterial smooth muscle responses.

Endothelins caused contractions with equal maximum but differing potency (ET$1=$ ET-2 > ET-3). ET-1 $1_{1-15}$ neither mimicked nor antagonized these effects in the absence and presence of $\mathrm{ET}_{16-21} .4^{\mathrm{Ala}} \mathrm{ET}-1$ ( $\mathrm{ET}_{\mathrm{B}}$ agonist) and BQ788 ( $\mathrm{ET}_{\mathrm{B}}$ antagonist) were without effects. BQ123 (peptidergic $\mathrm{ET}_{\mathrm{A}}$ antagonist) reduced the sensitivity and relaxed the contractile responses to endothelins. Both effects depended on the agonist $\left(\mathrm{pK}_{\mathrm{B}}\right.$ : $\mathrm{ET}-3=\mathrm{ET}-1>\mathrm{ET}-2$; \% relaxation: $\left.\mathrm{ET}-3=\mathrm{ET}-2>\mathrm{ET}-1\right)$. Also with PD156707 (non-peptidergic $\mathrm{ET}_{\mathrm{A}}$ antagonist) agonist-dependence and a discrepancy between preventive and inhibitory effects were observed. The latter was even more marked with bulky analogues of BQ123 and PD156707.

These findings indicate allosteric modulation of arterial smooth muscle $E_{\mathrm{A}}$ receptor function by endogenous agonists and by exogenous endothelin-receptor antagonists. This may have consequences for diagnosis and pharmacotherapy of diseases involving endothelins. 


\section{Introduction}

The endogenous mammalian endothelins ET-1, ET-2 and ET-3 are bicyclic 21 amino acid paracrine mediators. They share a 6 amino acid C-terminal tail but differ in 2 to 6 amino acids in the $\mathrm{N}$-terminal loop (Table 1). Their roles in physiology and in diseases are mediated by two subtypes of 7 transmembrane domain receptors (7TMR) [1-6]. Activation of $\mathrm{ET}_{\mathrm{A}}$ receptors causes cell growth and proliferation, vasospasm, oxidative stress and, inflammation. Endothelial $\mathrm{ET}_{\mathrm{B}}$ receptors scavenge endothelins from the circulation and are proposed to counterbalance the deleterious effects of endothelins [3, 7]. ET-1 and ET-2 bind with equal high affinity to $\mathrm{ET}_{\mathrm{A}}$ and $E T_{B}$ while $E T-3$ binds with considerably lower affinity to $\mathrm{ET}_{A}$ than $\mathrm{ET}_{\mathrm{B}}$ [8-10]. During the past two decades, several classes of low molecular weight compounds were discovered that prevent binding of endothelins to $E T_{A}$ and/or $E T_{B}$ (for review see $[8,11])$. These endothelin-receptor antagonists (ERAs) are regarded as neutral competitive antagonists although their binding-site does not necessarily coincide with the agonist-binding sites [12-16].

Structure-affinity, -selectivity and -activity relationships indicate a key role of the C-terminus of endothelins in $\mathrm{ET}_{B}$ binding and activation [14, 17]. $\mathrm{ET}_{\mathrm{A}}$ receptor function seems more complex. We and others proposed that ET-1 binds polyvalently to $\mathrm{ET}_{\mathrm{A}}$ receptors [14, 17-19]. For other peptidergic 7TMR-agonists such as calcitoningene related peptide (CGRP), corticotrophin-releasing factor (CRF) and parathyroid hormone (PTH), it has been reported that distinct parts of the agonist molecule and of the receptor govern binding-affinity (address domain) and signaling (message domain) [20, 21].

$\mathrm{ET}_{\mathrm{A}}$-mediated vasoconstrictor effects of ET-1 are potent, long-lasting and refractory to reversal by ERAs. In vitro and in vivo, they persist for long periods of time after washout or scavenging of the agonist [19, 22, 23]. While ERAs can prevent receptorbinding and effects of ET-1, they do not reverse established agonist-binding [24, 25] and have variable influences on ET-1-induced effects [19, 26, 27]. These unusual pharmacological properties may be due to tight binding of ET-1 to $E T_{A}$. The reported half-life of $E T-1 / E T_{A}$ complexes ranges from 7 to 77 hours (for review see [28]). Little is known about ET-2 and ET-3 in this respect. In contrast to ERAs, salicylates [24] and, more recently, the neuropeptide CGRP [19] were reported to promote dissociation of $E T-1 / E T_{A}$ complexes. This suggests that $\mathrm{ET}_{\mathrm{A}}$ receptor function is susceptible to allosteric modulation [18]. 


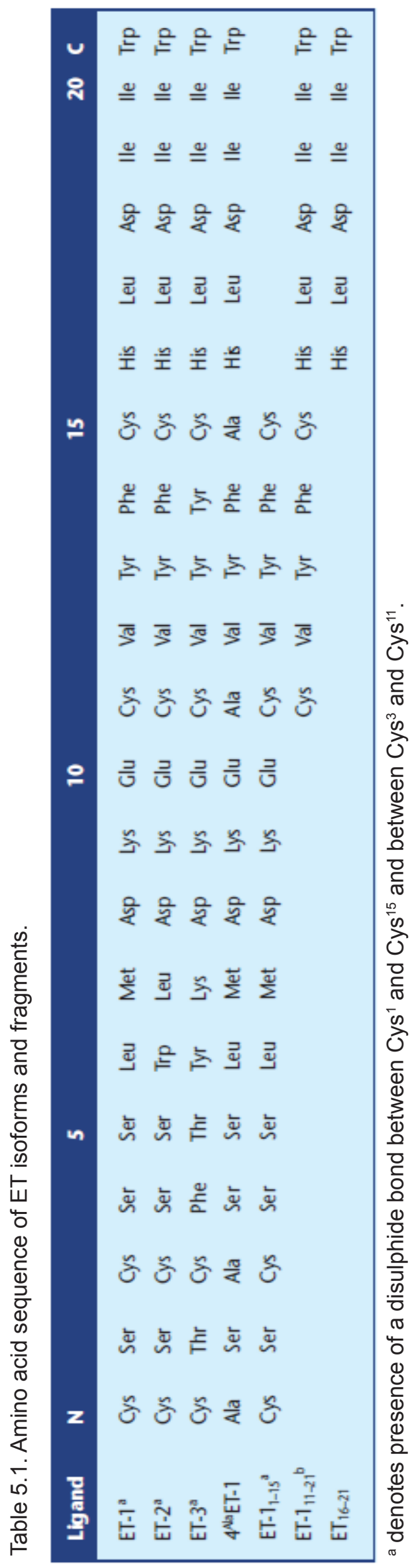

Here we tested the hypothesis that $\mathrm{ET}_{\mathrm{A}}$ receptor pharmacology meets at least two criteria of allosteric modulation namely probe-dependence and differential modulation of affinity and efficacy by antagonists (for recent reviews see [29, 30]). For this purpose we used (i) isolated rat mesenteric resistance arteries, (ii) isoforms and fragments of ET-1 (Table 5.1), (iii) the peptidergic and the non-peptidergic $E T_{A}$ selective antagonists BQ123 and PD156707, respectively and (iv) large analogues of these ERAs such as fluorescently labeled and homobivalent constructs (Fig. 5.1). The small muscular arteries that we used are involved in the regulation of local blood flow and blood pressure and in the development of hypertension [31]. ET receptors are expressed by their endothelial cells, smooth muscle cells and sensory-motor nerves [32], but we focused here on smooth muscle $\mathrm{ET}_{\mathrm{A}}$. We monitored effects of candidate ligands on the initiation, maintenance and persistence of arterial contractile responses and found that two prototypic $\mathrm{ET}_{\mathrm{A}}$ receptor antagonists acted as allosteric inhibitors of the binding and activation of arterial smooth muscle $\mathrm{ET}_{\mathrm{A}}$ receptors by endogenous $\mathrm{ET}$-isoforms.

\section{Methods}

Experiments were performed in accordance with the institutional guidelines and were approved by the Ethics Committee on Experimental Animal Welfare of the Maastricht University. 


\section{Solutions and compounds}

BQ123 (Sigma Aldrich, Zwijndrecht, NL) and BQ788 (Peptides International, Louisville, USA) were dissolved in DMSO. Capsaicin (CAPS) and indomethacin (INDO) (Sigma Aldrich, Zwijndrecht, NL) were dissolved in ethanol. Felodipine (Sigma Aldrich, Zwijndrecht, NL) was dissolved in polyethylene glycol 400. Human ET-1, human ET-2, ET-3, Ala ${ }^{1,3,11,15}$ ET-1 (4 ${ }^{\text {Ala ET-1), ET-1 }}{ }_{11-21}, \mathrm{ET}_{16-21}$ (Table 5.1) (Bachem, Weil am Rhein, D), noradrenaline (NA) and L-NAME (Sigma Aldrich, Zwijndrecht, $\mathrm{NL}$ ) were dissolved in Krebs Ringer bicarbonate buffer (KRB) containing (in $\mathrm{mM}$ ): $\mathrm{NaCl}: 118.5 ; \mathrm{KCl}: 4.7 ; \mathrm{CaCl}_{2}: 2.5 ; \mathrm{MgSO}_{4}: 1.2 ; \mathrm{KH}_{2} \mathrm{PO}_{4}: 1.2 ; \mathrm{NaHCO}_{3}: 25.0$; glucose: 5.5 .

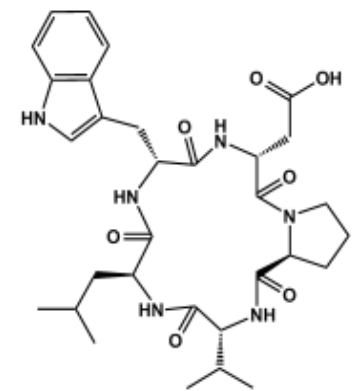

BQ123
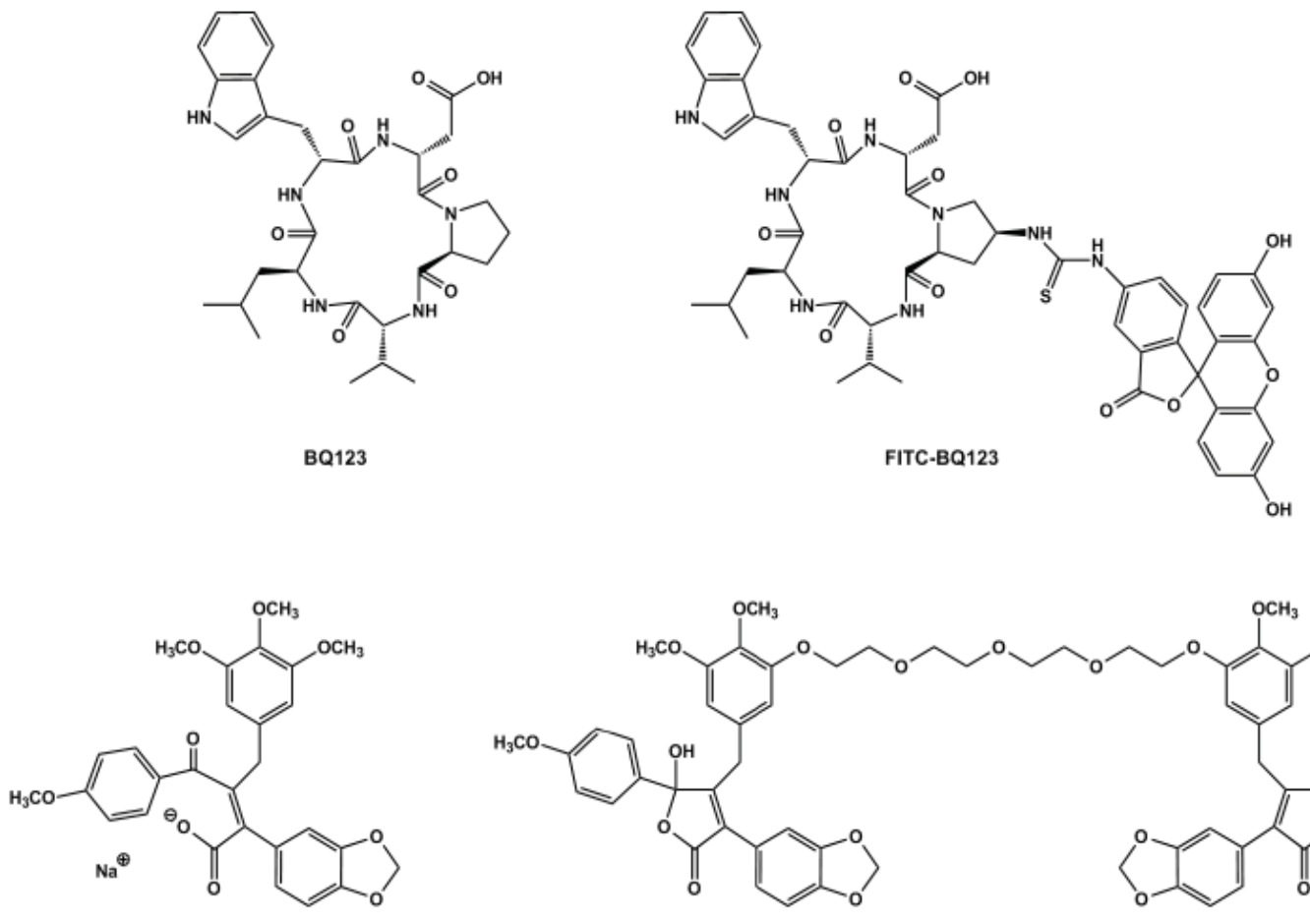

PD156707

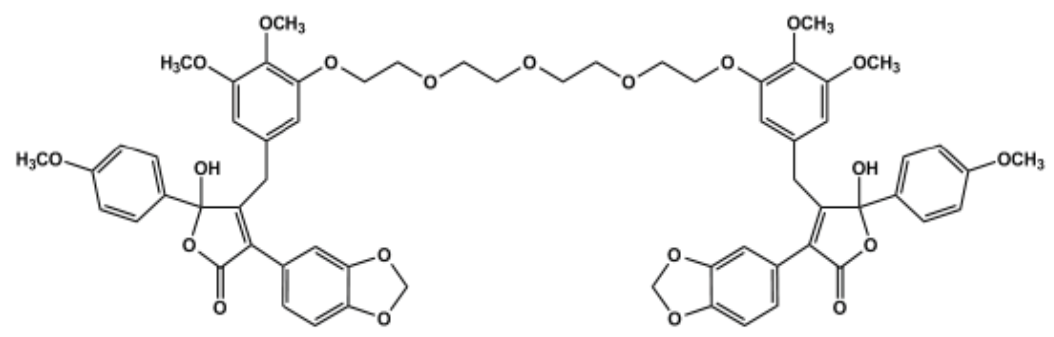

$(\text { PD156707) })^{2}$

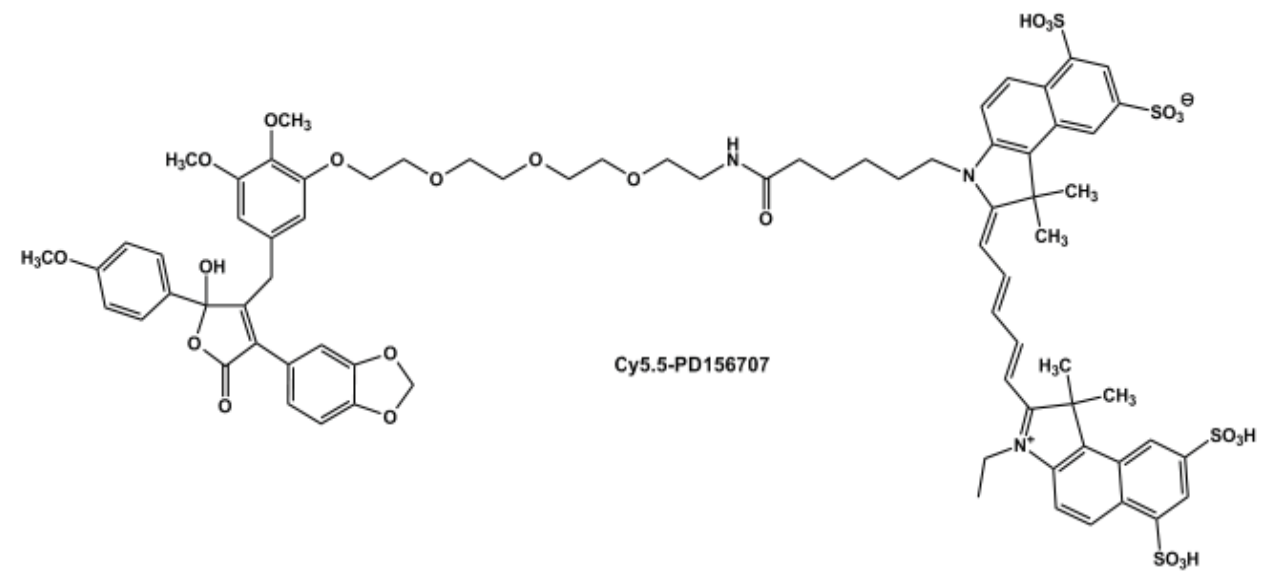

Figure 5.1. Structure of the low molecular weight ET receptor antagonists and their high molecular weight analogues used in this study. 
PD156707, Cy5.5- PD156707 and FITC-BQ123 (Fig. 1) were synthesized as described [33, 34]. Synthesis of the intact bicyclic loop of ET-1 (ET-1 1-15 $)$ and synthesis of homobivalent PD156707 (Fig. 5.1), are detailed in the supplementary data. $\mathrm{K}^{+}-$ $\mathrm{KRB}$ was $\mathrm{KRB}$ in which all $\mathrm{NaCl}$ was replaced by $\mathrm{KCl}$. Buffers with intermediate $\mathrm{K}^{+}$-concentration were prepared by mixing appropriate volumes of $\mathrm{KRB}$ and $\mathrm{K}^{+}-\mathrm{KRB}$. The maximal solvent concentration never exceeded $0.1 \%$ and did not significantly modify vascular reactivity.

\section{Recording of vasomotor responses}

Male, 16 weeks old WKY rats (Charles River, Maastricht, The Netherlands) were killed by $\mathrm{CO}_{2}$-inhalation. Second-order branches of the superior mesenteric artery were isolated by dissection in $\mathrm{KRB}$ at room temperature. To record isometric tension development, freshly isolated $2 \mathrm{~mm}$ long arterial segments were mounted in wire myographs (DMT, Aarhus, DK) in which $5 \mathrm{~mL} \mathrm{KRB}$ was maintained at $37^{\circ} \mathrm{C}$ and aerated with $95 \% \mathrm{O}_{2} / 5 \% \mathrm{CO}_{2}$. The arterial segments were progressively stretched to the diameter at which the largest contractile response to $10 \mu \mathrm{M}$ NA was observed $[19,32]$. The optimal internal diameter of the segments averaged $306 \pm 8 \mu \mathrm{m}$ and contractile responses to $10 \mu \mathrm{M} \mathrm{NA}$ averaged $3.7 \pm 0.1 \mathrm{~N} / \mathrm{m}$.

Except when specifically mentioned, arterial segments were pre-treated with $1 \mu \mathrm{M}$ CAPS for $20 \mathrm{~min}$ and were thereafter studied in the continuous presence of 100 $\mu \mathrm{M}$ L-NAME and $10 \mu \mathrm{M}$ INDO. These interventions desensitize peri-arterial sensory motor nerves and inhibit the synthesis of $\mathrm{NO}$ and prostaglandins, respectively [35]. They were used because in rat mesenteric resistance arteries not only arterial smooth muscle cells but also sensory- motor nerves and endothelial cells express immunoreactive $\mathrm{ET}_{\mathrm{A}}$ and $\mathrm{ET}_{\mathrm{B}}$ receptors $[32,36]$ and it was previously reported that $\mathrm{ET}-1$ and $\mathrm{ET}-3$ can induce the release of endothelium-derived relaxing factor (EDRF) [37].

\section{Pharmacological protocols}

We studied agonistic, antagonistic, competitive and inhibitory effects of putative ETA-receptor ligands and their reversibility as illustrated in Fig. 5.2.

Agonism. Increasing concentrations of an endothelin isopeptide or -fragment (cumulative concentration-response curve, CCRC) were administered to (i) resting arteries to record contractile effects and to (ii) arteries partly depolarized with $40 \mathrm{mM}$ $\mathrm{K}^{+}$to record relaxing effects (Fig. 5.2A). 
Figure 5.2. Typical tracings of arterial active wall tension versus time illustrating the study protocols. Contractile responses to increasing concentrations of an agonist (e.g. ET2, vertical green lines, indicated concentrations are final concentrations) were recorded in absence (A) and presence (B) of an antagonist (e.g. $1 \mu \mathrm{M}$ BQ123 (blue arrow)). Also, the inhibitory effect of this antagonist (blue arrow) was recorded during contractions observed in presence of the agonist $(C)$ and during contractions that persisted after removal (washout, Wo) of free agonist (D).

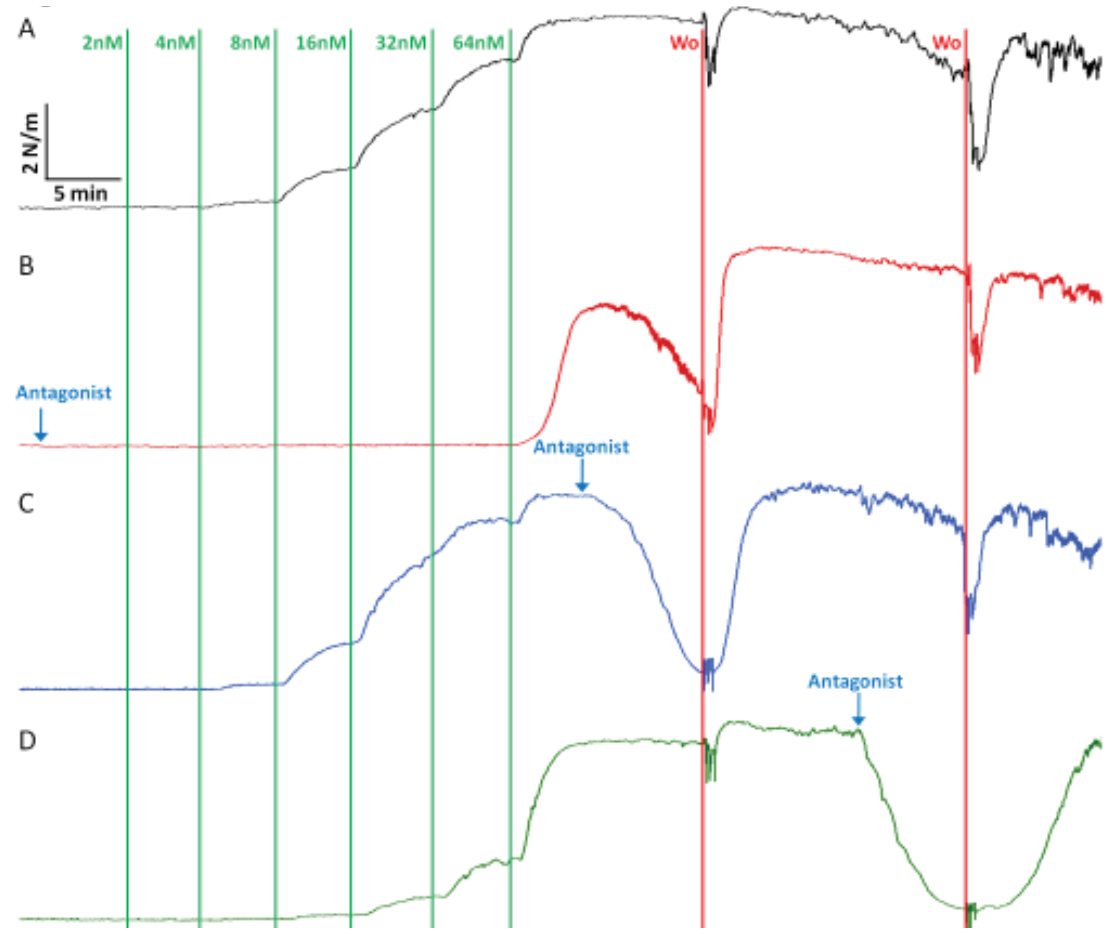

Antagonism. For peptides that did not display agonism, a CCRC for an agonist (ET1, ET-2 or ET-3) was constructed in the presence of $1 \mu \mathrm{M}$ of the compound. The sensitivity $\left(\mathrm{pD}_{2}\right)$ and the maximal response $\left(\mathrm{E}_{\mathrm{MAX}}\right)$ to the agonist were compared in parallel in presence and absence of the compound.

Competition Experiments. Using 4 arterial segments in parallel, CCRCs for an agonist were constructed in the absence and in the presence of a low, an intermediated and a high concentration of the putative antagonist (Fig. 5.2B). Effects of the compound on the position (ratio of $\mathrm{EC}_{50}, \mathrm{~A}^{\prime} / \mathrm{A}$ ) and on the height of the agonist CCRC $\left(\triangle \mathrm{E}_{\text {MAX }}\right)$ were monitored. $\log \left(A^{\prime} / A-1\right)$ was plotted as a function of the antagonist concentration ([B], Schild-plot).

Inhibition Experiments. Results from the competition experiments (contraction as a function of increasing agonist concentration ([A]) in absence and presence of 3 concentrations of putative antagonist $([\mathrm{B}])$ were plotted as a function of $[B]$. From this the inhibitory effect of a selected concentration of the antagonist $\left([B]_{y}\right)$ on the response to a selected concentration of an agonist $\left([\mathrm{A}]_{x}\right)$ was calculated (predicted inhibition, PI). Then two arterial segments from the same rats were used. Both were exposed to $[A]_{x}$ and the responses were allowed to stabilize. Next, one preparation was also exposed to $[\mathrm{B}]_{\mathrm{y}}$ and the other served as a time-control (Fig. 5.2C). The effect of $[B]_{y}$ was allowed to stabilize and was compared to the predicted inhibition $(\mathrm{PI})$. 
Because endothelins can cause long-lasting effects, comparable inhibition experiments were performed on agonist-initiated contractions. Here, $[A]_{x}$ was applied and the effect was allowed to stabilize. $[A]_{x}$ was removed from the organ chamber and the influence of $[B]_{y}$ on the remaining effect was monitored 8 min later (Fig. 5.2D) and was compared to the predicted inhibition $(\mathrm{PI})$.

Reversibility. Towards the end of each of the foregoing experiments, all putative $\mathrm{ET}_{\mathrm{A}}$ receptor ligands were removed from the organ chambers (washout) and wall tension was recorded for $>20 \mathrm{~min}$.

Only one set of experiments was performed in one set of arterial segments, i.e. distinct pharmacological protocols were not performed in series in the same set of arterial segments.

\section{Data analysis and statistics}

Data are shown as mean \pm SEM. Contractile responses are expressed as percentage of the maximal contractile response to NA observed prior to the administration of any pharmacological inhibitor $\left(N A_{\mathrm{MAX}}\right)$. Individual CCRC were fitted to a non-linear regression curve and $\mathrm{ED}_{50}, \mathrm{pA}_{2}$ and $\mathrm{pK}_{\mathrm{B}}$ values were calculated using GraphPad Prism 5.02. Data were analyzed using one-way ANOVA (comparison of $\mathrm{pD}_{2}, \mathrm{pA}_{2}$, $\mathrm{pK}_{\mathrm{B}}$ and $\mathrm{E}_{\text {MAX }}$ ) or two-way ANOVA (comparison of CCRC). Bonferroni's post-hoc test was used to compare multiple groups. Schild plots were constructed with linear regression analysis.

\section{Results}

Nanomolar concentrations of ET-1 (ET-1 $\left.1_{1-21}\right)$ and of ET-2 (Trp 6 -Leu'-ET-1 1-21 $)$ and

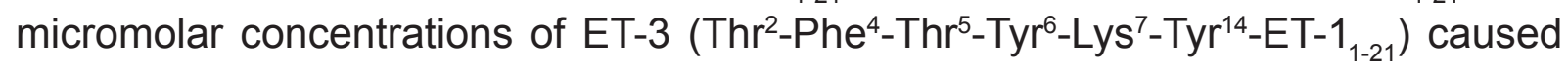
contractions in isolated mesenteric resistance arteries (Fig. 5.3A). ET-1 and ET-2 were similarly potent and significantly $(p<0.001$ and $p<0.01)$ more potent than ET-3 $\left(\mathrm{pD}_{2}: 8.4 \pm 0.1,8.5 \pm 0.1\right.$ and $6.8 \pm 0.1$, respectively). The maximal effects did not significantly differ between the peptides $\left(\mathrm{E}_{\text {MAX }}: 101.8 \pm 5.1 \%, 98.2 \pm 7.5 \%\right.$ and $101.8 \pm 10.9 \%$, respectively). They were sustained and faded only slowly after removal of the free agonist (Fig. 5.2 and 5.3B). Felodipine (1 nM), a dihydropyridine calcium channel blocker that inhibited tonic arterial contractile responses to 40 $\mathrm{mM} \mathrm{K}^{+}$, moderately reduced sentivity and maximal responses to ET-1 and ET-2; and this did not differ significantly between the two peptides (data not shown). 
Figure 5.3. Vasomotor effects of isoforms, analogues and fragments of ET-1. A, only intact ET isoforms cause arterial contractile responses. $B$, these responses are only slowly reversible. $\mathrm{C}$,

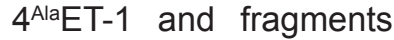
of ET-1 fail to induce relaxation in arteries contracted with $40 \mathrm{mM}$ $\mathrm{K}^{+}$. D, presence of $1 \mu \mathrm{M}$ $4^{\text {Ala ET-1 }}$ or fragments of ET-1 does not modify contractile responses to ET-1. Findings were expressed as \% of the contractile response to $10 \mu \mathrm{M}$ noradrenaline $\left(\mathrm{NA}_{\mathrm{MAX}}\right)$ or as $\%$ of the $\mathrm{K}^{+}$-induced pre-contraction $(\mathrm{C})$ and are shown as means \pm $\operatorname{SEM}(n=3-17)$.
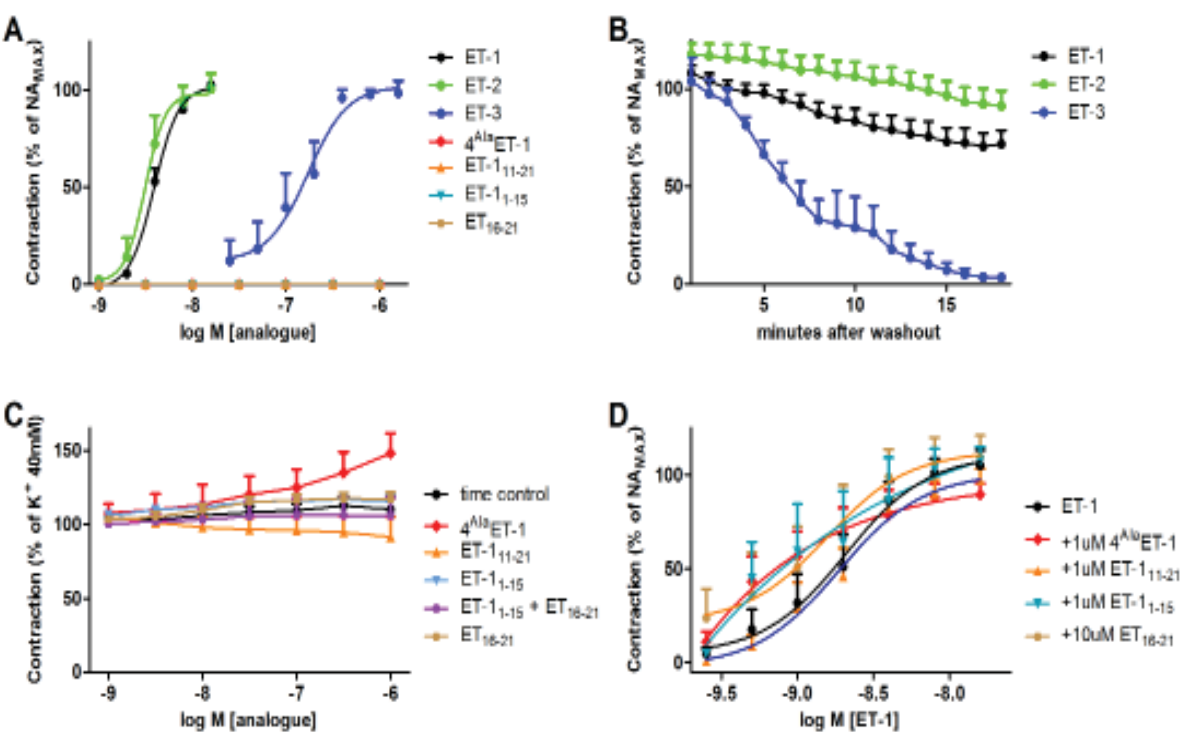

For ET-3 (T1/2: $\approx 5 \mathrm{~min})$ this was less pronounced than for ET-1 and ET-2 (T1/2; >18 min, Fig. 5.3B) but still more slowly than for equally strong contractile responses to for instance $10 \mu \mathrm{M}$ NA T1/2: < $1 \mathrm{~min}$, data not shown).

Presence of the $\mathrm{ET}_{\mathrm{B}}$ selective antagonist BQ788 (1 $\mu \mathrm{M}$, [38]) did not modify contractile effects of $E T-1\left(\mathrm{pD}_{2} ; 8.5 \pm 0.1\right.$ versus $\left.8.4 \pm 0.1\right)$ and $\mathrm{ET}-3\left(\mathrm{pD}_{2} ; 6.7 \pm 0.2\right.$ versus $\left.6.8 \pm 0.1\right)$.

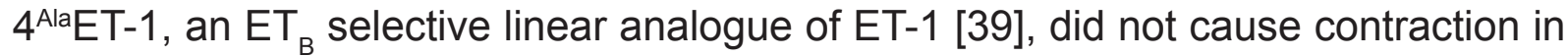
resting arteries (Fig. 5.3A), did not cause relaxation in depolarized arteries (Fig. 5.3C) and did not modify contractile effects of ET-1 (Fig. 5.3D) at up to $1 \mu \mathrm{M}$. Likewise, the fragments $E T-1_{11-21}, E T-1_{1-15}$ and $\mathrm{ET}_{16-21}$, and the combination of the N-terminal loop $\left(\mathrm{ET}_{-1} 1_{1-15}\right)$ plus the C-terminal tail of ET-1 (ET $\left.\mathrm{E}_{16-21}\right)$ failed to stimulate contraction or relaxation and did not modify the contractile potency of intact ET-1 ${ }_{1-21}$ at up to $1 \mu \mathrm{M}$ (Fig. 5.3A, C, D).

Presence of $1 \mu \mathrm{M} B$ Q123, a peptidergic $\mathrm{ET}_{\mathrm{A}}$-selective antagonist [40], did not modify basal tension but reduced the contractile effects of all three endothelin isoforms (Fig. 5.4). This effect of BQ123 was more marked versus ET-3 than versus ET-1 and less marked versus ET-2 than versus ET-1 (Fig. 5.4). Presence of BQ123 did not prevent initiation of long-lasting contractile responses by ET-1 or ET-2, i.e. sustained responses persisting in the absence of free agonist (Fig. 5.4A-D). Moreover, presence of $1 \mu \mathrm{M}$ BQ123 prevented contractile responses to $1 \mu \mathrm{M}$ ET-3 (Fig. 5.4E) but a strong contraction developed within $1 \mathrm{~min}$ after washout of the free agonist and antagonist (Fig. 5.4F). 

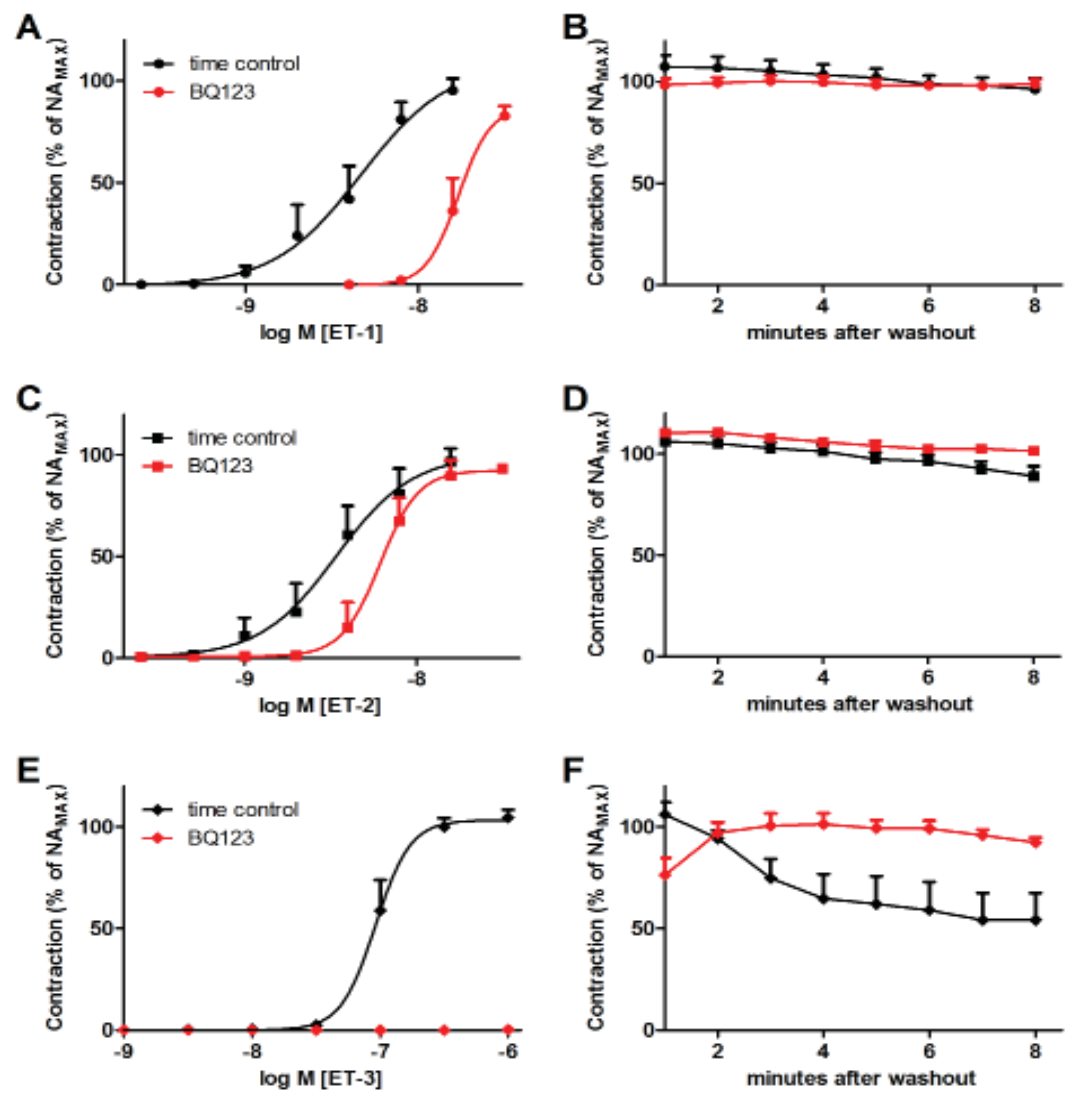

Figure $5.4 \quad$ Contractile responses to ET-1 (A), ET-2 (C) and ET-3 (E) in absence (black) and presence of 1 $\mu \mathrm{M}$ BQ123 (red). B, D and F show changes in vasomotor tone after washout of free agonist (black) and after washout of both free agonist and antagonist (red). Findings were expressed as $\%$ of the contractile response to $10 \mu \mathrm{M}$ noradrenaline $\left(\mathrm{NA}_{\mathrm{MAX}}\right)$ and are shown as means $\pm \operatorname{SEM}(n=4-7)$.

Effects of $\mathrm{ET}_{\mathrm{A}}$ selective antagonists were analyzed in more detail to gain insight in their agonist dependence. Using a range of concentrations, presence of BQ123 (3 $\mathrm{nM}-3 \mu \mathrm{M}$ ) was observed to reduce the sensitivity but not the maximal responses to ET-1 and ET-3 (Fig. 5.5).
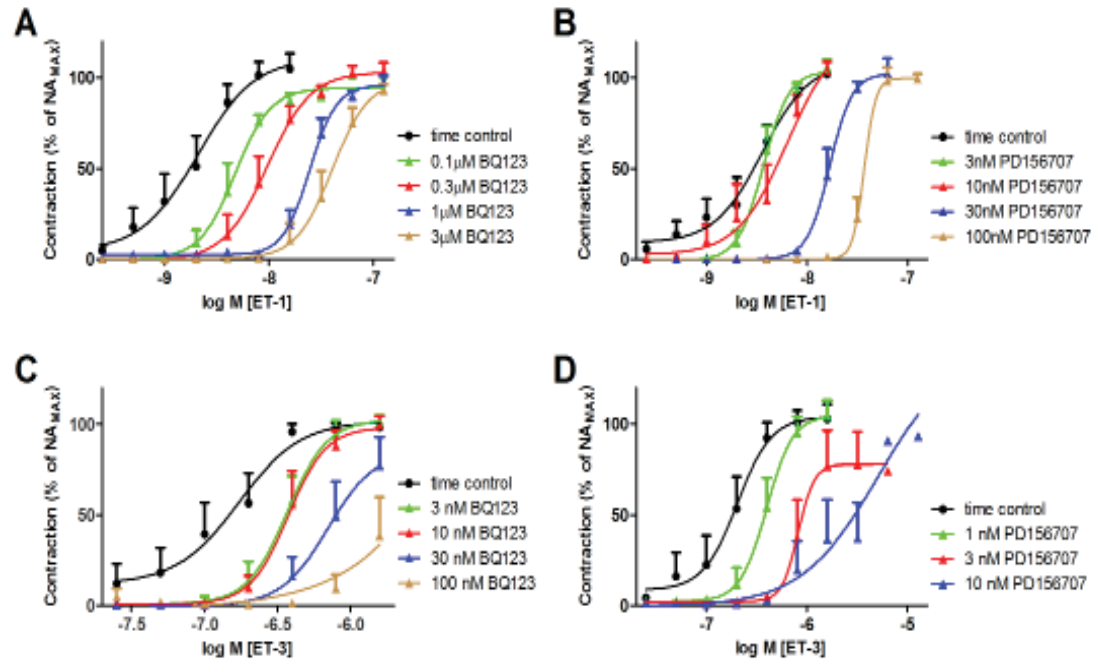

E

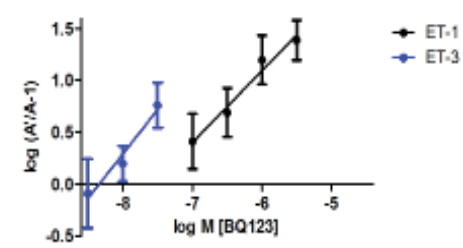

$\mathbf{F}$

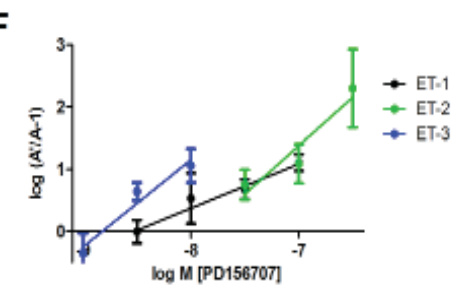

Figure 5.5. A-D, effects of presence of BQ123 (0.1 $3.0 \mu \mathrm{M}, \mathrm{A}, \mathrm{C})$ or PD156707 $(3-100 \mathrm{nM}, \mathrm{B}, \mathrm{D})$ on contractile responses to ET-1 (A, B) or ET-3 (C, D). Findings were expressed as $\% \mathrm{NA}_{\mathrm{MAX}}$ and are shown as means $\pm \operatorname{SEM}(n=4-7)$. $E$, F, Schild-plots for BQ123 (E) and PD156707 (F) versus ET-1, ET-2 and ET-3. 
The slopes of the Schild-plots did not significantly deviate from unity (Table 5.2). The apparent affinity of BQ123 did not differ significantly versus $\mathrm{ET}-3\left(\mathrm{pA}_{2}\right.$; $8.3 \pm 0.4)$ and ET-1 $\left(\mathrm{pA}_{2} ; 7.6 \pm 0.4\right)$ but both were significantly larger $(p<0.01)$ than the apparent affinity of BQ123 versus ET-2 (Fig. 5.4C, pK $\mathrm{B}_{\mathrm{B}} ; 5.6 \pm 0.4$ ). Also, presence of the non-peptidergic $\mathrm{ET}_{\mathrm{A}}$ selective antagonist PD156707 (1 - $300 \mathrm{nM}$, [41]) did not modify basal tension and reduced the sensitivity to the contractile effects of the ET
Table 5.2. Schild-analyses of contractile responses to endothelins in presence of $\mathrm{ET}_{\mathrm{A}}$ antagonists.

\begin{tabular}{|llcl|}
\hline Antagonist & Agonist & Slope & pA $_{\mathbf{2}}$ or $\mathbf{p K}_{\mathbf{B}} \mathbf{a}^{\mathbf{2}}$ \\
\hline BQ123 & ET-1 & $0.69 \pm 0.08$ & $7.6 \pm 0.4$ \\
BQ123 & ET-2 & $1.0 \pm 0$ & $5.6 \pm 0.4^{\mathrm{a}}$ \\
BQ123 & ET-3 & $0.86 \pm 0.35$ & $8.3 \pm 0.4$ \\
PD156707 & ET-1 & $0.71 \pm 0.15$ & $8.5 \pm 0.3$ \\
PD156707 & ET-2 & $1.55 \pm 0.6$ & $7.9 \pm 0.3$ \\
PD156707 & ET-3 & $1.4 \pm 0.35$ & $8.8 \pm 0.2$ \\
FITC-BQ123 & ET-1 & $0.65 \pm 0.13$ & $8.3 \pm 0.7$ \\
Cy5.5-PD156707 & ET-1 & $1.09 \pm 0.15$ & $8.2 \pm 0.5$ \\
(PD156707) $^{2}$ & ET-1 & $1.07 \pm 0.35$ & $7.7 \pm 0.5$ \\
\hline
\end{tabular}

Data shown as mean \pm SEM $(n=4-8)$.

a denotes calculation of a pKB value for BQ123 versus ET-2. isopeptides (Fig. 5.5; Table 5.2). Again this was agonist-dependent; apparent affinity $\left(\mathrm{pA}_{2}\right)$ of PD156707 averaged $8.5 \pm 0.3,7.9 \pm 0.3$ and $8.8 \pm 0.2$ versus ET-1, ET-2 and ET-3, respectively. This agonist-dependency of PD156707 (1 log unit) seems to be less marked than that of BQ123 (2.5 log units).

To evaluate whether $E T_{A}$ receptor activation influences effects of $E T_{A}$ selective antagonists, BQ123 and PD156707 were applied during contractions induced by ET-1, ET-2 or ET-3 (Fig. 5.2C) and the effects were compared to predictions from the "competition experiments" (Fig. 5.2B, Fig. 5.5). In view of the observed differences in apparent potency of the agonists and antagonists, we used different combinations of concentrations of the compounds. $1 \mu \mathrm{M} \mathrm{BQ} 123$ reduced the response to $8 \mathrm{nM}$ ET-1 to a lesser extent than predicted and $100 \mathrm{nM}$ PD156707 reduced the response to $16 \mathrm{nM}$ ET-1 to a lesser extent than predicted (Table 5.3). In contrast, $1 \mu \mathrm{M} \mathrm{BQ123}$ reduced the response to $64 \mathrm{nM} \mathrm{ET-2}$ to a larger extent than predicted and $30 \mathrm{nM}$ BQ123 reduced the response to $1.6 \mu \mathrm{M}$ ET-3 to a larger extent than predicted (Table 5.3). Unlike the agonist effects of all three endothelins, the inhibitory effects of both antagonists were rapidly reversible. In all cases, contractile responses recovered within minutes after washout of both the agonist and the antagonist (e.g. Fig. 5.2C, Table 5.3).

To obtain additional evidence for topographically distinct agonist- and antagonistbinding sites underlying the observed effects of the antagonists we used bulky analogues of BQ123 and PD156707 (Fig. 5.1). Presence of 0.1-3 $\mu$ M FITC-BQ123, 3-100 nM Cy5.5-PD156707 or 10-100 nM homobivalent PD156707 ((PD156707)2, two PD156707 molecules linked by a spacer, Fig. 5.1) reduced the sensitivity but not the maximal responses to ET-1 (Suppl Fig. 5.1.1). 
Table 5.3. Predicted and observed inhibitory effects of $E T_{A}$ antagonists on contractile responses in the presence of an ET and on contractile responses persisting after exposure to an ET.

\begin{tabular}{|c|c|c|c|c|}
\hline Agonist & Antagonist & Predicted" & $\begin{array}{l}\text { Observed In presence } \\
\text { of agonist }\end{array}$ & $\begin{array}{l}\text { Observed after } \\
\text { agonlst }\end{array}$ \\
\hline $8 \mathrm{nM}$ ET-1 & $1 \mu \mathrm{M}$ BQ123 & $-99 \pm 1^{b}$ & $-43 \pm 7^{b, c}$ & $-52 \pm 1^{b, c}$ \\
\hline 64 nM ET-2 & $1 \mu \mathrm{M}$ BQ123 & $-29 \pm 5^{b}$ & $-92 \pm 1^{b, c}$ & $-96 \pm 1^{b, c}$ \\
\hline $1.6 \mu \mathrm{M} \mathrm{ET}-3$ & $30 \mathrm{nM}$ BQ123 & $-17 \pm 17$ & $-89 \pm 4^{b, c}$ & $-90 \pm 4^{\mathrm{b}, \mathrm{c}}$ \\
\hline 16 nM ET-1 & $1 \mu \mathrm{M}$ FITC-BQ123 & $-82 \pm 11^{b}$ & $-26 \pm 26^{c}$ & $-14 \pm 12^{c}$ \\
\hline 16 nM ET-1 & $0.1 \mu \mathrm{M}$ PD156707 & $-99 \pm 1^{b}$ & $-51 \pm 8^{b, c}$ & $-20 \pm 13^{c}$ \\
\hline $16 \mathrm{nM} \mathrm{ET}-1$ & $0.1 \mu \mathrm{M}$ Cy5.5-PD 156707 & $-99 \pm 0^{b}$ & $+2 \pm 7^{c}$ & $-12 \pm 18^{c}$ \\
\hline $16 \mathrm{nM}$ ET-1 & $0.1 \mu \mathrm{M}(\mathrm{PD} 156707)^{2}$ & $-99 \pm 1^{b}$ & $-4 \pm 15^{c}$ & $-13 \pm 5^{c}$ \\
\hline
\end{tabular}

Data are expressed as percent change and are shown as means \pm SEM $(n=4-8)$.

a Inhibitory effects were predicted from the results of competition-design experiments (e.g. Fig. 5.5) under concentration- and contractile amplitude-matched conditions.

${ }^{b}$ the effect is statistically significant $(p<0.05)$.

${ }^{c}$ the difference from the predicted value is statistically significant $(p<0.05)$.

The apparent affinity of these compounds did not differ significantly from that of the smaller BQ123 and PD156707 pharmacophores, respectively (Table 5.2). However, unlike their low molecular weight counterparts, administration of $1 \mu \mathrm{M}$ FITC-BQ123, 100 nM Cy5.5-PD156707 or 100 nM (PD156707)2 did not significantly reduce contractile responses observed in the presence of $16 \mathrm{nM} \mathrm{ET-1}$ and neither did they reduce the contractile responses that had been initiated by $16 \mathrm{nM} \mathrm{ET}-1$ and persisted after agonist removal (Table 5.3).

\section{Discussion and Conclusions}

The main findings of this work are: (i) $\mathrm{ET}_{\mathrm{A}}$ mediated arterial contractile responses to not only ET-1 but also ET-2, and to a lesser extent ET-3, persist upon removal of free agonist, (ii) $E T-1_{1-15}$ does not cause $\mathrm{ET}_{\mathrm{A}}$ agonism or antagonism in the absence or presence of $\mathrm{ET}_{16-21}$ and (iii) effects of $\mathrm{ET}_{\mathrm{A}}$ selective antagonists depend on the presence and type of $\mathrm{ET}_{\mathrm{A}}$ agonist and on the size of the $\mathrm{ET}_{\mathrm{A}}$ antagonist. These findings indicate that distinct ligand-binding domains are present on arterial smooth muscle $\mathrm{ET}_{\mathrm{A}}$ receptors and that the antagonists used have distinct effects on these domains.

To unravel $\mathrm{ET}_{\mathrm{A}}$ receptor function we used native rat mesenteric resistance arteries that take part in the regulation of local and total peripheral vascular resistance and in the development of hypertension [31]. Experiments were performed after desensitization of peri-arterial sensory-motor nerves and during continuous inhibition of NO-synthases and cyclo-oxygenases. We have previously shown that mechanical removal of the endothelium does not alter the contractile response to 
ET-1 [19]. Contractile responses to ET-1 and ET-3 were not modified by the ET selective antagonist $B Q 788$ [19] and the selective $\mathrm{ET}_{\mathrm{B}}$ agonist $4^{\mathrm{Ala}} \mathrm{ET}-1$ did not cause contraction, relaxation or altered responses to ET-1. Our results are thus not influenced by the endothelium, sensory-motor nerves and $\mathrm{ET}_{\mathrm{B}}$ receptors.

In view of the observed potency order (ET-1 = ET-2 >> ET-3) and sensitivity to two $\mathrm{ET}_{\mathrm{A}}$ receptor selective antagonists, endothelin-induced contractions are mediated by arterial smooth muscle $\mathrm{ET}_{\mathrm{A}}$ receptors $[4,8,42,43]$. These receptors seem to function as monomers rather than as oligomeres [44]. This is suggested by the observation that the apparent affinity for homobivalent PD156707 is not larger but, if anything, smaller than that for PD156707 itself [45].

The arterial effects of ET-2, and to a lesser extent ET-3, are maintained and longlasting after removal of the free agonist, in line with earlier findings with ET-1 [19, 23]. For all three endothelins, the long-lasting response can be reversibly reduced by an ERA. For ET-1, this has been attributed to tight, slowly reversible binding of the peptidergic agonist to $\mathrm{ET}_{\mathrm{A}}$ receptors [19, 24, 25, 28]. This also seems to be case for $E T-2 / E T_{A}$ and for $E T-3 / E T_{A}$ complexes, as contractile responses to these peptides rapidly recovered after exposure to an ERA (Fig. 5.2 and Fig. 5.4F). Previous studies proposed the presence of multiple binding domains for $E T-1$ on $E T_{A}$ receptors with distinct binding and signaling properties [14, 15, 17, 19]. For several other peptide7TMR interactions, a clear functional distinction of these domains has been reported for the ligand and its receptor, with one domain mediating binding (address) and another one mediating signaling (message) $[20,21]$. However, distinctive roles for the $\mathrm{C}$-terminal tail and the $\mathrm{N}$-terminal loop of ET-1 in dynamic high affinity binding, tight binding and activation of $\mathrm{ET}_{\mathrm{A}}$ receptors [14], are not confirmed by the present study. $4^{\mathrm{Ala}} \mathrm{ET}-1, \mathrm{ET}-1_{11-21}$ and $\mathrm{ET}_{16-21}$ did not display $\mathrm{ET}_{\mathrm{A}}$ antagonist- or agonist-effects in line with earlier ligand-binding studies $[39,46]$. Moreover, ET- $1_{1-15}$, the intact $\mathrm{N}$-terminal loop segment of ET-1, did not display antagonism or agonism in the absence and in the presence of the C-terminal tail segment $\mathrm{ET}_{16-21}$. Hence, the entire intact 21 amino acid structure of an endothelin seems to be required to bind and activate $\mathrm{ET}_{\mathrm{A}}$ receptors $[17,47]$.

We next focused on differences between ET-1, ET-2 and ET-3, the endogenous ET receptor agonists that share the $\mathrm{C}$-terminal tail and differ in amino acid sequence of the N-terminal loop (Table 5.1). While many earlier studies addressed effects of $\mathrm{N}$-terminal loop amino acids on the affinity and selectivity for ET receptor subtypes $[9,17,39,48]$, our experiments aimed at their consequences for modulation of $\mathrm{ET}_{\mathrm{A}}$ receptor function. 
The cyclic pentapeptide BQ123 is one of the first selective inhibitors of ET-1/ET $T_{A}$ binding [40]. In line with competitive antagonism, it reduced the sensitivity and responses to ET-1, ET-2 and ET-3. Yet, preventive effects of BQ123 were more marked for ET-3 and ET-1 than for ET-2, in contrast to earlier reports where preventive effects were more marked for ET-3 and ET-2 than for ET-1 [49]. In addition, the relaxing effects of BQ123 were larger than predicted in the case of ET-2 and ET-3, but smaller than predicted for ET-1. An early review by Bax and Saxena reported on agonistdependence of competitive antagonists in the endothelin system [50]. However, probe-dependence in combination with differential effects on affinity and efficacy, as our results show, indicate allosteric modulation rather than neutral competitive antagonism [29, 30]. Not only BQ123 but also the butenolide PD156707 reduced the sensitivity to ET-2 less markedly than that to ET-1 and ET-3 and relaxed ET1 -induced contractions to a lesser extent than predicted. The latter was previously reported for other non-peptidergic ERAs such as bosentan and SB-234551 [19]. In contrast, presence of a vasodilator such as the $\mathrm{Ca}^{2+}$-channel blocker felodipine reduced the responses to $1-16 \mathrm{nM}$ ET-1 and ET-2 only moderately and this did not differ between the two peptides. This invites for a future detailed comparison of allosteric properties between the various classes of ERAs [11]. In order to evaluate saturability of antagonist effects, another criterion of allosterism [29, 30], this should include more antagonist concentrations and a thereby more powerful Schild analysis than used in the present study.

Fig. 6 illustrates $\mathrm{ET}_{\mathrm{A}}$ receptor function along the lines of a recent model of allosteric modulation of 7TMRs [30]. Because $\mathrm{ET}_{\mathrm{A}}$ receptors have not been observed to display constitutive activity, the receptor isomerization constant $(L)$ is large. Endothelins i) bind to the orthosteric binding site according to their dissociation constant $\left(\mathrm{K}_{\mathrm{A}}\right)$ that is considerably larger for ET-3 than for ET-1 and ET-2 and ii) promote receptor activation (agonist intrinsic efficacy $\beta>1$ ). An antagonist $(D)$ displaying negative allosteric modulation such as BQ123 i) binds to a topographically distinct site according to its dissociation constant $\left(\mathrm{K}_{\mathrm{D}}\right)$ and ii) does not activate the receptor (antagonist intrinsic efficacy $Y \leq 1)$. Binding of an orthosteric agonist and of an allosteric modulator changes the conformations of the receptors which may influence, besides receptor activation, also affinity and efficacy properties at the alternative sites. This is represented by cooperativity factors ( $\alpha$ and $\delta$ ). These are considered to be reciprocal, e.g. binding and efficacy of an endothelin influences binding and efficacy of BQ123 and vice versa $[29,30]$. Combined with this scheme, our observations suggest that i) binding of BQ123 reduces the sensitivity to subsequently administered ET-2 less markedly than that to ET-1 or ET-3 ( $\alpha$ : $1<\mathrm{ET}-2<<\mathrm{ET}-1 \leq \mathrm{ET}-3$ ) and that ii) receptor binding and activation by ET-2, compared to the other orthosteric agonists, more markedly 

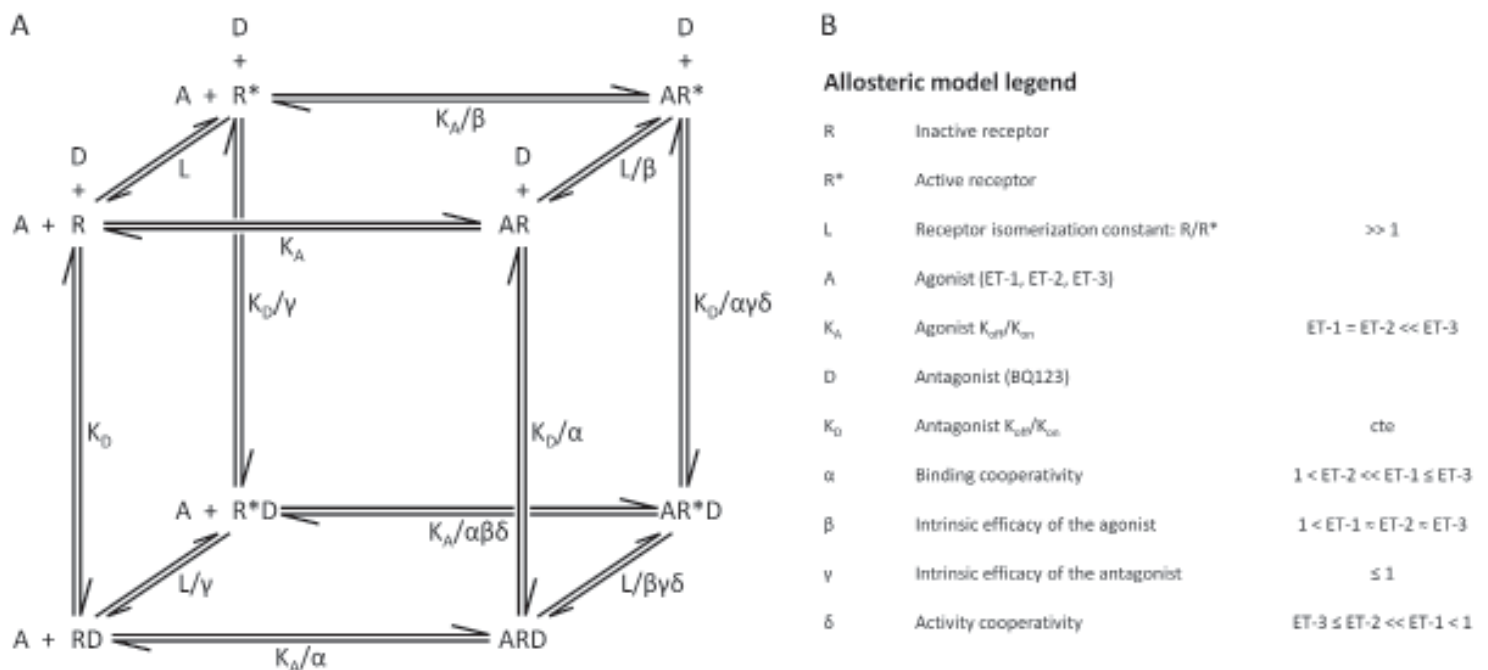

Figure 5.6. Proposed model of allosteric modulation of $\mathrm{ET}_{\mathrm{A}}$ receptors by an antagonist. $\mathrm{A}$, interactions of ligand, receptor and antagonist such as BQ123. B, definition of dissociation constants, efficacies and cooperativity factors along with their rank orders.

promotes an inverse agonistic effect of BQ123 ( $\mathrm{D}$ : ET-3 $\leq$ ET-2 << ET-1 < 1). More quantitative analysis of allosteric mechanisms as previously described [51] proves difficult in our functional assay as we did not observe antagonist-induced reduction of maximal responses to the agonists.

Observations with large analogues of the ERAs provide additional support for an allosteric mechanism. Fluorescently labeled BQ123, fluorescently labeled PD156707 and homobivalent PD156707 reduced the sensitivity to ET-1 to the same extent as the low molecular weight pharmacophores. However, the large ERA failed to cause a statistically significant relaxation of ET-1-induced responses. That each FITC, Cy5.5 and an additional PD156707 moiety would impair the inverse agonistic property of the antagonist can not be excluded at present. It is, however, more likely that tight binding of ET-1 to $\mathrm{ET}_{\mathrm{A}}$ limits the access of the antagonists to their allosteric binding sites and that this structural hindrance is more marked for large bulky antagonists than for their small molecular weight counterparts. Unfortunately this also complicates the potential use of molecular imaging techniques to directly prove the existence of distinct orthosteric and allosteric binding sites with the use of fluorescently labeled agonist and -antagonists.

Although ET-1 and ET-2 have been considered to display identical pharmacological properties [4, 8] we observed marked differences between these closely related peptides (summarized in Fig. 5.6). This points to pivotal roles of the amino acids at positions 6 and 7 in the orthosteric agonists. These residues do not interfere with the affinity of the peptide for $\mathrm{ET}_{\mathrm{A}}$ receptors in the resting state [8]. They would rather result in a different conformation of the $E T-1 / E_{A}$ and $E T-2 / E T_{A}$ complexes. Whether 
this contributes to different physiological and pathological functions of ET-1 and ET2 , despite similarity of binding affinities, may become the subject of future studies. In a recent study, Millecamps et al. described that the effects of ET-1 and ET-2 are modified to a markedly different extent in an experimental model of chronic pain [52].

Our observations may have consequences for diagnosis and drug discovery. Because endothelins are paracrine mediators [53] that bind tightly to their receptors, circulating levels of free peptides may not be informative. As an alternative, effects of ERAs can be evaluated. BQ123 has been administered into the human forearm with the goal to monitor the contribution of ET-1 to basal peripheral vascular resistance in health and disease [54-58]. If allosteric modulation by BQ123 also applies for human vascular smooth muscle $\mathrm{ET}_{\mathrm{A}}$, reported findings for hypertensive, heart failure and diabetic patients must be regarded as an underestimation. Furthermore, the observation that not only affinity but also efficacy can be modulated by $\mathrm{ET}_{\mathrm{A}}$ antagonists and that this displays agonist-dependence may redirect drug-discovery programs. Potent inhibitors of $\mathrm{ET}-1 / \mathrm{ET}_{\mathrm{A}}$ binding have been observed to be only partly effective or even ineffective on agonist-occupied receptors $[19,26]$. This may be remedied by shifting the attention from agonist-binding to allosteric modulation of receptor activation.

In summary, two prototypic $\mathrm{ET}_{\mathrm{A}}$ receptor antagonists were observed to act as allosteric inhibitors of the binding and activation of arterial smooth muscle $\mathrm{ET}_{\mathrm{A}}$ receptors by endogenous ET isoforms. This included differential effects on the sensitivity and on the responses to the endogenous endothelin isopeptides ET-1, ET-2 and ET-3. Ultimately this may be helpful for the design of diagnostics and drugs that discriminate between the roles of these closely related endogenous mediators in health and disease.

\section{Acknowledgments}

We thank Liesbeth Scheer for technical assistance with the synthesis of ET-1 $1_{1-15}$ and we thank J.-P. Brosseau for synthesis of FITC-BQ123. 


\section{References}

1. Bagnato, A., and Rosano, L. (2008) The endothelin axis in cancer. Int J Biochem Cell Biol 40, 1443-1451

2. Hans, G., et al. (2008) Endothelin-1-induced pain and hyperalgesia: a review of pathophysiology, clinical manifestations and future therapeutic options. Neuropeptides 42, 119-132

3. Kirkby, N.S., et al. (2008) The endothelin system as a therapeutic target in cardiovascular disease: great expectations or bleak house? $\mathrm{Br} \mathrm{J}$ Pharmacol $153,1105-1119$

4. Masaki, T. (2004) Historical review: Endothelin. Trends Pharmacol Sci 25, 219224

5. Masaki, T., et al. (1991) Molecular and cellular mechanism of endothelin regulation. Implications for vascular function. Circulation 84, 1457-1468

6. Yanagisawa, H., et al. (1998) Role of Endothelin-1/Endothelin-A receptormediated signaling pathway in the aortic arch patterning in mice. J Clin Invest 102, 22-33

7. Hynynen, M.M., and Khalil, R.A. (2006) The vascular endothelin system in hypertension--recent patents and discoveries. Recent patents on cardiovascular drug discovery $1,95-108$

8. Davenport, A.P. (2002) International Union of Pharmacology. XXIX. Update on endothelin receptor nomenclature. Pharmacol Rev 54, 219-226

9. Sakurai, T., et al. (1992) Molecular characterization of endothelin receptors. Trends Pharmacol Sci 13, 103-108

10. Inoue, A., et al. (1989) The human endothelin family: three structurally and pharmacologically distinct isopeptides predicted by three separate genes. Proc Natl Acad Sci U S A 86, 2863-2867

11. Palmer, M.J. (2009) Endothelin receptor antagonists: status and learning 20 years on. Prog Med Chem 47, 203-237

12. Breu, V., et al. (1995) Separable binding sites for the natural agonist endothelin-1 and the non-peptide antagonist bosentan on human endothelin-A receptors. Eur J Biochem 231, 266-270

13. Lee, J.A., et al. (1994) Tyr-129 is important to the peptide ligand affinity and selectivity of human endothelin type A receptor. Proc Natl Acad Sci U S A 91, 7164-7168

14. Sakamoto, A., et al. (1993) Distinct subdomains of human endothelin receptors determine their selectivity to endothelinA-selective antagonist and endothelinBselective agonists. J Biol Chem 268, 8547-8553 
15. Sokolovsky, M. (1993) BQ-123 identifies heterogeneity and allosteric interactions at the rat heart endothelin receptor. Biochem Biophys Res Commun 196, 32-38

16. Webb, M.L., et al. (1996) Mutational analysis of the endothelin type A receptor (ETA): interactions and model of selective ETA antagonist BMS-182874 with putative ETA receptor binding cavity. Biochemistry 35, 2548-2556

17. Lattig, J., et al. (2009) Structural determinants for selective recognition of peptide ligands for endothelin receptor subtypes ETA and ETB. J Pept Sci 15, 479-491

18. De Mey, J.G., et al. (2011) ETA-receptor antagonists or allosteric modulators? Trends Pharmacol Sci 32, 345-351

19. Meens, M.J., et al. (2010) Stimuli of sensory-motor nerves terminate arterial contractile effects of endothelin-1 by CGRP and dissociation of ET-1/ET(A)receptor complexes. PLoS One 5, e10917

20. Conner, A.C., et al. (2007) Ligand binding and activation of the CGRP receptor. Biochem Soc Trans 35, 729-732

21. Hoare, S.R. (2007) Allosteric modulators of class B G-protein-coupled receptors. Curr Neuropharmacol 5, 168-179

22. Meens, M.J., et al. (2011) Calcitonin gene-related peptide terminates longlasting vasopressor responses to endothelin 1 in vivo. Hypertension 58, 99-106

23. Yanagisawa, M., et al. (1988) A novel potent vasoconstrictor peptide produced by vascular endothelial cells. Nature $332,411-415$

24. Blandin, V., et al. (2000) Allosteric inhibition of endothelin ETA receptors by 3 , 5-dibromosalicylic acid. Mol Pharmacol 58, 1461-1469

25. Hilal-Dandan, R., et al. (1997) The quasi-irreversible nature of endothelin binding and $G$ protein-linked signaling in cardiac myocytes. J Pharmacol Exp Ther 281, 267-273

26. Adner, M., et al. (2001) Evidence that ET-1, but not ET-3 and S6b, ET(A)-receptor mediated contractions in isolated rat mesenteric arteries are modulated by coactivation of $\mathrm{ET}(\mathrm{B})$ receptors. Br J Pharmacol 133, 927-935

27. Pierre, L.N., and Davenport, A.P. (1999) Blockade and reversal of endothelininduced constriction in pial arteries from human brain. Stroke 30, 638-643

28. De Mey, J., et al. (2009) Endothelin-1, an Endogenous Irreversible Agonist in Search of an Allosteric Inhibitor. Molecular and Cellular Pharmacology 1, 246

29. Kenakin, T., and Miller, L.J. (2010) Seven transmembrane receptors as shapeshifting proteins: the impact of allosteric modulation and functional selectivity on new drug discovery. Pharmacol Rev 62, 265-304

30. Keov, P., et al. (2011) Allosteric modulation of G protein-coupled receptors: a pharmacological perspective. Neuropharmacology 60, 24-35

31. Mulvany, M.J., and Aalkjaer, C. (1990) Structure and function of small arteries. Physiol Rev 70, 921-961 
32. Meens, M.J., et al. (2009) Calcitonin gene-related peptide selectively relaxes contractile responses to endothelin-1 in rat mesenteric resistance arteries. $J$ Pharmacol Exp Ther 331, 87-95

33. Brosseau, J.P., et al. (2009) Design, synthesis and pharmacological characterization of fluorescein-derived endothelin antagonists Bq-123 and Bq788. Adv Exp Med Biol 611, 443-444

34. Holtke, C., et al. (2007) A fluorescent photoprobe for the imaging of endothelin receptors. Bioconjug Chem 18, 685-694

35. De Mey, J.G., et al. (2008) Functional antagonism between endogenous neuropeptide $Y$ and calcitonin gene-related peptide in mesenteric resistance arteries. J Pharmacol Exp Ther 324, 930-937

36. Wang, Y., and Wang, D.H. (2004) Prevention of endothelin-1-induced increases in blood pressure: role of endogenous CGRP. Am J Physiol Heart Circ Physiol 287, $\mathrm{H} 1868-1874$

37. Warner, T.D., et al. (1989) Endothelin-1 and endothelin-3 release EDRF from isolated perfused arterial vessels of the rat and rabbit. J Cardiovasc Pharmacol 13 Suppl 5, S85-88; discussion S102

38. Ishikawa, K., et al. (1994) Biochemical and pharmacological profile of a potent and selective endothelin B-receptor antagonist, BQ-788. Proc Natl Acad Sci U S A 91, 4892-4896

39. Saeki, T., et al. (1991) [Ala1,3,11,15]endothelin-1 analogs with ETB agonistic activity. Biochem Biophys Res Commun 179, 286-292

40. Ihara, M., et al. (1992) Biological profiles of highly potent novel endothelin antagonists selective for the ETA receptor. Life Sci 50, 247-255

41. Maguire, J.J., etal. (1997)Affinity and selectivity of PD156707, a novel nonpeptide endothelin antagonist, for human ET(A) and ET(B) receptors. J Pharmacol Exp Ther 280, 1102-1108

42. D'Orleans-Juste, P., et al. (1993) Characterization of receptors for endothelins in the perfused arterial and venous mesenteric vasculatures of the rat. $\mathrm{Br} \mathrm{J}$ Pharmacol 110, 687-692

43. Warner, T.D. (1990) Simultaneous perfusion of rat isolated superior mesenteric arterial and venous beds: comparison of their vasoconstrictor and vasodilator responses to agonists. Br J Pharmacol 99, 427-433

44. Christopoulos, A., and Kenakin, T. (2002) G protein-coupled receptor allosterism and complexing. Pharmacol Rev 54, 323-374

45. Portoghese, P.S. (1989) Bivalent ligands and the message-address concept in the design of selective opioid receptor antagonists. Trends Pharmacol Sci 10, 230-235 
46. Doherty, A.M., et al. (1993) Structure-activity relationships of C-terminal endothelin hexapeptide antagonists. J Med Chem 36, 2585-2594

47. Randall, M.D., et al. (1989) Vascular activities of endothelin-1 and some alanyl substituted analogues in resistance beds of the rat. $\mathrm{Br} \mathrm{J}$ Pharmacol 98, 685-699

48. Tam, J.P., et al. (1994) Alanine scan of endothelin: importance of aromatic residues. Peptides 15, 703-708

49. Donoso, M.V., et al. (1996) Pharmacological characterization of the ETA receptor in the vascular smooth muscle comparing its analogous distribution in the rat mesenteric artery and in the arterial mesenteric bed. Peptides 17, 1145-1153

50. Bax, W.A., and Saxena, P.R. (1994) The current endothelin receptor classification: time for reconsideration? Trends Pharmacol Sci 15, 379-386

51. Ehlert, F.J. (2005) Analysis of allosterism in functional assays. J Pharmacol Exp Ther 315, 740-754

52. Millecamps, M., et al. (2010) Role of peripheral endothelin receptors in an animal model of complex regional pain syndrome type 1 (CRPS-I). Pain 151, 174-183

53. Wagner, O.F., et al. (1992) Regional effects and clearance of endothelin-1 across pulmonary and splanchnic circulation. Eur J Clin Invest 22, 277-282

54. Bohm, F., et al. (2002) Combined endothelin receptor blockade evokes enhanced vasodilatation in patients with atherosclerosis. Arterioscler Thromb Vasc Biol 22, 674-679

55. Cardillo, C., et al. (2004) Enhanced vascular activity of endogenous endothelin-1 in obese hypertensive patients. Hypertension 43, 36-40

56. Cardillo, C., et al. (2002) Improved endothelium-dependent vasodilation after blockade of endothelin receptors in patients with essential hypertension. Circulation 105, 452-456

57. Stauffer, B.L., et al. (2010) Sex differences in endothelin-1-mediated vasoconstrictor tone in middle-aged and older adults. Am J Physiol Regul Integr Comp Physiol 298, R261-265

58. Nohria, A., et al. (2003) Endothelin-1 and vascular tone in subjects with atherogenic risk factors. Hypertension 42, 43-48 
Chapter 5.1

Supplementary Data concerning Chapter 5 

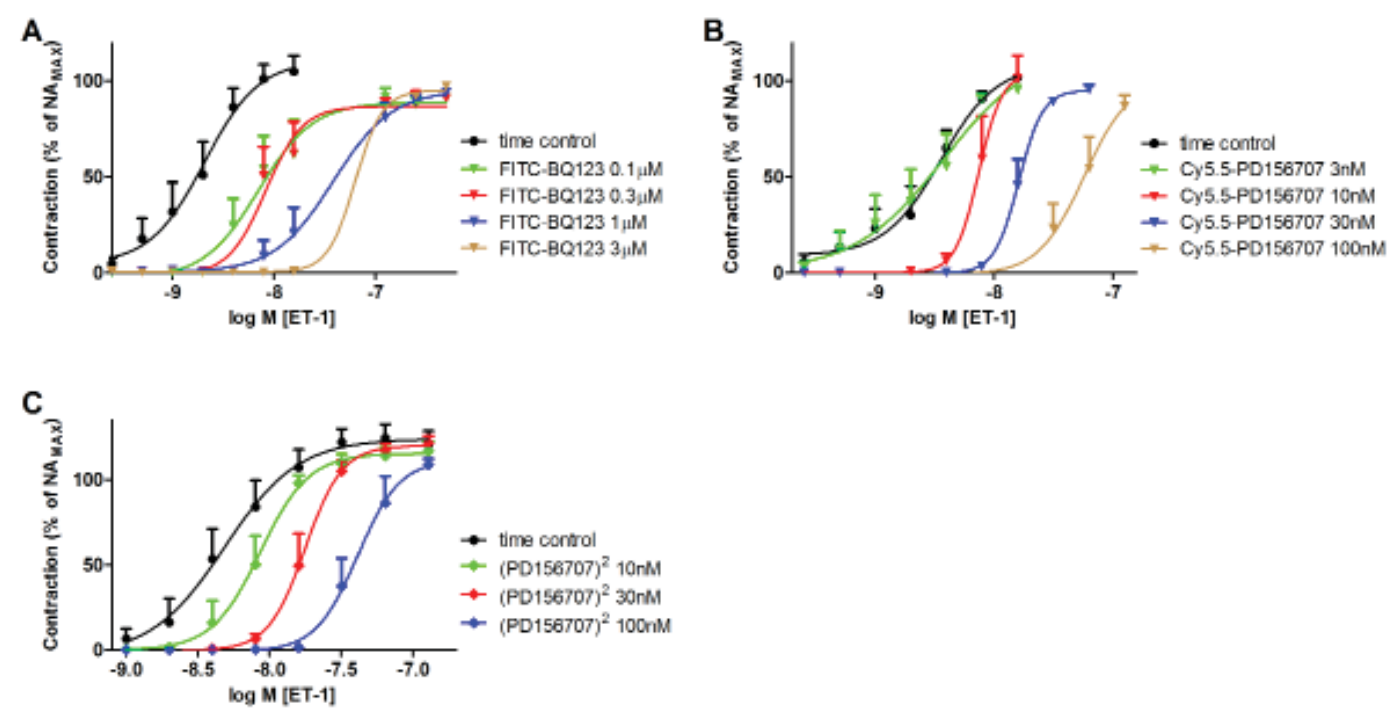

Supplementary Figure 5.1.1. Effects of presence of FITC-BQ123 $(0.1-3.0 \mu \mathrm{M}, \mathrm{A})$, Cy5.5-PD156707 (3 - $100 \mathrm{nM}, \mathrm{B})$ or PD156707² (10 - $100 \mathrm{nM}, \mathrm{C})$ on contractile responses to ET-1.

Synthesis of $E T-1_{1-15}$

Peptide H-CSC(Acm)SSLMDKEC(Acm)VYFC-NH ${ }_{2}$ was synthesized on a MBHApolystyrene resin $(0.44 \mathrm{mmol} / \mathrm{g})$ by manual SPPS on a $0.3 \mathrm{mmol}$ scale using in situ neutralization/HCTU activation for Boc-chemistry as previously described [1]. After chain assembly $\mathrm{N}^{\alpha}$-Boc-groups were removed and the resin-bound peptide was cleaved with anhydrous $\mathrm{HF}$ for $1 \mathrm{~h}$ at $0^{\circ} \mathrm{C}$ with $4 \% p$-cresol as a scavenger. After cleavage the peptide was dissolved in a sodium acetate buffer $(0.1 \mathrm{M}, \mathrm{pH}$ 4), containing $6 \mathrm{M} \mathrm{Gn} . \mathrm{HCl}$ and purified on a Vydac $\mathrm{C}_{18}$ RP-HPLC column $(50 \mathrm{~mm} x$ $250 \mathrm{~mm}, 25 \mathrm{ml} / \mathrm{min}$ ) with a lineair gradient of acetonitrile in water $/ 0.1 \%$ TFA, yielding $26.2 \mathrm{mg}$. After HF cleavage Cys ${ }^{3}$ and $\mathrm{Cys}^{11}$ stayed protected with acetamidomethylprotecting groups (Acm), Cys ${ }^{1}$ and Cys $^{15}$ were deprotected. To generate the first disulfide bond $\left(\right.$ Cys $^{1}-$ Cys $\left.^{15}\right), 5.6 \mathrm{mg}$ of the purified peptide $(3.0 \mu \mathrm{mol}$, 1eq) was dissolved in $28 \mathrm{ml} 0.1 \mathrm{M}$ ammonium bicarbonatebuffer $(\mathrm{pH} 7.8)$. The solution was incubated at room temperature and stirred during the reaction. The reaction progress was monitored by ESI-MS and analytical HPLC. After 3 hours the reaction was completed and the solution was acidified to $\mathrm{pH} 4$ with acetic acid. After lyophilization the second disulfide bond $\left(\mathrm{Cys}^{3}{ }^{3}-\mathrm{Cys}^{11}\right)$ was formed by iodine treatment in methanol as previously described [2]. The lyophilized product was solved in $1.375 \mathrm{ml}$ of a 80:20 methanol:water mixture containing $5 \mathrm{M} \mathrm{HCl}$ and purged with nitrogen. Then $247.5 \mu \mathrm{l}$ of iodine $0.24 \mathrm{M}$ in methanol $(59 \mu \mathrm{mol}, 20 \mathrm{eq})$ was added. The reaction mixture was purged with nitrogen and kept at room temperature for 40 minutes. To stop the reaction an excess of ascorbic acid $5 \%$ in a sodium acetate buffer $(0.1 \mathrm{M}, \mathrm{pH} 4)$ containing $6 \mathrm{M} \mathrm{Gn} . \mathrm{HCl}$ was added. After purification, product containing fractions were pooled and lyophilized to yield $1.1 \mathrm{mg}$. ESI-MS showed a mass of $1712.54 \pm 0.50$, fitting well between the calculated monoisotopic mass (1711.62) and average mass (1713.01). 


\section{Synthesis of (PD156707)2}

The homobivalent ligand (PD156707) 2 has been synthesized by a two-step procedure starting from commercially available 3,4-dimethoxy-5-hydroxybenzaldehyde (Frinton Laboratories, Inc., Vineland, NJ) and tetraethyleneglycole dimethanesulfonate (1). The resulting bisaldehyde (2) was then converted to the final bifunctional $E_{A}$ antagonist (4) by reaction with two equivalents of ketoester (3) (Suppl. Fig. 5.1.2).

To a solution of $3.64 \mathrm{~g}(20.0 \mathrm{mmol})$ 3,4-dimethoxy-5-hydroxybenzaldehyde in $30 \mathrm{ml}$ of DMF are added $3.47 \mathrm{~g}(9.9 \mathrm{mmol})$ tetraethyleneglycole dimethanesulfonate (1) and $7.17 \mathrm{~g}(22.0 \mathrm{mmol}) \mathrm{Cs}_{2} \mathrm{CO}_{3}$ and the mixture is heated at $100^{\circ} \mathrm{C}$ for 4 hours. The final solution is poured on ice and extracted with ethyl acetate. The organic layers are combined and washed with brine, dried over magnesium sulfate and filtered.

Evaporation ofthesolventyields 4.97g(9.5 mmol, 95\%)of3-(2-(2-(2-(2-(2,3-dimethoxy5-formylphenyloxy)ethoxy)ethoxy)-ethoxy)ethoxy)-4,5-dimethoxybenzaldehyde (2) as a waxy light-yellow solid. ${ }^{1} \mathrm{H}-\mathrm{NMR}\left(300 \mathrm{MHz}^{\mathrm{CDCl}}{ }_{3}\right) \delta=9.83(\mathrm{~s}, 2 \mathrm{H}), 7.13(\mathrm{~d}, 2 \mathrm{H}$, $\mathrm{J}=1.8 \mathrm{~Hz}), 7.11(\mathrm{~d}, 2 \mathrm{H}, \mathrm{J}=1.8 \mathrm{~Hz}), 4.24-4.20(\mathrm{~m}, 4 \mathrm{H}), 3.93(\mathrm{~s}, 6 \mathrm{H}), 3.91(\mathrm{~s}, 6 \mathrm{H})$, 3.90-3.86 (m, 4H), 3.74-3.70 (m, 4H), 3.69-3.65 (m, 4H). ${ }^{13} \mathrm{C}-\mathrm{NMR}\left(75 \mathrm{MHz}, \mathrm{CDCl}_{3}\right)$ $\delta=191.0,153.7,152.8,144.1,131.5,109.0,106.4,77.5,77.2,77.0,76.6,70.8$, $70.7,69.6,68.9,61.0,56.3$.

To a solution of $600 \mathrm{mg}(26.1 \mathrm{mmol})$ sodium in $120 \mathrm{ml}$ of methanol under argon are added $6.85 \mathrm{~g}$ (20.0 mmol) of methyl-2-(benzo[1,3]dioxol-5-yl)-4-(4-methoxyphenyl)4-oxobutanoate (3) and the mixture is heated at $50^{\circ} \mathrm{C}$ for $3 \mathrm{~h}$. Then an amount of $5.22 \mathrm{~g}(10.0 \mathrm{mmol})$ of the bisaldehyde (2) dissolved in $20 \mathrm{ml}$ of methanol is added and the reaction mixture is heated at reflux for $48 \mathrm{~h}$. Acetic acid $(2 \mathrm{ml})$ is added and the mixture is further heated at reflux for $24 \mathrm{~h}$. After evaporation of the solvent water and ethyl acetate are added and the organic layer is separated, washed with brine and dried over $\mathrm{MgSO}_{4}$.

Filtration and evaporation of the solvent yields $9.07 \mathrm{~g}$ of a foamy, pale solid (7.94 mmol, 79\%). ${ }^{1} \mathrm{H}$ NMR (300 MHz, $\mathrm{CDCl}_{3}$ ) $\delta=7.38$ (d, 4H, J = 8.3 Hz), 6.94-6.73 (m, $10 \mathrm{H}), 6.20(\mathrm{~s}, 2 \mathrm{H}), 5.96(\mathrm{~s}, 2 \mathrm{H}), 5.94(\mathrm{~s}, 4 \mathrm{H}), 5.34(\mathrm{br}, 2 \mathrm{H}), 3.98-3.91(\mathrm{~m}, 4 \mathrm{H}), 3.78$ $(\mathrm{s}, 6 \mathrm{H}), 3.75-3.50(\mathrm{~m}, 16 \mathrm{H}), 3.72(\mathrm{~s}, 6 \mathrm{H}), 3.59(\mathrm{~s}, 6 \mathrm{H}) .{ }^{13} \mathrm{C}$ NMR $\left(75 \mathrm{MHz} \mathrm{CDCl}_{3}\right)$ $\delta=175.3,160.6,160.2,152.8,152.0,148.1,147.6,136.9,131.9,128.8,128.1$, $127.4,123.2$, 123.0, 113.9, 109.5, 108.4, 108.1, 106.2, 106.0, 101.3, 70.7, 70.5, $69.7,68.5,60.8,55.8,55.3,32.1 . \mathrm{HRMS}(\mathrm{ESI}): \mathrm{m} / \mathrm{z}=1165.3662(\mathrm{M}+\mathrm{Na}+$ ), calc. $\mathrm{m} / \mathrm{z}=1165.3676$. 

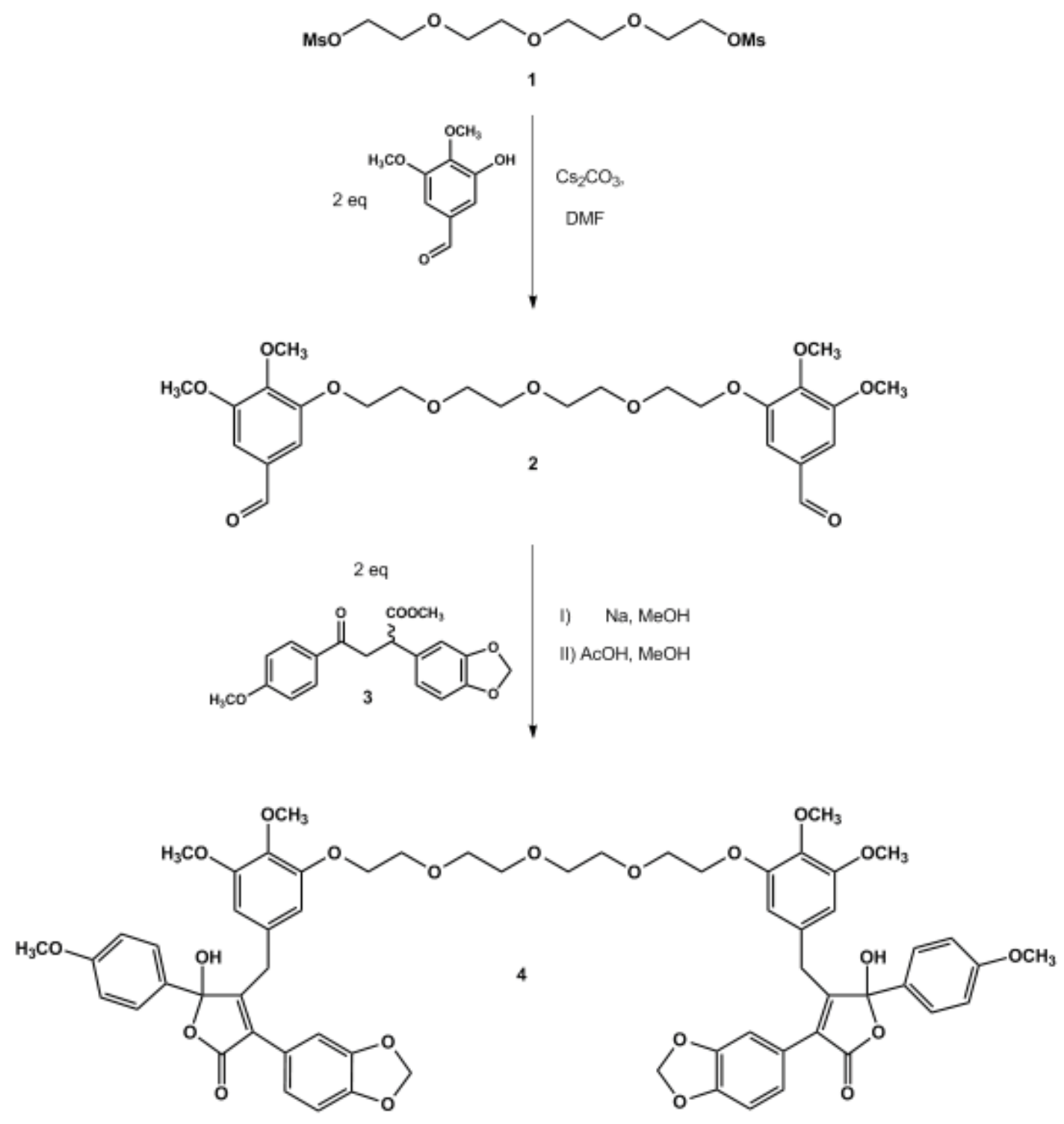

Supplementary Figure 5.1.2. Synthesis of PD156707².

\section{References}

1. Schnolzer, M., et al. (1992) In situ neutralization in Boc-chemistry solid phase peptide synthesis. Rapid, high yield assembly of difficult sequences. Int J Pept Protein Res 40, 180-193

2. Kudryavtseva, E.V., et al. (2000) Hydrogen peroxide for disulfide bridge formation in methionine-containing peptides. J Pept Sci 6, 208-216 
Chapter 6

Discussion and Future Directions 
Since its discovery and characterization, the ET system was, and is, considered to be a therapeutic target with large potential. Involvement of $\mathrm{ET}_{\mathrm{A}}$ receptors and/or $\mathrm{ET}_{\mathrm{B}}$ receptors, in combination with one or more $\mathrm{ET}$ isoforms, in hypertension and other cardiovascular diseases, has become evident over the past years. Seizing the opportunity for anti ET drugs, the search was on for compounds that could bind to ET receptors and prevent binding of agonists. Leads were then 'rushed' into trials but, as only bosentan and more recently ambrisentan are currently used in clinical practice, for treatment of pulmonary arterial hypertension, pulmonary fibrosis and scleroderma, the full therapeutic potential of ERAs is far from reached. Therefore, opportunities to more effectively target the ET system for the treatment of hypertension should not be overlooked. In addition, this more effective targeting of the ET system may, in the near future, prove valuable for pathologies such as cancer and chronic pain, in which the role of the ET system has only started to become apparent over the past few years.

Due to the rather unique pharmacology of ETs however, a neutral competitive antagonist may not fit the need to displace an ET isoform and the focus to inhibit the ET system may, or should, shift to other mechanisms. These may include, but should not be limited to, compounds that promote dissociation of $E$ Ts from $\mathrm{ET}_{\mathrm{A}}$ receptors, ERAs, that by tight binding can also be long-acting, and ERAs that can act ET isoform specifically and have an effect despite the tightly bound agonists. These latter two would benefit from an allosteric mechanism of action rather than a competitive antagonistic mechanism. Additionally, one of the mechanisms to displace ETs from $\mathrm{ET}_{\mathrm{A}}$ receptors should be an endogenous system, as long-lasting $\mathrm{ET}$ agonism is not compatible with vascular homeostasis.

In Chapter 2 of this thesis, we aimed to find which physiological mechanism could effectively counterbalance the vascular responses to ET-1-induced, $\mathrm{ET}_{\mathrm{A}}$ mediated responses. We found that the long-lasting contractions induced by ET-1 were due to the quasi-irreversible nature of its binding to $\mathrm{ET}_{\mathrm{A}}$ receptors. The effects of $E T-1$ could only be partially and transiently reversed by ERAs, indicative of irreversible agonism and reversible antagonism. In addition, endothelium-derived and exogenous vasodilators could only transiently reverse the effects of ET-1. Only CGRP, either exogenously applied or endogenously released from sensory motor-nerves via stimuli of TRP-channels, could effectively relax ET-1-induced contractions. Using a fluorescently-labeled ET-1 that, regarding affinity and efficacy for $\mathrm{ET}_{\mathrm{A}}$ receptors did not differ from unlabeled ET-1, we could visualize the binding to smooth muscle $E_{A}$ receptors. We confirmed that this was due to tight binding by labeled ET-1 to $\mathrm{ET}_{\mathrm{A}}$ receptors and that this was unaltered by ERAs. Yet, exogenous and endogenously 
released CGRP could displace labeled ET-1 from $\mathrm{ET}_{\mathrm{A}}$ receptors, after which labeled ET-1 could again label the arterial smooth muscle.

These findings indicate that $E T-1$ binding to $\mathrm{ET}_{\mathrm{A}}$ receptors is a complex mechanism in which binding and signaling are mediated by different parts of the ET-1 molecule. Once ET-1 is bound to $E T_{A}$ receptors, vasodilator mechanisms or ERAs do not displace $E T-1$, resulting in a fully signaling $E T-1 / E_{A}$ complex upon removal of the vasodilators or ERAs. CGRP however, which is released endogenously when sensory-motor nerves are stimulated by e.g. compounds found in red pepper and garlic, does promote dissociation of $\mathrm{ET}-1$ from $\mathrm{ET}_{\mathrm{A}}$ receptors. This may explain, in part, the cardiovascular health benefits of the Mediterranean diet and should be an incentive for everyone to include garlic and red pepper in their diet, not just because it tastes great, but also because it might provide better cardiovascular health.

Subsequent experiments demonstrated that CGRP can act as a "physiological" antagonist of $E T-1 / E_{A}$-function not only in rat mesenteric resistance arteries but also of pressor responses and regional vasoconstrictor responses in intact rats. Also, we could identify that activated CGRP-receptors have arterial anti-endothelinergic effects via G-protein $\beta y$ subunits and not via cAMP, a second messenger that plays a major role in its general vasodilator effects.

In Chapter 3, we aimed to characterize to which extent the amino acid structure of the endogenous agonists contributes to the tight binding to and activation of ETA receptors. So, we dug deeper into the characteristic interactions of ET isoforms with $\mathrm{ET}_{\mathrm{A}}$ receptors. We confirmed that $\mathrm{ET}_{\mathrm{B}}$ agonists did not induce any effect and neither $\mathrm{ET}_{\mathrm{B}}$ agonists nor $\mathrm{ET}_{\mathrm{B}}$ antagonists altered sensitivity and maximal responses to ET-1. We also confirmed that ET-1 and ET-2 display similar potency and maximal effect and found that they induce similar vasospasms, as removal of the free ETs did not affect their induced contractions. An $\mathrm{ET}_{\mathrm{A}}$ antagonist, however, inhibited ET1-induced contractions to a larger extent than it did ET-2-induced contractions. And in contrast, it relaxed ET-2-induced vasospasms to a larger extent than it did ET-1induced vasospasms. Interchanging the amino acids that differ between ET-1 and ET-2 makes the agonists lose affinity and highlights the agonist-selective extent of inhibition by an antagonist.

These findings indicate that, despite their initial, apparently similar pharmacology, ET-1 and ET-2 differently activate $\mathrm{ET}_{\mathrm{A}}$ receptors as shown by the inhibitory effect of an antagonist, likely due to their amino acid sequence, as supported by the results of interchanging the amino acids that distinguish ET-1 and ET-2. This knowledge 
should drive the smart design of an antagonist that can ET isoform-selectively target $\mathrm{ET}_{\mathrm{A}}$ receptors. In addition, as an $\mathrm{ET}_{\mathrm{A}}$ antagonist exerts greater inhibition of activated rather than inactive receptors, this could reduce antagonistic effects on part of the ET system that is not over-activated.

Because we now know that ET-1 and ET-2 induce vasoconstrictions and consecutive vasospasms by binding tightly to $\mathrm{ET}_{\mathrm{A}}$ receptors, in Chapter 4, we aimed to determine which of the intracellular signaling mechanisms is responsible for the long-lasting, persistent responses to $\mathrm{ET}_{\mathrm{A}}$ agonists. Using functional antagonists, i.e. compounds that inhibit contractile mechanisms or stimulate relaxing mechanisms, we studied which mechanisms are responsible for the vasoconstrictions and for the vasospasms, if this differed between ET-1 and ET-2 and if this knowledge could be useful in a system that does not potently respond to ERAs or CGRP: the basilar artery. We found that mainly PLC is responsible for the initial vasoconstrictor responses and for the consecutive vasospasm, but that these are mediated by different mechanisms downstream of PLC. Again we found agonist-dependent effects of $E T_{A}$ activation, regarding intracellular signaling pathways, and that this pathway in the basilar arterial system differs from that in mesenteric arteries. Functional antagonists could effectively relax ET-induced vasospasms without affecting the initial contractile response.

Firstly, these results emphasize that taking into account which ET isoform activates $\mathrm{ET}_{\mathrm{A}}$ receptors can help finding the best inhibitory approach and that it is worth considering in which arterial system one wishes to intervene. Secondly, since functional antagonists exert their effects against vasospasms rather than the initial contraction, a long-acting/slowly dissociating vasodilator could effectively counterbalance the long-lasting effects induced by ETs. This could be a preferable option in a system that does not respond well to ERAs or our endogenous functional antagonist CGRP.

Inhibiting a downstream mediator of $\mathrm{ET}_{\mathrm{A}}$ induced effects may not fit the need of selectively inhibiting the ET system, as these mediators are generally involved in several intracellular 7TMR signaling mechanisms. However, a few mediators, such as TRPC3, may be rather specific for $\mathrm{ET}_{\mathrm{A}}$ signaling and antagonizing this target may help counteracting ET-induced vasospasms.

Finally, in Chapter 5, we aimed to define in more detail the interaction of $E T s$ with $\mathrm{ET}_{\mathrm{A}}$ receptors and to define a role for allosteric modulators rather than neutral competitive antagonists to interact with $\mathrm{ET}_{\mathrm{A}}$ receptors. So, we got into the mechanism of agonist- 
dependent modulation of ETA receptors. In an attempt to relate the structure of the agonist to its functional effects, i.e. the initial contractile response and the consecutive vasospasm, we studied fragments of ETs but found that only the intact 21 amino acid peptide can bind to and activate the receptor. We found that, in addition to ET-1 and ET-2, ET-3 also induces vasospasms, although to a smaller extent. The inhibitory effect of an antagonist of this receptor activation was dependent on both presence and type of ETA agonist, and on the size of the antagonist. The agonist-dependence of the antagonist affinity differed between two distinct ETA antagonists, and these modulate receptor activity differently, depending on the agonist responsible for receptor activation.

To visualize antagonist-binding, preferably to an ETA receptor that was already labeled with fluorescently labeled ET-1, we characterized fluorescently labeled antagonists. The fluorescent label did not alter antagonist affinity for ETA receptors, but the labeled, and thereby bulky antagonists were unable to relax ET-1-induced vasospasms. The bulkiness of the antagonist was likely to sterically hinder the binding to $E T \neg A$ receptors with the agonist bound, and these bulky antagonists were therefore unable to induce relaxation. Unfortunately this complicated visualization of fluorescently labeled and bound agonist and antagonist, but it indicated that only small molecules would be fit to antagonize activated ETA receptors. This in turn complicates the use of fluorescently labeled antagonists as diagnostic tools, as they would only visualize receptors that are not bound to the endogenous agonists.

These findings support that the effects of at least some ETA antagonists are caused allosterically, rather than competitively. With this in mind, new or improved ETA antagonists could be able to more effectively target and inhibit ETA receptors, without having to displace the tightly bound agonist from the receptors, or to more effectively displace the agonist from the receptors (in a CGRP-like manner) without the antagonists having to inhibit the receptor activity in itself.

In figure 6.1, the mechanisms underlying the effects of $\mathrm{ET}_{\mathrm{A}}$ activation by $\mathrm{ETs}$, as well as the mechanisms that could antagonize activated $\mathrm{ET}_{\mathrm{A}}$ receptors, are summarized. It becomes apparent that the choice of a particular antagonizing method with either allosteric $\mathrm{ET}_{\mathrm{A}}$ receptor antagonists (yellow compound in the magnification), functional antagonists (inhibitors of contractile mechanisms or stimuli of relaxing mechanisms) or physiological antagonists (such as CGRP) will be based upon selectivity to the ET system, long-lasting relaxing effects and the ability to promote dissociation of ETs from $\mathrm{ET}_{\mathrm{A}}$ receptors. 


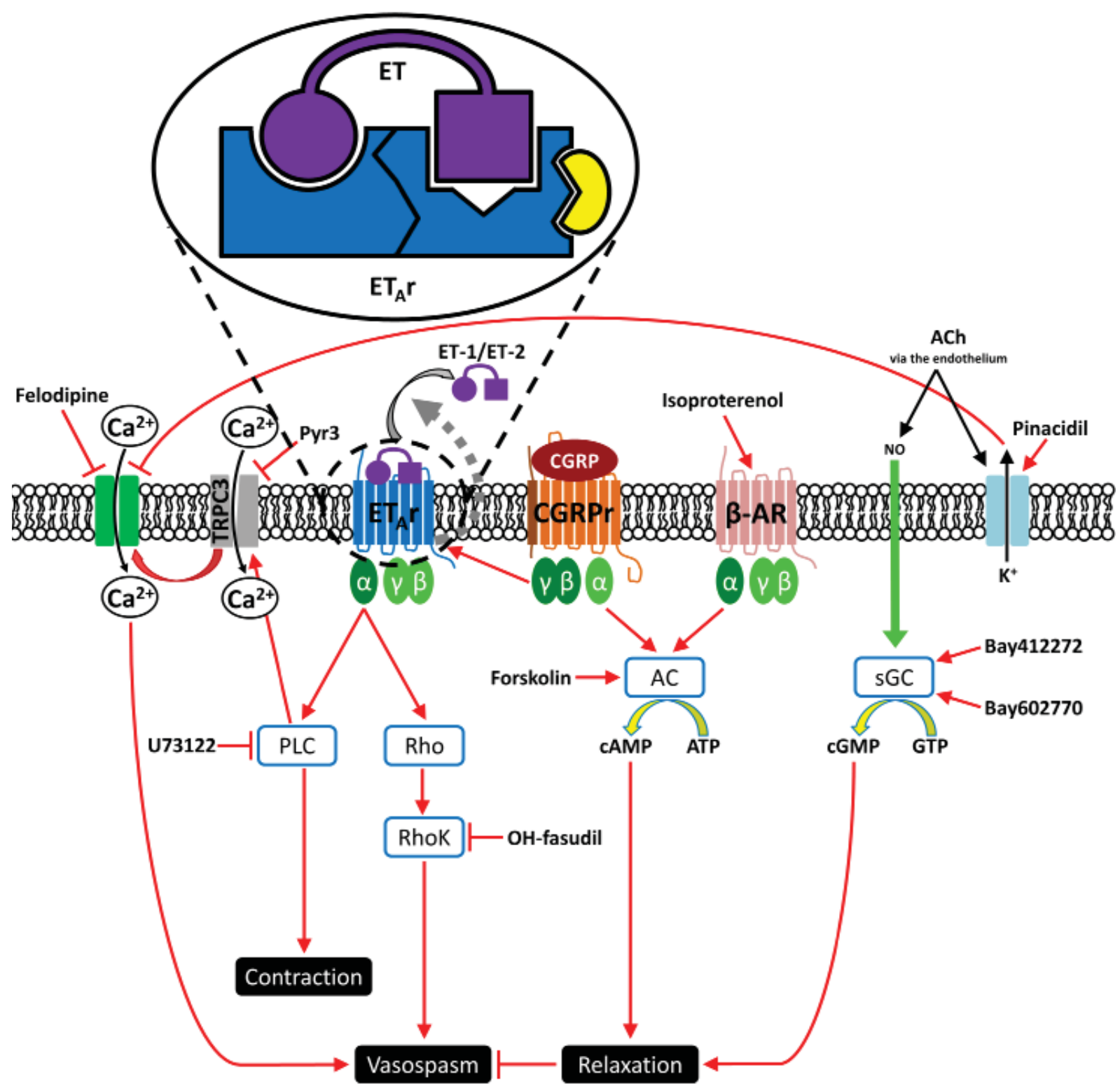

Fig. 6.1. The intracellular signaling pathway leading to $\mathrm{ET}_{\mathrm{A}}$ mediated contractions and vasospasms and targets to inhibit these pathways. U73122, the PLC inhibitor, is the only compound that inhibits both contractions and vasospasms and is therefore likely to be the main mediator of the initiating contraction. Antagonizing the $\mathrm{ET}_{\mathrm{A}}$ receptors can be done by using an allosteric modulator that can inhibit $\mathrm{ET}_{\mathrm{A}}$ receptor activity (yellow compound in the magnification), using an endogenous physiological antagonist (CGRP, which promotes dissociation of $E$ Ts from $\mathrm{ET}_{\mathrm{A}}$ receptors) or using functional antagonists to counterbalance $\mathrm{ET}_{\mathrm{A}}$ receptor activity (inhibitors of contractile mechanisms or stimuli of relaxing mechanisms).

$\alpha$ : G-protein $\alpha$ subunit; $\beta$ : G-protein $\beta$ subunit; $\beta$-AR: $\beta$-adrenoceptor; $\gamma$ : G-protein $\gamma$ subunit; AC: adenylate cyclase; ACh: acetylcholine; ATP: adenosine triphosphate: Bay412272: sCG stimulator; Bay602770: sCG activator; cAMP: cyclic adenosine monophosphate; cGMP: cyclic guanosine monophosphate; ET-1: endothelin-1; ET-2: endothelin-2; $E T_{A}$ r: endothelin ${ }_{A}$ receptor; felodipine: calcium channel blocker; forskolin; AC activator; GTP: guanosine triphosphate; isoproterenol: $\beta$-adrenoceptor agonist; NO: nitric oxide; $\mathrm{OH}-$ fasudil: RhoK-inhibitor; pinacidil: ATP-sensitive potassium channel opener; PLC: phospholipase C; Pyr3: TRPC3-blocker; RhoK: Rho-kinase; sGC: soluble guanylate cyclase; TRPC3: Transient receptor potential cation channel 3; U73122: PLC -inhibitor. 
In conclusion, in this thesis on the molecular pharmacology of $\mathrm{ET}_{\mathrm{A}}$ receptors, these receptors are, more than 20 years after their discovery, still considered as a therapeutic target with large potential. In the years to come, the focus should shift towards methods to more effectively target $\mathrm{ET}_{\mathrm{A}}$ receptors, taking into consideration the system in which an antagonist should act, and taking into consideration the agonist that the antagonist should be designed against. New or improved antagonists should act as allosteric modulators rather than competitive antagonists, taking full advantage of this new window of opportunities. As an antagonist against a longacting agonist, the allosteric modulator would ideally be a long-acting compound itself that can effectively displace $E T s$ from $E T_{A}$ receptors, thereby returning $E T_{A}$ receptors back to the inactive state. This concept of allosteric modulation of $E_{A}$ receptors should be extrapolated to other pathologies in which the ET system is a promising target, and anti-ET drugs may (finally) live up to its promise. 


\section{Chapter 7}

Summary 
In this thesis on the molecular pharmacology of $\mathrm{ET}_{\mathrm{A}}$ receptors, we started by highlighting the importance of this type of studies (chapter 1). Since its discovery it soon became apparent that the ET system plays a significant part in blood pressure regulation. Despite extensive efforts however, most ET-targeting drugs did not find their way into clinical practice. This may in part be due to the 'rush to the clinic' of ERAs, which may have hampered or attenuated the process of optimally designing drugs that best suited the need to inhibit the ET system, and rather just focused on binding to $\mathrm{ET}_{\mathrm{A}}$ (and/or $\mathrm{ET}_{\mathrm{B}}$ ) receptors, thereby hoping to block the binding of $\mathrm{ETs}$.

Unfortunately, the rather unique pharmacology of $\mathrm{ET}_{A}$ receptors complicates inhibition by neutral competitive antagonists. In chapter 2 , we found that the persistent arterial contractile effects of ET-1 were caused by tight binding of ET-1 to $E T_{A}$ receptors. ERAs were unable to continuously inhibit these active $E T-1 / E_{A}$ receptor complexes, as the ERAs did not bind tightly to $\mathrm{ET}_{\mathrm{A}}$ receptors, which results in continuously activated $\mathrm{ET}_{\mathrm{A}}$ receptors, also after removal of the ERAs. In addition, ERAs did not promote dissociation of $\mathrm{ET}-1$ from $\mathrm{ET}_{\mathrm{A}}$ receptors. As tightly-bound, continuously active $E T-1 / E T_{A}$ receptor complexes are not compatible with vascular homeostasis, we identified a role for CGRP, released from sensory-motor nerves as a terminator of $\mathrm{ET}-1 / \mathrm{ET}_{\mathrm{A}}$ receptor complexes, as CGRP promotes immediate dissociation of these complexes. This may explain to some extent the cardiovascular protection attributed to a diet high in peppers and garlic, as compounds from these plants trigger release of CGRP.

This atypical receptor pharmacology can complicate the use of potentially therapeutic drugs. To better understand the interaction of the agonists with $\mathrm{ET}_{\mathrm{A}}$ receptors, we characterized the importance of the agonist amino acid structure for the binding to and activation of $E T_{A}$ receptors in chapter 3 . We found that $E T_{A}$ receptors on arterial smooth muscle cells display agonist-dependent properties that depend on the amino acids on position 6 and 7 of the ET sequence. Although ET-1 and ET-2 display similar affinity to and maximal effect on $\mathrm{ET}_{\mathrm{A}}$ receptors and that both agonists bind tightly to these receptors, their $\mathrm{ET}_{\mathrm{A}}$ mediated activities are differently modulated by an ERA. Moreover, the substitution of a single amino acid in the agonist sequence drastically reduces affinity for $\mathrm{ET}_{\mathrm{A}}$ receptors and therefore has profound pharmacological consequences.

As ERAs display agonist-dependent effects regarding $\mathrm{ET}_{\mathrm{A}}$ receptor activity, we continued to find which intracellular signaling mechanisms were involved in the persistent $\mathrm{ET}_{\mathrm{A}}$ agonist responses in chapter 4 . We again found that the intracellular signaling mechanisms involved in contractile responses were dependent on which 
agonist activated $\mathrm{ET}_{\mathrm{A}}$ receptors, and that there were different mechanisms involved in the initial contractile response and the sequential vasospasm. The main facilitator of both the contractions and vasospasms was identified as PLC, downstream of which TRPC3 and L-VOCC were intermediate steps in the mechanism of vasospasm. The $\mathrm{ET}_{\mathrm{A}}$ mediated activation of the intracellular signaling mechanism was not only agonist-dependent, but also system-dependent.

Then, in chapter $\mathbf{5}$, we present evidence that two ERAs act as allosteric modulators rather than as competitive antagonists. After establishing that $\mathrm{ET}_{\mathrm{A}}$ receptor binding and activation requires the full 21 amino acid sequence of the agonists, we found that the effects of ERAs depend on the presence and type of $\mathrm{ET}_{\mathrm{A}}$ agonist and on the size of the ERA. These effects can only be attributed to an allosteric mechanism rather than to a competitive antagonist mechanism.

In chapter 6 we discuss these findings in light of our current understanding of anti$E T$ therapy and we suggest that in order to more effectively target $E T_{A}$ receptors, we should take into consideration which of the $\mathrm{ET}_{\mathrm{A}}$ agonists are involved and that when designing novel ERAs or improving on current ERAs, some attention should go out to possible long-acting effects of the ERA that would ideally dissociate $E T s$ from $E T_{A}$ receptors. 
Chapter 8

SAMENVATting 


\section{Chapter 8}

In dit proefschrift over de moleculaire farmacologie van Endotheline ${ }_{A}\left(E T_{A}\right)$ receptoren zijn we begonnen met het benadrukken van het belang van dit soort studies (hoofdstuk 1). Sinds de ontdekking werd het snel duidelijk dat het ET systeem een belangrijke bijdrage levert aan reguleren van de bloeddruk. Ondanks intensieve pogingen zijn de meeste op ET gerichte medicijnen op weg naar klinische toepassing gesneuveld. Dit kan deels te wijten zijn aan de 'sprint naar de kliniek' van ET receptor antagonisten (ERAs), wat er voor gezorgd kan hebben dat het design proces van medicijnen, gericht op het remmen van het ET systeem, niet volledig zorgvuldig is doorlopen. Dit proces heeft zich misschien te veel gefocust op het binden van medicijnen aan $\mathrm{ET}_{\mathrm{A}}$ (en/of $\mathrm{ET}_{\mathrm{B}}$ ) receptoren, waarmee in theorie het binden van ETs voorkomen zou worden.

Helaas is de unieke farmacologie van $\mathrm{ET}_{\mathrm{A}}$ receptoren een complicerende factor met betrekking tot de inhibitie door neutrale competitieve antagonisten. In hoofdstuk 2 hebben we gevonden dat de aanhoudende arteriële contracties van ET-1 worden veroorzaakt door een moeilijk omkeerbare binding van $E T-1$ aan $\mathrm{ET}_{\mathrm{A}}$ receptoren. ERAs waren niet in staat om de geactiveerde ET-1/ET $\mathrm{A}_{\mathrm{A}}$ receptor complexen continu te remmen, omdat de ERAs wel dynamisch en gemakkelijk omkeerbaar binden aan $\mathrm{ET}_{\mathrm{A}}$ receptoren. Dit resulteert in langdurige, aanhouden geactiveerde $\mathrm{ET}_{\mathrm{A}}$ receptoren, ook na het verwijderen van ERAs. Daar komt bij dat ERAs niet zorgen voor een dissociatie van ET-1 van de $\mathrm{ET}_{\mathrm{A}}$ receptoren af. Aangezien moeilijk omkeerbaar gebonden, continu actieve $\mathrm{ET}^{-1 / \mathrm{ET}_{\mathrm{A}}}$ receptor complexen niet compatibel zijn met vasculaire homeostase, hebben we een rol voor calcitonine-gen gerelateerd peptide (CGRP) kunnen identificeren. CGRP wordt vrijgemaakt uit sensorische motor zenuwen en werkt als een terminator van $E T-1 / E T_{A}$ receptor complexen, daar het een directe dissociatie van deze complexen induceert. Dit zou deels een verklaring kunnen zijn van de cardiovasculaire bescherming die wordt toebedeeld aan een dieet waarin veel peper en knoflook wordt gebruikt, omdat stoffen uit deze planten zorgen voor een vrijmaking van CGRP uit de sensorische motor zenuwen.

De ongebruikelijke, atypische receptor farmacologie van $\mathrm{ET}_{\mathrm{A}}$ receptoren kan het gebruik van medicijnen met een potentieel therapeutische toepassing bemoeilijken. Ter vergroting van het begrip van de interacties tussen de agonisten en de $E_{A}$ receptoren hebben we in hoofdstuk 3 het belang van de aminozuur structuur van de agonist voor het binden aan en activeren van $\mathrm{ET}_{\mathrm{A}}$ receptoren gekarakteriseerd. We hebben gevonden dat $\mathrm{ET}_{\mathrm{A}}$ receptoren op arteriële gladde spiercellen agonistafhankelijke eigenschappen vertonen die afhankelijk zijn van de aminozuren op posities 6 en 7 van de ET sequentie. Ook al lijken ET-1 en ET-2 vergelijkbare affiniteit voor en maximaal effect op $\mathrm{ET}_{\mathrm{A}}$ receptoren te hebben en lijken beide agonisten 
moeilijk omkeerbaar te binden aan deze receptoren, hun $\mathrm{ET}_{\mathrm{A}}$ gemedieerde activiteiten lijken verschillend te worden gemoduleerd door een ERA. Daarbij is de uitwisseling van een enkel aminozuur in de agonist sequentie verantwoordelijk voor een drastische afname van affiniteit voor $\mathrm{ET}_{\mathrm{A}}$ receptoren en heeft daarom grote farmacologische gevolgen.

Daar ERAs agonist-afhankelijke effecten hebben met betrekking tot $\mathrm{ET}_{\mathrm{A}}$ receptor activiteit, hebben we verder gezocht naar het intracellulaire signaleringsmechanisme dat betrokken is bij de persisterende $\mathrm{ET}_{\mathrm{A}}$ agonist responses in hoofdstuk 4 . We hebben gevonden dat ook welk intracellulaire signaleringsmechanisme betrokken wordt bij de contractiele response afhankelijk is van met welke agonist de $E_{A}$ receptoren worden geactiveerd. Daarbij zijn er verschillende mechanismes betrokken bij de initiële contractiele response en het daaropvolgende vasospasme. Het signaleringsmolecuul PLC was geïdentificeerd als de faciliterende factor van zowel de contracties als de vasospasmes, en downstream van PLC waren TRPC3 en L-VOCC betrokken bij het mechanisme van vasospasme. De $\mathrm{ET}_{\mathrm{A}}$ gemedieerde activatie van het intracellulaire signaleringsmechanisme was daarbij niet alleen agonist-afhankelijk, maar ook systeem-afhankelijk.

Vervolgens tonen we in hoofdstuk $\mathbf{5}$ aan dat twee ERAs als allosterische modulators in plaats van competitieve antagonisten functioneren. Nadat we hadden vastgesteld dat de volledige 21 aminozuur sequentie van de agonist noodzakelijk is om $\mathrm{ET}_{\mathrm{A}}$ receptoren te kunnen binden en activeren, hebben we gevonden dat de effecten van ERAs afhankelijk zijn van het type en de aanwezigheid van de $\mathrm{ET}_{\mathrm{A}}$ agonist en van het formaat van de ERA. Deze effecten kunnen enkel worden toegeschreven aan een allosterisch mechanisme en niet zozeer aan een competitief antagonist mechanisme.

In hoofdstuk 6 bediscussiëren we de bevindingen tegen het licht van onze huidige kennis van anti-ET therapie. We stellen voor dat, om $\mathrm{ET}_{\mathrm{A}}$ receptoren effectiever als therapeutisch doelwit te gebruiken, we rekening moeten houden met welk van de $\mathrm{ET}_{\mathrm{A}}$ agonisten betrokken zijn bij de specifieke situatie. Daarnaast moet, wanneer er nieuwe ERAs worden ontworpen, of wanneer huidige ERAs worden verbeterd, er aandacht moet worden geschonken aan mogelijke langdurige effecten van de ERA zelf, die uiteindelijk idealiter de $\mathrm{ETs}$ moet dissociëren van $\mathrm{ET}_{\mathrm{A}}$ receptoren. 
ApPendix

DANKWOORD

List of Publications About the Author 
Appendix

\section{Dankwoord}

Een thesis is nooit het werk van slechts een individu; een van de redenen dat in papers altijd wordt gesproken van de wetenschappelijke 'wij'. Tot deze mensen wil ik me dan ook richten in dit dankwoord. Daarnaast zijn er ook enkele anderen die zeker nog een woord van dank verdienen.

Allereerst wil ik mijn promotor bedanken. Jo, je hebt mijn interesse voor de farmacologie optimaal aangewakkerd. Dit begon al bij het aanleren van onze voornaamste labtechniek, het myograafwerk en je hebt gelijk: iemand kan helemaal tot rust komen wanneer hij of zij bezig is met de isolatie en het monteren van de vaatjes. Daarnaast was je altijd plezierig betrokken vanaf het meedenken over (opzet van) experimenten tot het geduldig maar snel reviseren van manuscripten. Verder wil ik je ook bedanken voor de ruime mogelijkheden die je hebt geboden om mijn werk aan een zo breed mogelijk publiek te presenteren. Dit heeft mij meer dan alleen een betere wetenschapper gemaakt.

Ik wil ook mijn collega's van de afdeling Farmacologie bedanken. Merlijn, je was begonnen als mijn begeleider tijdens mijn master, en vervolgens hebben we een mooie samenwerking gehad als collega-experts van die langdurige endothelineresponses. Verder was het een plezier om het lab te delen met Pieter, Ramesh, Paul, Ger en Gregorio en om mijn kamer te delen met Bart en Jelly en later Raffaele. Daarnaast wil ik ook collega-aio's Kevin, Tessa en Pamela bedanken voor de gezellige aio-dagen. En natuurlijk dank aan alle collega's die geholpen hebben het werk op de afdeling Farmacologie leuk en interessant te maken.

Naast de bijdrages van mijn Farmacologie-collega's heb ik veel samengewerkt met collega's van de andere afdelingen van Maastricht University en van andere universiteiten. Naast de frisse kijk van anderen op het eigen werk nodigde de samenwerking ook uit tot het verbreden van de eigen interesse.

Verder wil ik ook de stagiaires bedanken. Het was leuk om als jullie dagelijkse begeleider betrokken te zijn, om jullie de praktische vaardigheden bij te brengen van de myograaf-methode in de vasculaire farmacologie en om jullie te helpen bij de eerste kennismaking met wetenschappelijk onderzoek tijdens de bachelor of bij de verdieping in het onderzoek tijdens de master. Dit was hopelijk voor jullie net zo leerzaam als voor mij. Bovendien hebben jullie een veelal nuttige bijdrage weten te leveren aan ons onderzoek. 
Mijn onderzoek heb ik kunnen doen vanuit het Top Institute Pharma. De projectbijeenkomsten die wij twee keer per jaar hadden in Rotterdam, Allschwill en Maastricht waren bijzonder informatief, stimulerend en altijd gezellig. Daarom wil ik mijn collega's van TI Pharma project T2-301, en in het bijzonder Jan als principal investigator en Walter als aanspreekpunt van Actelion, onze farmaceutische partner, bedanken voor de fijne samenwerking.

Naast al deze professionele betrekkingen wil ik ook nog een aantal mensen op persoonlijk vlak bedanken. Jorrick, onder het genot van een Highland Label/Red Park, Lagavulin of een Straffe hebben we over de meest uiteenlopende dingen gefilosofeerd, van onze leraren van de middelbare school tot kwalitatief onderzoek. Dit heeft me altijd geholpen om met beide benen op de grond te blijven, en ook al maak ik me soms erg druk over dingen, uiteindelijk blijf ik vrijwel stressvrij.

Ook mijn andere vrienden wil ik bij dezen bedanken. Ward, Thomas, Ralph, Janneke, Siamack en Ellen: ook al is iedereen uitgewaaierd over Nederland, dat maakt het plezier van 1-3-5, Saboteur, de strijd om de tuinbonen, of 'Ralph wint" niet minder. Ik ben blij dat dit ook na onze studententijd nog altijd zo is.

Uiteraard gaat mijn dank ook speciaal uit naar mijn paranimfen, niet geheel toevallig ook mijn broers. Bas en Alexander, hoe lang geleden het ook was dat ik jullie had gezien, wanneer ik weer in Vlissingen kwam was het alsof we elkaar de dag daarvoor nog hebben gesproken. De ontspanning tijdens een weekendje Vlissingen of een vakantie, en het plezier van een stuiter-ei of periscoop maakt jullie onmisbaar. Vandaar mijn blijk van dank aan jullie in de vorm van het paranimf-zijn.

Pa en ma, al vanaf kinds af aan hebben jullie mij gemotiveerd (of moedige pogingen gedaan tot) om door te zetten of net dat beetje meer moeite te doen. Dit heeft er minstens voor gezorgd om zelf het initiatief te houden en niet zomaar achterover te leunen. Dit heeft er veel aan bijgedragen dat ik met veel plezier heb kunnen doen wat ik leuk vind tijdens mijn promotie. Daarnaast ben ik natuurlijk ook gewoon heel erg blij met zulke fijne ouders.

Als laatste gaat veel dank uit naar mijn lieve verloofde, Elly. Naast dat je als geen ander om kan gaan met iemand die vindt dat hij altijd gelijk heeft en die wat weinig geduld heeft om een heel enkele keer overtuigd te worden van zijn ongelijk, stel ik je oneindige steun, het meedenken met mijn experimenten en het sturen in de goede richting ongelofelijk veel op prijs. Hoe leuk het werk ook was, thuiskomen was toch altijd net iets leuker. 
Appendix

\section{List of Publications}

Labruijere S, Van den Boogaerdt AJ, Maassen van den Brink A, Compeer MG, De Mey JG, Danser AH, Batenburg WW. Long-lasting physiological antagonism of calcitonin gene-related peptide towards endothelin-1 in rat and human blood vessels. Submitted.

Geenen IL, Kolk FF, Molin DG, Wagenaar A, Compeer MG, Tordoir JH, Schurink GW, De Mey JG, Post MJ. Reduced AV fistula maturation in chronic kidney disease is due to NO-resistance. Submitted.

Compeer MG, Janssen GM, De Mey JG. Endothelin-1 and Endothelin-2 initiate and maintain contractile responses by different mechanisms in rat mesenteric and cerebral arteries. Submitted.

Meens MJ, Mattheij NJ, van Loenen PB, Spijkers LJ, Lemkens P, Nelissen J, Compeer MG, Alewijnse AE, De Mey JG. G-protein betagamma subunits in vasorelaxing and anti-endothelinergic effects of calcitonin gene-related peptide. $\mathrm{Br} \mathrm{J}$ Pharmacol. 2012;166(1):297-308.

Compeer MG, Suylen DP, Hackeng TM, De Mey JG. Endothelin-1 and -2: Two amino acids matter. Life Sci. 2012;91(13-14):607-12.

Compeer MG, Meens MJ, Hackeng TM, Neugebauer WA, Höltke C, De Mey JG. Agonist-dependent modulation of arterial endothelinA receptor function. $\mathrm{Br} J$ Pharmacol. 2012;166(6):1833-45.

Büther K, Compeer MG, De Mey JG, Schober O, Schafers M, Bremer C, Riemann $B$, Höltke C. Assessment of endothelin-A receptor expression in subcutaneous and orthotopic thyroid carcinoma xenografts in vivo employing optical imaging methods. Endocrinology. 2012;153(6):2907-18.

Meens MJ, Mattheij NJ, Nelissen J, Lemkens P, Compeer MG, Janssen BJ, De Mey JG. Calcitonin gene-related peptide terminates long-lasting vasopressor responses to endothelin 1 in vivo. Hypertension. 2011;58(1):99-106.

De Mey JG, Compeer MG, Lemkens P, Meens MJ. ETA-receptor antagonists or allosteric modulators? Trends Pharmacol Sci. 2011;32(6):345-51. 
Meens MJ, Compeer MG, Hackeng TM, van Zandvoort MA, Janssen BJ, De Mey JG. Stimuli of sensory-motor nerves terminate arterial contractile effects of endothelin-1 by CGRP and dissociation of ET-1/ET(A)-receptor complexes. PLoS One. 2010;5(6):e10917.

De Mey JG, Compeer MG, Meens MJ. Endothelin-1, an Endogenous Irreversible Agonist in Search of an Allosteric Inhibitor. Molecular and Cellular Pharmacology. 2009;1(5):246. 
Appendix

\section{About the Author}

Matthijs Gerrit Compeer was born on February 8, 1985 in Vlissingen, where he attended and graduated from Scheldemond College in 2003 completing the Nature \& Health profile and Latin.

He then moved to Maastricht to attend the transnationale Universiteit Limburg (tUL), a collaboration between Maastricht University and Universiteit Hasselt. In 2007, he completed his Bachelor in Molecular Life Sciences after an internship in Vascular Pharmacology with Prof. De Mey. Following this Bachelor Degree, in 2009 he completed his Master in Cardiovascular Biology \& Medicine, a 2 year research master program organized by the Cardiovascular Research Institute Maastricht (CARIM). Again, his final internship was at the lab of Prof. De Mey.

In 2009, he continued his work in Vascular Pharmacology starting his PhD program on the molecular pharmacology of endothelin receptors at the department of Pharmacology within CARIM, at Maastricht University. His PhD program was funded by TI Pharma, a public-private partnership which in this case consisted of Maastricht University, Erasmus MC and Actelion. During his PhD program, he has published his data in peer-reviewed international scientific journals. Additionally, he has presented his work on (inter)national research conferences for which he was honored with, amongst others, the Best Poster Prize at the $10^{\text {th }}$ International Symposium on Resistance Arteries in Rebild, Denmark, and the Promising Investigator Award at the New Investigator Symposium of the $24^{\text {th }}$ Meeting of the International Society of Hypertension in Sydney, Australia.

Parallel with his scientific research, he has also been active as a teaching associate within the Bachelor program of Biomedical Sciences at Maastricht University and has supervised a number of Bachelor and Master students in the lab of Vascular Pharmacology. 